\title{
EFFECTS OF WILDLAND-URBAN INTERFACE FUEL TREATMENTS ON POTENTIAL FIRE BEHAVIOR AND ECOSYSTEM SERVICES IN THE CENTRAL SIERRA NEVADA MOUNTAINS OF CALIFORNIA
}

A Thesis Presented to the Faculty of California Polytechnic State University In Partial Fulfillment of the Requirements for the Master of Science in Forestry Sciences

Christopher C. Hamma

March 2011 
(C) 2011

Christopher C. Hamma

ALL RIGHTS RESERVED 
COMMITTEE MEMBERSHIP

TITLE:

EFFECTS OF WILDLAND-URBAN INTERFACE FUEL TREATMENTS ON POTENTIAL FIRE BEHAVIOR AND ECOSYSTEM SERVICES IN THE CENTRAL SIERRA NEVADA MOUNTAINS OF CALIFORNIA
AUTHOR:
Christopher C. Hamma
DATE SUBMITTED: $\quad$ March, 2011
COMMITTEE CHAIR: Dr. Christopher Dicus, Professor
COMMITTEE MEMBER: Dr. Richard Thompson, Professor
COMMITTEE MEMBER: Dr. Scott Steinmaus, Professor 


\begin{abstract}
EFFECTS OF WILDLAND-URBAN INTERFACE FUEL TREATMENTS ON POTENTIAL FIRE BEHAVIOR AND ECOSYSTEM SERVICES IN THE CENTRAL SIERRA NEVADA MOUNTAINS OF CALIFORNIA
\end{abstract}

\author{
Christopher C. Hamma
}

For the past several decades, the wildland-urban interface (WUI) has been expanding in the low- to mid-elevation mixed-conifer belt of California's Sierra Nevada mountain range. Concurrently, the effects of fire exclusion and shifting climatic patterns in this region have led to increases in wildfire size and severity, posing an ever-greater risk to life and property. As a result, the need for implementation of fuel treatments to reduce fire hazard is generally recognized to be urgent. However, by removing vegetation, these treatments may also diminish the ability of forest ecosystems to provide valuable ecosystem services to society. Forest managers, landowners, and other WUI stakeholders would therefore benefit from a better understanding of the effects of various fuel treatment types on both fire hazard reduction and ecosystem benefits. The present study examined the effects of four commonly-used fuel treatment types on stand-level forest structural characteristics, surface and canopy fuel loading, potential fire behavior, air pollution removal, and carbon sequestration and storage. Fuel treatments involving thinning and/or prescribed burning were largely successful at reducing live and dead fuel loading, with corresponding reductions in predicted fire behavior. The little-studied but increasingly popular practice of mastication (chipping or shredding small trees and brush and leaving the debris on the ground) was associated with significantly increased surface fuel loading, although deleterious effects on potential fire behavior were not found. Overall, the findings from the fire and fuels portion of the present research largely match those reported in other, similar studies in Sierra Nevada mixed-conifer forest. However, the current analysis found little in the way of significant treatment effects on stand-level air pollution removal or carbon dynamics. This study was affected by challenges including small sample size and high variability in the data; nonetheless, the results underscore the general validity of fuel treatment implementation in central Sierra Nevada WUI areas for moderating wildfire severity and effects, with the recognition that the efficacy of such treatments may be limited under extreme weather conditions. 


\section{ACKNOWLEDGMENTS}

\section{WITHOUT WHOM}

Kelli and Shane Hamma, and the Hamma and Summers families

Dr. Chris Dicus, Cal Poly State University

Isaiah Hirschfield, (formerly) Yosemite National Park

Denise Tolmie, Sierra National Forest

Joint Fire Science Program

California Agricultural Research Initiative

and

Cal Poly: Dr. Richard Thompson; Dr. Scott Steinmaus; Dr. Doug Piirto; Dr. Norm Pillsbury; Dr. Heather Smith; Dr. Samantha Gill; Dr. Mark Shelton; Melanie Gutierrez; Becky Powell; Ellen Calcagno; Jeff Reimer; Jon Large; Alexandra Kirkpatrick; Tyler Nethaway; Merritt Cutten; Kevin Osborne; Russ White

Sierra National Forest: Francie Blaugrund; Dave McCandliss; Mark Guerrero; Carolyn Ballard; Keith Ballard

Stanislaus National Forest: Linda Johnstone; Anna Payne; John Payne; Nick Jeros; Scott Cones; Margo Erickson; Karl Graves; Kathleen Castro; Jim Serra

Yosemite National Park: Mike Beasley; Dr. Gus Smith

plus

Dr. Malcolm North; Dr. Scott Stephens; Stephanie Rebain; Erin Smith-Mateja; Andrew Sanchez-Meador; Don Vandendriesche; Dr. Elizabeth Reinhardt; Larry Gangi; Dr. Mike Battaglia; Dr. Bill Romme; Dr. Monique Rocca; Dr. Kurt Mackes; Dr. Gere diZerega; Mrs. Laura diZerega 


\section{TABLE OF CONTENTS}

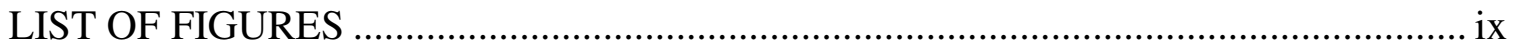

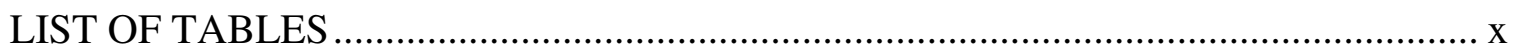



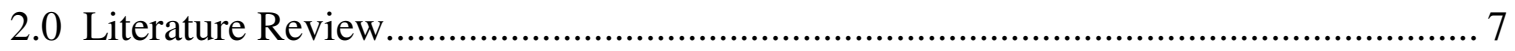

2.1 The Wildland-Urban Interface …………………........................................... 7

2.1.1 Overview .............................................................................................. 7

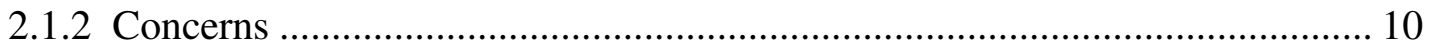

2.1.2.1 Wildland Fire Hazard................................................................... 12

2.1.2.2 Human-caused Ignitions ..................................................................... 13

2.1.2.3 Structure Protection Difficulties ........................................................... 14

2.1.2.4 Costs and Losses ............................................................................ 15

2.1.2.5 Lack of Land Use Planning Controls ...................................................... 19

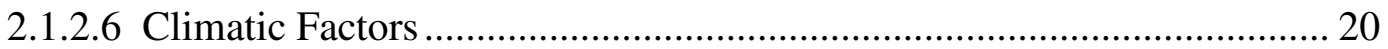

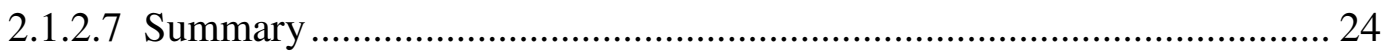



2.1.3.1 Wildland Fire and Fuels Management .................................................. 25

2.1.3.2 Landowner Education .......................................................................... 26

2.1.3.2.1 Home/Lot Ignitability ………………………………………....... 27

2.1.3.2.2 Response to the Imminent Threat of Wildfire .................................. 29

2.1.3.2.2 Cultural Attitudes Towards Fire and Fire Protection......................... 30

2.1.3.3 Economic Incentives and Disincentives ................................................. 31

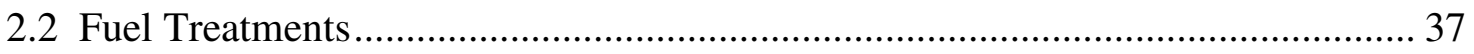

2.2.1 Definition and Purpose .............................................................................. 37



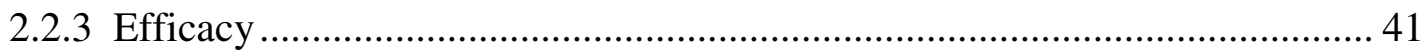





2.2.6 Treatment Implementation and Types ........................................................ 52

2.2.6.1 Prescribed Fire ………………………......................................... 53

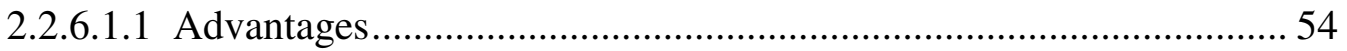

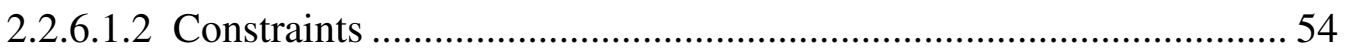


2.2.6.2 Thinning/Silvicultural Treatments ..................................................... 57

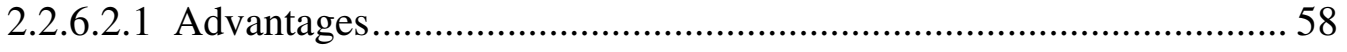

2.2.6.2.2 Constraints ……………………………………........................... 59

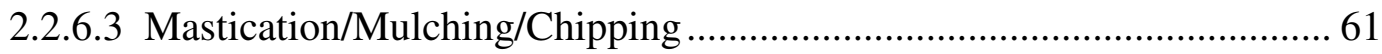

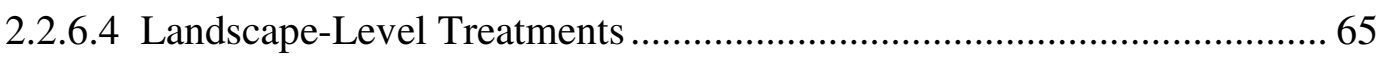

2.2.7 Implementation and Integration with Ecological Concerns............................. 67

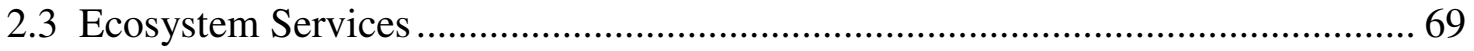

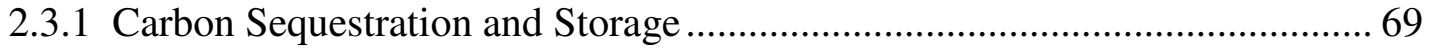



2.4 The Central Sierra Nevada .......................................................................... 74

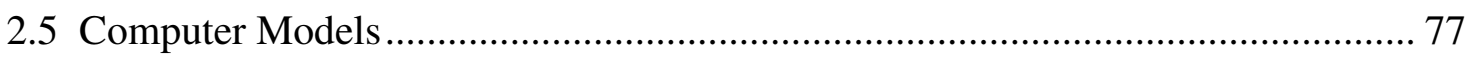

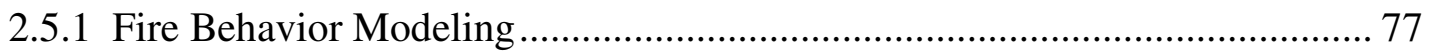

2.5.1.1 Fire Behavior and Climate Change ...................................................... 85

3.0 A Comparison of Fuel Reduction Treatment Effects on Simulated Fire Behavior in Mixed-Conifer Forests of the Central Sierra Nevada Mountains ...................................... 87



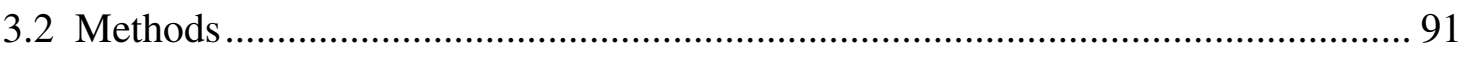

3.2.1 Site Description........................................................................................ 91

3.2.2 Treatment Types and Field Measurements ………………………............... 93

3.2.3 Fuels and Fire Behavior Calculations ............................................................ 97

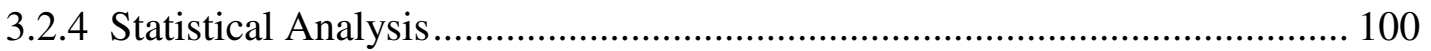

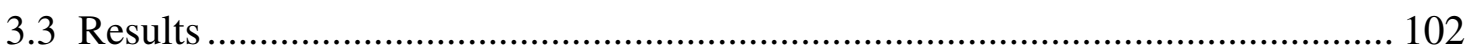

3.3.1 Stand Structural and Fuel Loading Characteristics..................................... 102

3.3.1.1 Stand Structural Characteristics ............................................................... 104

3.3.1.2 Woody Debris Characteristics ........................................................... 106

3.3.1.3 Shrub and Canopy Fuels ....................................................................... 108

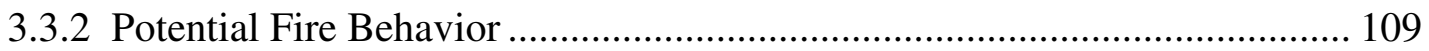

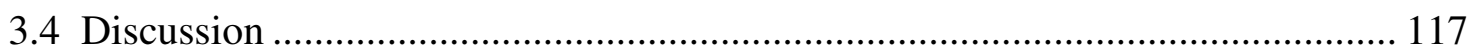

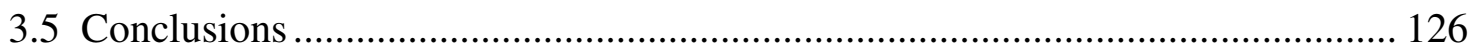

4.0 A Comparison of Fuel Reduction Treatment Effects on Ecosystem Services in Mixed-Conifer Forests of the Central Sierra Nevada Mountains ................................. 129

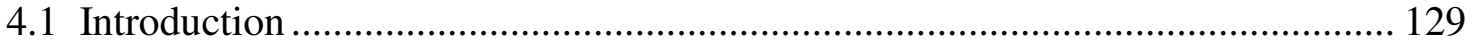




4.2.1 Site Description................................................................................. 133



4.2.3 Ecosystem Services Calculations ........................................................... 138

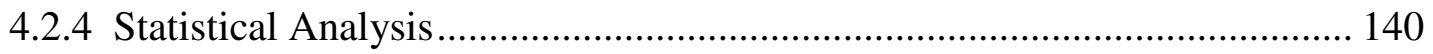



4.3.1 Leaf Area and Air Pollution Removal ...................................................... 143

4.3.2 Carbon Sequestration and Storage ........................................................ 146



4.4.1 Leaf Area and Air Pollution Removal ........................................................ 148

4.4.2 Carbon Sequestration and Storage ....................................................... 150

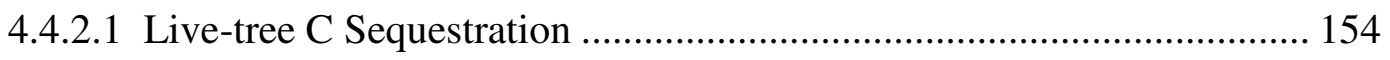

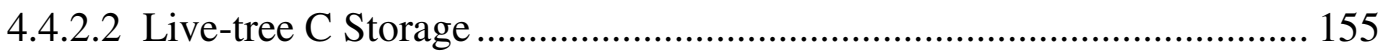

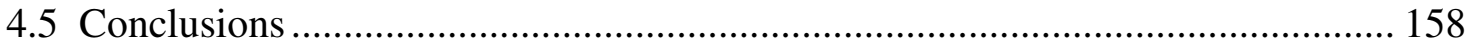

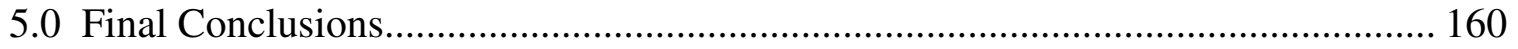

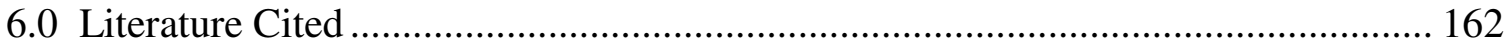




\section{LIST OF FIGURES}

Figure 1.1. Study region - the central Sierra Nevada; stars indicate sampling sites......... 2

Figure 1.2. Mean annual area burned in western US wildfires during the 20th century.... 2

Figure 1.3. An example of wildland-urban interface (WUI) development....................... 3

Figure 1.4. Adjacent wildfire-burned untreated (L) and treated (R) forest stands, Tahoe

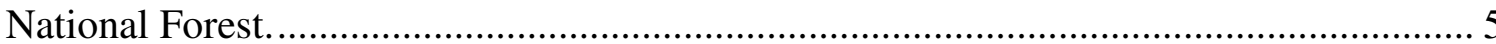

Figure 1.5. Conducting fuels inventory on a study site, summer 2008. .......................... 6

Figure 3.1. Study region - the central Sierra Nevada; stars indicate sampling sites....... 92

Figure 3.2. Mean percent difference and standard error between untreated and treated stands for basic stand characteristics; significant differences between treatment means ( $p$ $<0.10)$ are indicated by differing letters.

Figure 3.3. Mean percent difference and standard error between untreated and treated stands for 1- through 1000-hr surface fuel loads; significant differences between treatment means $(p<0.10)$ are indicated by differing letters.

Figure 3.4. Mean percent difference and standard error between untreated and treated stands for various woody surface fuel loads and fuelbed depth; significant differences between treatment means $(p<0.10)$ are indicated by differing letters.

Figure 3.5. Mean percent difference and standard error between untreated and treated stands for potential fire behavior characteristics under $50^{\text {th }}$ percentile fire weather conditions; significant differences between treatment means $(p<0.10)$ are indicated by differing letters.

Figure 3.6. Mean percent difference and standard error between untreated and treated stands for potential fire behavior characteristics under $90^{\text {th }}$ percentile fire weather conditions; significant differences between treatment means $(p<0.10)$ are indicated by differing letters.

Figure 3.7. Fuel treatment effects on flame length under $50^{\text {th }}$ percentile fire weather conditions.

Figure 3.8. Fuel treatment effects on flame length under $90^{\text {th }}$ percentile fire weather conditions

Figure 4.1. Study region - the central Sierra Nevada; stars indicate sampling sites..... 134

Figure 4.2. Mean percent difference and standard error between untreated and treated stands for leaf area and air pollution removal.

Figure 4.3. Mean percent difference and standard error between untreated and treated stands for gross live-tree $\mathrm{C}$ sequestration and storage. 


\section{LIST OF TABLES}

Table 3.1. Fuel treatment types, locations, and dates of implementation....................... 94

Table 3.2. Average fire weather values used in NEXUS 2.0 for two weather conditions.99

Table 3.3. Mean (standard error) stand structural and fuel loading characteristics in untreated stands.

Table 3.4. Mean (standard error) stand structural and fuel loading characteristics in treated stands

Table 3.5. Mean percent difference between untreated and treated stands, general linear model p-value $(\alpha=0.10)$, and standard error for stand structural and fuel loading characteristics

Table 3.6. Mean (standard error) potential fire behavior under $50^{\text {th }}$ and $90^{\text {th }}$ percentile weather conditions in untreated and treated stands.

Table 3.7. Mean percent difference between untreated and treated stands, general linear model p-value $(\alpha=0.10)$, and standard error for potential fire behavior under $50^{\text {th }}$ and $90^{\text {th }}$ percentile weather conditions.

Table 3.8. Mean percent difference between untreated and treated stands, general linear model p-value $(\alpha=0.10)$, and standard error for potential fire behavior under $50^{\text {th }}$ and $90^{\text {th }}$ percentile weather conditions, with the Masticate treatment type removed.

Table 4.1. Fuel treatment types, locations, and dates of implementation. 136

Table 4.2. Mean (standard error) air pollution removal, live-tree $\mathrm{C}$ sequestration, and live-tree $\mathrm{C}$ storage in untreated and treated stands.

Table 4.3. Mean percent difference between untreated and treated stands, general linear model p-value $(\alpha=0.10)$, and standard error for air pollution removal, $\mathrm{C}$ sequestration, and $\mathrm{C}$ storage.

Table 4.4. Mean whole and aboveground-only live-tree $\mathrm{C}$ storage $\left(\mathrm{Mg} \mathrm{C} \mathrm{ha}^{-1}\right)$ in untreated and treated stands, as compared to results of similar studies. 


\subsection{Introduction and Project Overview}

In the semiarid, fire-adapted mixed-conifer forests of California's Sierra Nevada Mountains (Figure 1.1), frequent, low-intensity wildfire is a critically important ecological disturbance, necessary for removing excess live and dead fuels (i.e., biomass including trees, other vegetation, and associated debris), maintaining nutrient cycles, and supporting overall forest health (Skinner and Chang, 1996). However, the past 100+ years of resource extraction and anthropogenic wildfire exclusion have allowed these fuels to build up to unnaturally high levels (McKelvey et al., 1996), aided by a mid-20 ${ }^{\text {th }}$ century climatic trend of increased moisture availability across northern California (Crimmins et al., 2011). This fuel accumulation, in combination with increased atmospheric warming (resulting in reduced snowpack accumulation and more intense summer drought) (Westerling et al., 2006), has led to increases in wildfire frequency, size, and area burned (Figure 1.2) as well as increased high-severity, stand-replacing fire behavior to which these forests are not evolutionarily adapted (Miller et al., 2009).

Over the same time period, but particularly during the postwar years, human population and infrastructure have increased tremendously in these forestlands, giving rise to the mosaic of developed and wildland areas known as the "wildland-urban interface" (WUI) (Radeloff et al., 2005; Figure 1.3). The combined effect of these ecological and demographic changes has been to place ever more lives and property in the path of devastating wildfires (Massada et al., 2009); by one estimate, over 3.5 million homes in California, Oregon, and Washington alone are located in high fire hazard areas (Hammer 




Figure 1.1. Study region - the central Sierra Nevada; stars indicate sampling sites.



Figure 1.2. Mean annual area burned in western US wildfires during the 20th century. Source: Littell et al., 2009 
et al., 2007). Despite annual firefighting expenditures of over $\$ 1$ billion throughout much of the past decade, thousands of homes and hundreds of lives have nonetheless been lost in WUI fires (Liang et al., 2008). The vast majority of these firefighting costs are expended on very few fires - the largest ones - often during periods of extreme fire weather, precisely when it is least likely that control efforts will have any success whatsoever (Ingalsbee, 2010).

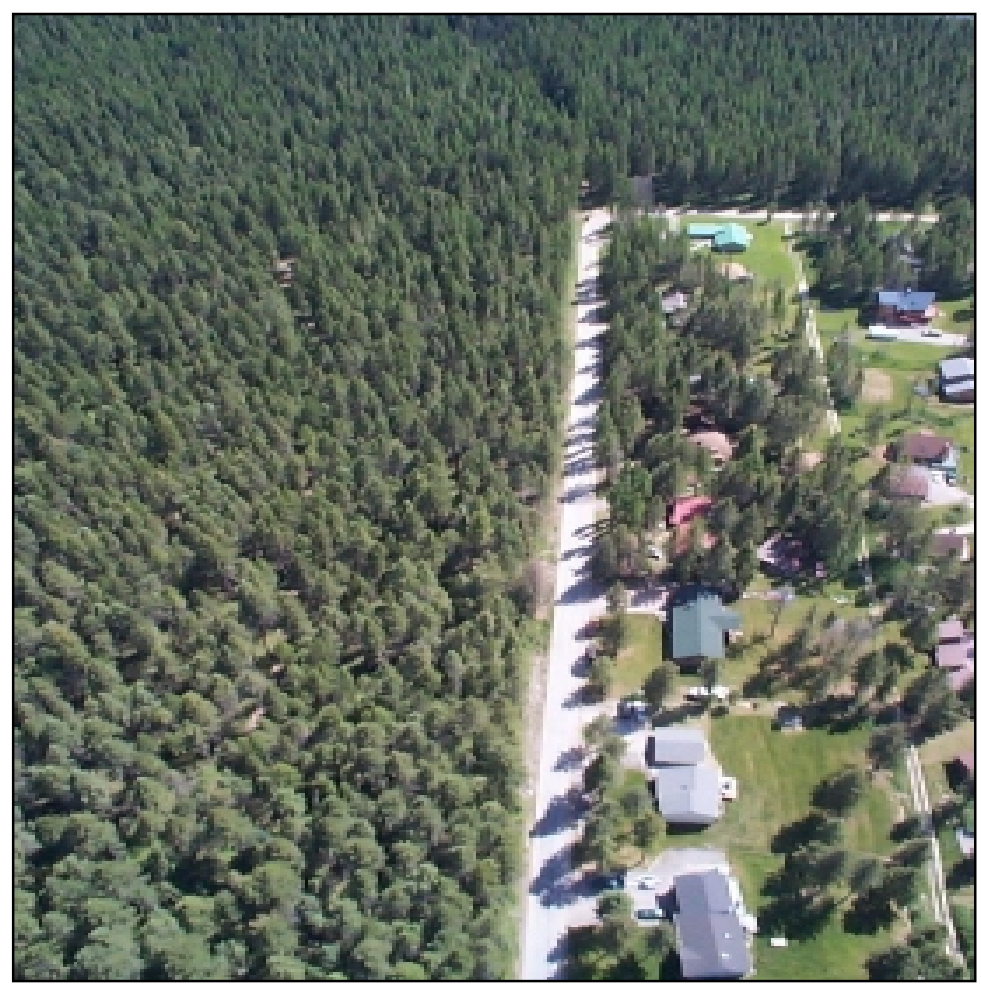

Figure 1.3. An example of wildland-urban interface (WUI) development. Source: http://dnrc.mt.gov/forestry/fire/prevention/happyvalley.asp

One result of this situation is that forest land managers have recognized an urgent need to reduce the potential for severe wildfire behavior and effects in order to protect human lives and property, as well as natural resources at risk of destruction (GAO, 1999). Although topography and weather/climate are major factors affecting fire activity, and 
climate projections indicate that greater warming and drought may be in store for California (IPCC, 2007), these factors are not subject to human control. Thus, the focus of fire hazard reduction efforts has typically been on fuel reduction. This is ordinarily accomplished via mechanical treatments (e.g., thinning, mastication), prescribed fire treatments, or some combination of the two (Peterson et al., 2005), activities which may also meet ecological restoration goals in this forest type. Federal fuel treatment and wildfire suppression efforts are now directed largely at the WUI; however, the fact that the WUI is mostly private property limits federal involvement to some degree (Rasker, 2009; Mell et al., 2010).

Although fuel treatments tested under experimental burning conditions appear to be effective at reducing fire intensity (Graham et al., 2004; Stephens et al., 2009a), empirical evidence for their efficacy in uncontrolled wildfire situations, particularly under extreme fire weather conditions, is restricted to a handful of examples (Martinson and Omi, 2008; Figure 1.4). Furthermore, fire management is not the only consideration that forest managers must take into account during land use planning efforts. The removal of forest vegetation can have detrimental effects on numerous ecosystem components, many of which provide little-recognized but crucial services to society (Dicus et al., 2009). These ecosystem services include, but are not limited to, drinking water supply, wildlife habitat, recreational opportunities, microclimate amelioration/home energy savings, noise reduction, and aesthetic benefits (Chen and Jim, 2008). 

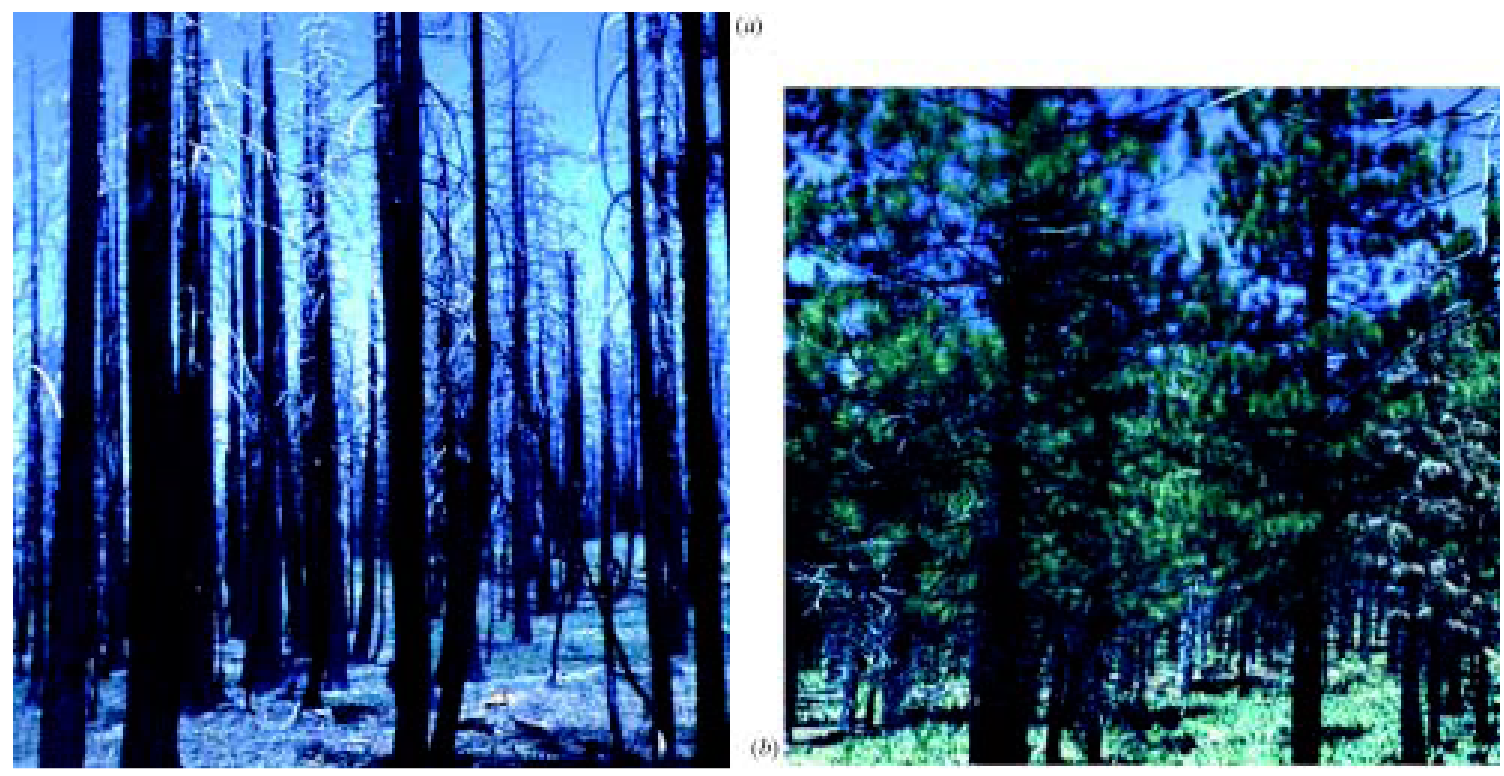

Figure 1.4. Adjacent wildfire-burned untreated (L) and treated (R) forest stands, Tahoe National Forest.

Source: Pollet and Omi, 2002

The purpose of this study was to compare the effects of four fuel treatment types (thinning plus mastication, thinning plus pile burning, thinning plus prescribed fire, and prescribed fire alone) on forest fuel loading, predicted fire behavior, and two ecosystem services: air pollution removal, and carbon sequestration and storage in the mixed-conifer forests of the central Sierra Nevada. Various live and dead fuel parameters were measured using standard forest inventory methods on US Forest Service and National Park Service lands during summer 2008 (Figure 1.5). Several software packages were then used to compile and analyze the data. For all response variable and treatment combinations, the null hypothesis was that treatments would have no significant effect.

A review of pertinent scientific literature is provided in Chapter 2 of this thesis. Background information, methodology, results, and discussion are provided in Chapter 3 (fuel loading and fire behavior) and Chapter 4 (ecosystem services). Duplication of text, 
figures, and tables in Chapters 3 and 4 exists due to a specific request by the author's graduate advisor. It is hoped that the results of this study will be conveyed to land managers, landowners, and other WUI stakeholders through publications, workshops, and other media, in order to contribute to sound, science-based decision-making and management on forest lands at high risk of severe wildfire.



Figure 1.5. Conducting fuels inventory on a study site, summer 2008. 


\subsection{Literature Review}

\subsection{The Wildland-Urban Interface}

\subsubsection{Overview}

Housing growth in the US has been strong in recent decades, and homeowner preferences for rural landscapes, natural amenities and large lots developed at a low density have given rise to an extensive wildland-urban interface (WUI) (Hammer et al., 2007; Gude et al., 2008). The WUI is defined by the federal government as any location "where houses meet or intermingle with undeveloped wildland vegetation" (USDA-USDI, 2001b), although other definitions have been used (Mell et al., 2010). Definitions may vary in whether they use housing density or population density as a distinguishing metric, but all WUI definitions contain three components: human presence, wildland vegetation, and a buffer distance that represents the distance from homes to untreated wildland fuels (Stewart et al., 2007; Mell et al., 2010).

Three subcategories of WUI are recognized: interface, intermix, and occluded (USDAUSDI, 2001b). The interface contains relatively high-density developed areas that abut wildland fuels. The intermix consists of low-density, rural development interspersed with wildlands. Occluded areas are islands of wildland fuels surrounded by urbanization (Davis, 1990). As operationalized by Stewart et al. (2007), the WUI is the area where housing density is greater than or equal to roughly 2.5 housing units per ha and (1) 
wildland vegetation covers more than 50 percent of the land area (intermix) or (2) wildland vegetation covers less than 50 percent of the land area, but a large area (over $500 \mathrm{ha})$ covered with more than 75 percent wildland vegetation is within $2.4 \mathrm{~km}$ (interface).

Total WUI area and growth rate have been estimated in several recent studies (e.g. Radeloff et al., 2005; Hammer et al., 2007; Theobald and Romme, 2007; Gude et al., 2008). Typically, WUI studies involve the use of a geographic information system (GIS) to overlay historic fire regime, current fuel loading, and current US Census population or housing data (Haight et al., 2004).

Until recently, fuel loading inputs for WUI studies were typically based on fire regime condition class (FRCC; Schmidt et al., 2002), a measure of a fire regime's departure from its historic range of variability. However, numerous authors have noted that although FRCC is commonly cited in policy debates as being a basis for making fuel treatment decisions (FRCC reduction is an explicit goal under HFRA), FRCC mapping is far too coarse be used at any scale finer than regional level to assess fuel conditions (Franklin and Agee, 2003; Dellasala et al., 2004). It is expected that this concern will be resolved in the near future with the availability of spatially comprehensive data layers for surface and crown fuels through the LANDFIRE (Rollins and Frame, 2006) project (Hammer et al., 2007). 
The majority of WUI area and housing are found in the eastern US (Radeloff et al., 2005; Theobald and Romme, 2007) and on privately owned land (Theobald and Romme, 2007). The WUI has been estimated as occupying anywhere from six percent (Theobald and Romme, 2007) to 9.4 percent (Radeloff et al., 2005) of the conterminous US $(465,614$ $\mathrm{km}^{2}$ and $719,156 \mathrm{~km}^{2}$, respectively), and containing from 13 percent (Theobald and Romme, 2007) to 39 percent (Radeloff et al., 2005) of all housing in the same area (12.5 million and 44.3 million housing units, respectively). Discrepancies between the extant studies in estimates of WUI parameters are the result of differences in methodology (Syphard et al., 2007); however, the single most influential factor in determining WUI area appears to be housing density (Stewart et al., 2007).

Several studies have investigated the issue of how fast the WUI is growing and what can be expected in the future. Theobald and Romme (2007) reported that between 1970 and 2000, WUI areas expanded by 52 percent in the US, from $159,500 \mathrm{~km}^{2}$ to $465,614 \mathrm{~km}^{2}$; much of this growth occurred in the western US. Hammer et al. (2007) found that of all new housing units built in California, Oregon, and Washington between 1990 and 2000, 61 percent (just over one million) were located in the WUI; as a result, WUI area increased by 11 percent to nearly $53,000 \mathrm{~km}^{2}$. Most of this was intermix growth. Even higher housing growth (15 percent) was seen in previously existing (prior to 1990) WUI areas. Nonetheless, only 14 percent of the WUI has actually been developed, leaving 86 percent available for future urbanization (Gude et al., 2008). The expansion of the WUI is expected to continue, with the Intermountain West (Nevada, Arizona, Colorado, 
Montana, Utah, and Idaho) predicted to experience the greatest amount of WUI growth between 2000 and 2030 (Theobald and Romme, 2007).

The number of homes in California's WUI grew by roughly nine percent between 1990 and 2000, leading to the current total of at least 5.1 million homes, or over one-third of the WUI in the entire western US (Radeloff et al., 2005; Hammer et al., 2007; Gude et al., 2008). Looking specifically at the Sierra Nevada Mountains, including the more heavily populated foothills, total growth between 1990 and 2000 was estimated at nearly 55,000 housing units, for an average growth rate of 15.6 percent (Hammer et al., 2007). Nearly all (> 90 percent) of housing units and housing growth in the Sierra Nevada are located in areas identified as WUI, due to (1) the dearth of any large, non-WUI urban areas nearby, (2) favorable attitudes towards growth combined with less strict zoning laws, and (3) relatively affordable land prices that encourage the development of lowdensity, ranchette housing (Ibid.).

\subsubsection{Concerns}

The ongoing expansion of low-density residential development in the WUI has raised concern among natural resource managers and has been cited as a primary factor influencing the management of national forests (Theobald and Romme, 2007). In at least some regions of the US, lives and property have become increasingly at risk from wildfire due to the confluence of fire suppression-induced increases in wildland fuel loading, large increases in the number of private homes located near public forestlands, 
increases in human-caused ignitions as a result of urbanization, and the effects of climate change (Syphard et al., 2007; Gude et al., 2008; Massada et al., 2009; Rasker, 2009); roughly 70 million ha of WUI land area in the US may be at high wildfire risk (Mell et al., 2010). Indeed, average annual wildland area burned increased by 70 percent during 2000-2005 as compared to the 1990s (GAO, 2007). Over 95 percent of wildfires are extinguished when they are small (less than 0.8 ha); the 2 to 5 percent that are not suppressed burn 95 percent of the area (Dodge, 1972).

Other WUI-related concerns include habitat loss and degradation, spread of invasive species, and water and air pollution (Theobald and Romme, 2007). Fire suppression has become increasingly directed at protecting lives and property at the expense of fire containment or protection of other resources, and suppression costs and insurance losses have increased dramatically (Dombeck et al., 2004; Hammer et al., 2007; Liang et al., 2008). Although some states have set minimum standards for development in high fire hazard areas, it is unlikely that these will slow the growing cost of fighting wildfires (Gude et al., 2008).

Mell et al. (2010) identified various concerns with the current state of research into WUI wildfire risk. There is currently no single, standard definition for "wildland-urban interface", nor is there a standardized, nationwide method of pre- and post-fire data collection or hazard assessment for WUI areas. Extant research into WUI fire risk (e.g. Menakis et al., 2003; Theobald and Romme, 2007) has thus far identified and prioritized WUI communities at risk using only housing density or population density, not actual 
exposure conditions (risk) from wildland fire, and the same studies have also assumed that all homes are easily ignitable. Thus far, much of the focus of WUI fire risk reduction has been on wildland fuel treatments, but because this issue is, at its core, a structure ignition problem, greater focus on reducing the potential for residential ignitions is needed (Mell et al., 2010).

\subsubsection{Wildland Fire Hazard}

During the period 2003 to 2009, an annual average of 3 million ha and 1,435 homes burned in wildland and WUI fires in the US, and annual firefighting costs exceeded \$1 billion in several of those years, although it should be noted that these averages are influenced upward by the large southern California wildfires of 2003 and 2007 (NIFC, 2010; NOAA, 2010). Additionally, in the 10 years from 1999 to 2008, an annual average of 21 wildland fire personnel and dozens of other people died in such fires (USFA, 2009; NOAA, 2010). These unsettling statistics are due in large part to the fact that 65 percent of all WUI housing in the US is located in "high" or "high (historically low or variable)" fire hazard areas; for California, the number is 95 percent, or roughly 4.9 million homes (Radeloff et al., 2005; Theobald and Romme, 2007). "High" fire hazard areas are

ecosystems given to stand-replacing crown fire (e.g., chaparral shrublands or Rocky Mountain lodgepole pine forests), while "high (historically low or variable)" areas are ecosystems such as ponderosa pine or mixed conifer forest, in which the preEuroamerican regime of frequent, low-intensity fire now experiences infrequent, highseverity fire due to a century or more of fire suppression (Theobald and Romme, 2007). 
In both cases, wildfires occurring during extreme fire weather conditions can be nearly impossible to control (Ibid.).

Fire frequency and area burned tend to be highest at intermediate levels of development, a condition typical of intermix WUI (Syphard et al., 2007). However, not all areas identified as WUI are at risk of wildfire; degree of fire hazard to human resources in the WUI appears to vary strongly by region (Ibid.). Researchers have found that population density is positively correlated with fire risk in the northern Great Lakes states (Cardille et al., 2001) and southern California (Keeley et al., 1999), but not in Florida (Prestemon et al., 2002; Mercer and Prestemon, 2005) or the northern Sierra Nevada foothills (CAFRAP, 2001).

\subsubsection{Human-caused Ignitions}

Growth in the wildland-urban interface (WUI) in recent years has placed more people in contact with wildlands, thereby increasing the likelihood of human-caused ignitions, whether accidental or arson-caused (Keeley, 1982; Cardille et al., 2001; Fried et al., 2008). Population density, proportion of intermix WUI, and distance to WUI were found to significantly affect fire frequency in California, although area burned appeared to be controlled more by vegetation type (Syphard et al., 2008). Additionally, Stephens (2005) found that between 1940 and 2000, total number of ignitions and area burned by humancaused fires on US Forest Service lands in California significantly increased, while area burned by lightning-caused fires did not increase. Furthermore, total annual area burned 
across the western US increased, but oddly, in California it did not. The fact that ignitions increased in California while total area burned did not was unique in the US, and is probably due to California's highly effective initial attack system. The increased number of ignitions in California was attributed to the state's increasing population and use of wildlands for recreation, trends that are likely to continue (Stephens, 2005).

\subsubsection{Structure Protection Difficulties}

It is in the WUI where protection of structures from wildland fires is most challenging (Radeloff et al., 2005). Unlike in typical urban structure fires, fires in the WUI can overwhelm fire agencies and destroy hundreds of homes in a matter of hours, in large part because WUI fires often burn under extreme weather conditions that result in long flame lengths, high fireline intensity, and showers of firebrands thrown several kilometers ahead of the fire front. Subsequent to the initial ignition of one or more homes, these burning homes can then become fuel for the fire and catch adjacent homes on fire in a cascading effect (Cohen, 2000; Murphy et al., 2007). This situation is exacerbated by non-fire resistant home construction and the nearby presence of dense, flammable landscaping, wood piles, or wood outbuildings. Homes are rarely damaged in WUI fires; they either survive or are totally destroyed (Cohen and Saveland, 1997). Thus, at the scale of the individual home, the WUI fire problem is in large part a question of home ignitability (Cohen, 2000). 
The WUI intermix zone consists of large areas dominated by complex mosaics of built environment and wildland fuels, stretching resources thin and making firefighting more difficult than in the interface where homes are clustered together (Hammer et al., 2007; Gude et al., 2008). Remoteness, steep slopes, and narrow roads increase the danger to firefighters (Gude et al., 2008). Furthermore, many rural WUI areas currently have insufficient firefighting resources as it is, and available resources will likely be strained further as more homes are built in these areas (Fried et al., 2004; Fried et al., 2008). Thus, the emphasis on structure protection in the WUI often comes at the cost of progress in fireline containment, resulting in larger fire sizes (Hammer et al., 2007).

Nonetheless, despite these obstacles, wildland firefighting efforts are in most cases successful at protecting threatened structures (Hammer et al., 2007). Ironically, this fact is itself growth-inducing and contributes to the overall problem, as it reinforces the idea among the public that the building in fire-prone areas is safe and that government will take responsibility for their safety no matter the cost, engendering complacency among WUI residents (Gude et al., 2009).

\subsubsection{Costs and Losses}

Both fire prevention and wildland fire suppression efforts have been increasingly directed at protecting private property in the WUI in recent years, at tremendous expense (Hammer et al., 2007). Average federal firefighting and wildland fuel treatment expenditures increased from $\$ 1.3$ billion annually during 1996-2000 to $\$ 3.1$ billion 
during 2001-2005 (GAO, 2007). An audit by the US Office of the Inspector General identified the WUI as one of the primary factors in this cost escalation (OIG, 2006). This is because the low-density housing that is typical of the WUI, and particularly the intermix zone, is much more costly to protect than, for instance, one dense subdivision with the same number of homes (Rasker, 2009). The OIG audit found that 87 percent of large wildfires were fought primarily to protect private property (OIG, 2006); the fact that less than 20 percent of burned area is private property (Liang et al., 2008) gives an indication of suppression effectiveness.

It has further been pointed out that the landowners and local governments who benefit most from federal WUI fire protection do not bear their fair share of the cost; instead, these costs are borne by all US taxpayers (Gude et al., 2008). Homeowner reliance on the federal government to provide fire protection is an enormous financial burden to all taxpayers, yet benefits the relatively few, including wealthy second home owners who could afford to pay for fire protection (OIG, 2006). Thus, the government is subsidizing the true cost of development (Rasker, 2009). Furthermore, if a home burns despite federally-funded efforts to save it, and the homeowner rebuilds with a FEMA grant, then they have received a double subsidy to perpetuate the problem, courtesy of the US taxpayers.

Gude et al. (2008) calculated that if residential development in western US WUI were to increase from its current 14 percent of buildout to 50 percent, annual fire suppression costs could potentially reach $\$ 4.3$ billion - 96 percent of the total annual budget of the 
US Forest Service. Fire suppression costs in California alone exceeded $\$ 1.7$ billion in FY 2008 , of which roughly $\$ 700$ million was federal costs and over $\$ 1$ billion was sustained by the State (Boxall, 2008). FY 2008 included the large southern California fires of October 2007.

An unfortunate and counterproductive result of the focus on structure protection in the WUI is that fuel treatment and other important resource management programs have had their funding diverted to provide for "emergency" fire suppression resources, to the tune of $\$ 2.7$ billion between 1999 and 2003, of which only 80 percent was reimbursed (GAO, 2004; Gude et al., 2008). Any potential ecological benefits to letting fires burn, including fuel reduction, are lost when fires must be suppressed in the WUI (OIG, 2006). The effect on the US Forest Service has been the continuing erosion of its ability to meet its legal mandate of multiple-use management. In the last six years, the available staff on the National Forest System has declined 35 percent (USFS Chiefs, 2008).

In response to this problem, in 2009 Congress passed, and President Obama signed, the Federal Land Assistance, Management and Enhancement (FLAME) Act (H.R. 1404; Committee on Natural Resources, 2009). The FLAME Act establishes an emergency funding source for catastrophic wildland fire suppression activities on Department of the Interior and US Forest Service lands. The Act also requires the Secretaries of Interior and Agriculture to develop regional maps of communities most at risk of wildfire and in need of hazardous fuel treatment, review wildland fire incidents that result in expenses greater than $\$ 10$ million, and develop a cohesive wildland fire management strategy, among 
other items. However, it should be noted that while protecting other programs' funds from being raided, the FLAME Act does nothing to address the problem of increasing housing growth in the WUI.

Recent policy initiatives focus on fuel treatments (Stephens and Ruth, 2005), but these can be expensive (although not in comparison to fire suppression), and the smalldiameter, non-merchantable trees removed in fuel treatments often cannot be sold to help pay for the treatment, because no market exists for such material (Gude et al., 2009). The fact that fuel treatments in the WUI tend to be more intensive, and therefore more expensive, than wildland fuel treatments, exacerbates the situation (Safford et al., 2009). Finally, the extent to which fuel treatments reduce wildfire suppression costs, particularly in the WUI, is unknown (Gude et al., 2009).

A study focusing on the State of Montana recently calculated that the cost of wildland fire suppression rises by $\$ 1$ million for every 125 homes threatened (Gude et al., 2009). Because it is easier to protect one dense subdivision than the same number of homes spread across a large area of land, firefighting in the WUI, especially the intermix zone, is far more expensive than in non-WUI areas (Rasker, 2009). The authors found that if current WUI growth and climate trends in Montana continue, the cost of fire suppression in the WUI could double to quadruple, increasing from the current annual average of $\$ 28$ million to anywhere from $\$ 61-113$ million, by 2025 (Ibid.). Since the state pays at least 25 percent of these costs, Montana could be responsible for $\$ 15-28$ million - a large burden for a state with a population of less than one million. 
Insurance losses from wildfire account for about 2.2 percent of all insurance losses, a lower number than for any other type of natural disaster (Rocky Mountain Insurance Information Association, 2009). Nonetheless, the scale of these losses is increasing (AIR Worldwide, 2010).

Over the past 25 years wildfires have caused \$10 billion (2005 dollars) in insured property losses in the U.S., with the majority occurring in California. The 1991 Oakland Hills Fire destroyed 2,900 structures and cost insurers more than \$3 billion in 2009 dollars; the 2003 Cedar and Old Fires in Southern California destroyed 3,700 homes and cost insurers more than \$2 billion; and the "October Fire Siege" of 2007, in which 23 wildfires raged simultaneously, ultimately caused more than $\$ 2$ billion in insured losses and the destruction of some 3,300 homes and other structures (Ibid.).

\subsubsection{Lack of Land Use Planning Controls}

In the western US, housing development occurs at much lower densities and on much larger lots in the WUI than on non-WUI private lands (Gude et al., 2008). The majority of this development (73 percent) occurs at exurban densities, where lot size is between roughly 4 and 16 ha. Roughly 20 percent of the homes in the WUI are second homes (Ibid.). This situation is of concern for a number of resource management-related reasons, not the least of which is that during a major wildland fire, rural fire protection resources can be stretched to the breaking point. Yet, in most places there is little political will to 
implement fire-hazard related zoning in the WUI (Ibid.). Such zoning could allow counties to regulate housing densities in high-risk areas and/or ensure that current and future construction is compliant with fire-safe building standards. However, zoning is controversial throughout the rural West, because it is seen as a "taking" of private property, even though statewide "zoning" already exists in many forms, including statewide building codes and subdivisions regulations (Ibid.).

\subsubsection{Climatic Factors}

Despite the extensive land use and vegetation changes that have occurred across the western US during the era of Euroamerican settlement (roughly the past 150 years), wildfire activity in the region is still strongly, if not primarily, driven by annual and longterm climatic patterns and their interactions with the aforementioned factors (Swetnam and Betancourt, 1990; Heyerdahl et al., 2002; Westerling and Swetnam, 2003; Littell et al., 2009). The Fourth Assessment Report of the Intergovernmental Panel on Climate Change (IPCC) predicts that the ongoing atmospheric accumulation of greenhouse gases such as $\mathrm{CO}_{2}$ and $\mathrm{CH}_{4}$ could result not only in temperature increases of about $0.2^{\circ} \mathrm{C}$ per decade, but also substantial changes to sea level, ocean acidity, wind patterns, precipitation, extreme weather events, and ice distribution (IPCC, 2007). Despite the fact that existing global climate models are neither accurate enough nor precise enough to allow for the projection of fire weather conditions into the future at regional or local scales (Millar et al., 2007), increased temperature and more frequent and intense drought are predicted worldwide, with the resulting implication of increased wildfire activity 
through effects on fuel moisture, vegetation distribution, and lightning frequency (Price and Rind, 1994; Bachelet et al., 2001; Fried et al., 2008).

Predicted changes in vegetation patterns and fire behavior due to climate change are also likely to impact the ability of homeowners and federal, state, and local authorities to protect homes in the wildland-urban interface from damage by wildfires; hence, suppression costs and economic losses can be expected to rise (Fried et al., 2004; Westerling and Bryant 2008). A recent study in Montana concluded that a 0.56 degree (C) increase in average spring and summer temperature could result in a 305 percent increase in area burned and a 107 percent increase in home protection costs (Gude et al., 2009).

Fire activity in the western US is strongly seasonal, with $94 \%$ of fires and $98 \%$ of area burned occurring between May and October (Westerling et al., 2003). Climate variability affects fire activity by influencing the production, distribution, and drying of vegetation (fuels); warm, dry conditions during fire season increase the ignitability and flammability of fuels, while cool, wet conditions suppress fire activity and can promote the growth of new fuels, setting the stage for increased fire activity in subsequent years (Chandler et al., 1991; Agee, 1993; Veblen et al., 2000). "Extreme" ( 1.5 million ha) fire seasons in the 1910s-1930s, and starting again in the mid-1980s, correlate strongly with drought conditions in the western US, while fire activity was greatly reduced between the 1940s and mid-1980s during a period of anomalously high moisture availability (Graumlich, 1993; Littell et al., 2009). In the Sierra Nevada, low precipitation, high temperature, and 
negative Palmer Drought Severity Index (PDSI) immediately preceding and during a given year are positively associated with wildfire area burned, while high winter precipitation levels are negatively associated with area burned (Littell et al., 2009).

The relationship between climate and fire patterns is supported by both historical documentary records as well as dendrochronological (tree ring) and statistical reconstructions (Swetnam and Betancourt, 1998; Veblen et al., 2000; Heyerdahl et al., 2002; Westerling et al., 2003; Brown and Wu, 2005; Kitzberger et al., 2007). The El Niño-Southern Oscillation (ENSO), Pacific Decadal Oscillation (PDO), and Atlantic Multidecadal Oscillation are interannual ocean-atmosphere climatic patterns that have been identified as having significant influence on moisture availability, and therefore fire behavior, in the western US at differing temporal scales (Swetnam and Betancourt, 1990; Westerling and Swetnam, 2003; Collins et al., 2006). In general, the El Niño phase of ENSO tends to result in weather that is cooler and wetter than average in the Southwest, while warmer and drier than average in the Northwest; the La Niña phase of ENSO results in conditions that are the opposite. However, ENSO also interacts with the various phases of PDO and AMO to create conditions that differ by region and time period (years to decades) (Collins et al., 2006). Because the Sierra Nevada Mountains are located between the Northwest and the Southwest, its responses to these climatic patterns are sometimes more closely aligned with one of these regions than the other, making climate and fire predictions more difficult (Dettinger et al., 1998). 
Recent climatic trends in the western US, including increased spring and summer temperatures, reduced annual precipitation and snowpack depth, earlier spring snowmelt, and lengthened fire season, have been correlated with significantly increased wildfire activity over the past two decades (Westerling et al., 2006). However, Crimmins et al. (2011) found that even as average temperature rose in the Sierra Nevada during the 20th century, water availability increased as well, causing plant species to migrate downhill instead of uphill as might have been expected. One possible explanation for this counterintuitive situation of increased fire activity occurring simultaneously with increased moisture availability is that more precipitation is falling as rain, and snowpacks are melting earlier, thus resulting in earlier and more intense summer drought, as identified in Westerling et al. (2006).

In research conducted for the State of California, Westerling and Bryant (2008) found that the largest changes in property damages under their climate change scenarios occurred in WUI areas proximate to major metropolitan areas in coastal southern California, the Bay Area, and in the Sierra foothills northeast of Sacramento. Specifically, by the late $21^{\text {st }}$ century under several climate scenarios identified as plausible by the IPCC, frequency of large fires (> 200 ha) in California is projected to increase by 12 to 128 percent; statewide area burned to increase by 12 to 169 percent; number of structures burned to increase by six to 16 percent; and economic losses from wildfire to increase by 15 to 36 percent (Westerling and Bryant, 2008; Westerling et al., 2009). Fried et al. (2004) found that under a scenario of doubled atmospheric $\mathrm{CO}_{2}$, area burned in a Sierra Nevada WUI zone would increase by 41 percent, while the number of wildfires escaping 
initial attack would increase by 125 percent, mainly because of the low staffing of fire suppression resources in rural areas.

In summary, although anecdotal evidence exists from throughout the western US that fuel treatments can be effective under moderate fire weather conditions, the increases in drought and temperature that are predicted over the next few decades for areas such as the Sierra Nevada, where fire activity appears to be more strongly limited by climate than by fuel availability, could well decrease this effectiveness significantly.

\subsubsection{Summary}

In summary, continued population growth, the spatial pattern of development that accompanies that growth, and the prospect of a warmer and drier climate are likely to directly affect wildfire regimes through their effects on the availability and continuity of fuels and the availability of ignitions (Westerling and Bryant, 2008). They are also likely to impact both wildfire occurrence and property losses due to wildfire, through both their effects on the number of structures proximate to wildfire risks, and fire suppression strategies and effectiveness (Ibid.). 


\subsubsection{Solutions}

\subsubsection{Wildland Fire and Fuels Management}

Most parties involved now acknowledge that despite increasingly enormous expenditures over the past few years, fire suppression, while a necessary component of wildland fire management, cannot solve the problem of growing fire danger in the WUI. Therefore, in large part, the focus has turned to improving wildland fuels management (Stephens and Ruth, 2005), despite the fact that researchers have yet to empirically demonstrate the effectiveness of specific fuel treatments in modifying severe wildfire behavior (Carey and Schumann, 2003; GAO, 2007; Martinson and Omi, 2008). Wildland fuels management has traditionally been the responsibility of government, while residential fuels have been the domain of homeowners or local community organizations (Mell et al., 2010). Federal policy directives like the National Fire Plan (USDA-USDI, 2000) and Healthy Forests Restoration Act (HFRA, 2003) focus heavily on fuel treatments planned through a collaboration between the federal government, local governments, and other stakeholders, and based on HFRA-authorized Community Wildfire Protection Plans (CWPPs).

However, due to the vast amount of area where treatment is warranted, inadequate funding, and fears over use of prescribed fire, it is not possible for federal agencies to keep up with the ongoing accumulation of live and dead forest biomass (Weatherspoon and Skinner, 1996); by some measures, hazardous wildland fuels are accumulating three times faster than they can be treated (Fong, 2007). Furthermore, fuel treatments may not 
prevent the ignition of homes by other homes even when the treatments successfully protected flammable vegetation nearby, as was seen during Lake Tahoe's Angora Fire in 2007 (Murphy et al., 2007). In addition, fuel treatments are expensive, and while in some cases costs may be defrayed by selling thinned biomass, often there is no market for the small-diameter material removed, and proposals to remove larger-diameter timber meet with public resistance (Reinhardt et al., 2008). Fuel treatments are also subject to delay by lawsuits for a variety of reasons. And while fuel treatments have been shown to reduce severe fire behavior, the extent to which fuel treatments reduce wildfire suppression costs, whether inside or outside the WUI, is unknown (Gude et al., 2009).

\subsubsection{Landowner Education}

Landowner education about fire safety in the WUI highlights personal responsibility, emphasizing modification of the physical characteristics of a home and lot to reduce the chance of structure ignition, raising awareness of appropriate actions to take in case of fire, and also attempting to provide an ecological context or background as well namely, that wildfire is a crucial, natural ecosystem process that cannot be eliminated, but must be accommodated by humans. Organizations such as Firewise Communities play a crucial role in disseminating such information to WUI residents (Firewise Communities, 2010). 


\subsection{Home/Lot Ignitability}

Fire hazard in the WUI is largely a question of a home's ability to resist ignition (Cohen, 2000). Regardless of wildland fuel conditions at large, wildfire is unlikely to destroy a home with low ignitability. The likelihood of a structure's ignition is dependent both on its physical attributes (e.g. roofing material, decks, vents) and the fire exposure conditions (e.g. magnitude and duration of heat flux from flames and firebrands) (Mell et al., 2010). Cohen (2000) found that home ignitions are not likely unless flames and firebrand ignitions occur within 40 meters of a home. Hence, common recommendations and/or regulations directed at homeowners in high fire hazard areas include the creation of defensible space around homes and making safety-enhancing improvements to both existing and new homes.

Defensible space is typically created by clearing dense, flammable vegetation, woodpiles, and other flammable items within 10 to 50 meters from the house and keeping a wellwatered zone of reduced flammability adjacent to the house. In California, this is process is regulated under Public Resources Code 4291 (PRC 4291). The "Lean, Clean, and Green" zone surrounds a house out to 10 meters and includes low, well-watered, less flammable vegetation; beyond this is the "Reduced Fuel" zone, which extends another 20 meters, or to the property line. Additional recommendations include removing tree limbs that overhang the roof or deck, or are near the chimney or overhead lines; keeping the roof and its gutters free of leaves, etc.; keeping lawns mowed and trees and shrubs 
trimmed; maintaining three to five meters of vertical and horizontal spacing between shrubs and trees; clearing at least three meters around propane tanks; using nonflammable surfaces for walkways; and placing woodpiles and flammable outbuildings at least 10 meters away from the house.

Physical attributes of a home that can affect ignitability include the roof, vents, eaves, and decks. The roof is probably the most important of these. Case studies from WUI fires in southern California have shown that approximately 70 percent of homes with nonflammable roofs survived, compared to only 19 percent of homes with flammable roofs (Foote, 1994). With the addition of 10 to 20 meters of vegetation clearance, the survival rate of homes with non-flammable roofs increased to roughly 90 percent. Other design features that can reduce fire hazard include double-pane windows, attic vent screens with 0.3-cm or smaller mesh, and boxed eaves. In addition, the siting of new homes away from topographic features such as chimneys and steep slopes can reduce the home's potential for exposure to high-intensity fire.

Because of the expense involved, many people would likely refuse to observe defensible space or fire-resistant construction standards if they were not mandatory. Hence, strict governmental fire hazard regulations have been enacted in some locations. For instance, after nearly every large, destructive WUI fire that has occurred within the past several decades in California, the State has created more restrictive defensible space regulations and mandated new, more stringent fire-resistant construction standards for high fire hazard areas (Dicus, personal communication). However, it should be noted that while 
defensible space and firewise construction standards do improve the safety of existing homes in fire-prone WUI areas, these measures cannot control future firefighting costs and may unintentionally have the effect of increasing residential growth and subsequent fire suppression costs near fire-prone lands (Rasker, 2009).

\subsection{Response to the Imminent Threat of Wildfire}

In the US, the standard approach to the threat of an approaching wildfire is mass evacuation (McCaffrey and Rhodes, 2009). However, there is a growing acknowledgment that evacuation may not always be safe or feasible in some locations. Furthermore, experience has shown that many people refuse to evacuate when ordered to do so, and numerous WUI fire deaths have occurred when people attempted to evacuate at the last minute in a panic. Therefore, some fire agencies in the US have begun to explore the feasibility of adopting the Australian "stay and defend or leave early (SDLE)" approach (Ibid.).

Unlike in the US, where the focus tends to be on reliance upon government fire prevention and protection measures, Australian fire authorities encourage residents to accept responsibility for how they will respond to the threat of wildfire (McCaffrey and Rhodes, 2009). Residents are asked to decide well before a fire occurs whether they will choose to leave when a fire threatens but is not yet in the area, or stay and actively defend their property, and to make appropriate preparations in advance for either option. SDLE is extensively publicized by the state governments in Australia through large-scale 
educational programs including publications, web sites, statewide media campaigns, telephone information lines, and public meetings.

The SDLE approach is supported by Australian research showing that most homes destroyed in bushfires were not burned by direct flame impingement, but by smoldering embers over a period of hours when nobody was present to defend the home (Wilson and Ferguson, 1985; Blanchi et al., 2006). In contrast, the passage of the flaming front (i.e., the greatest danger to life) may only last a few minutes. Thus, if a homeowner is sufficiently prepared to survive the brief passage of the flaming front, he or she is then available to actively patrol the property and extinguish the smoldering embers that pose the greatest threat to the home, and possibly neighbors' homes as well. Hence the Australian saying, "people protect houses and houses protect people." In contrast, the "shelter in place" method, usually mentioned in the US in the context of a last-ditch effort to survive the fire, does not involve pre-fire planning and connotes passively sheltering inside the house (McCaffrey and Rhodes, 2009).

\subsection{Cultural Attitudes Towards Fire and Fire Protection}

Another crucial aspect of landowner education is getting the message out that wildlands should not, and indeed cannot, be fireproofed (Reinhardt et al., 2008). Fire is a natural and critically important process, Smokey Bear and Bambi notwithstanding. If private property owners and the various levels of government can work together to reduce both unnaturally dense fuels and home ignitability, fire can be allowed to perform its 
ecosystem functions with minimal disruption to society, although because of health risks from smoke, and the potential for pockets of more intense fire behavior, homeowners will still have to make accommodations in the name of long-term fire hazard reduction. In short, an atmosphere of personal responsibility for fire safety in the WUI needs to be fostered, replacing the current situation in which it is assumed that the government should take full responsibility, at an unacceptable burden to all US taxpayers.

\subsubsection{Economic Incentives and Disincentives}

Rasker (2009) noted that the problem is rooted largely in the fact that the WUI is mostly private property - by one estimate, 71 percent in the western US (Schoennagel et al., 2009). The pace, scale and pattern of development on private property is controlled mostly at the county level. Thus, the federal government is limited in its options for addressing WUI fire hazard. Although its current approaches, including better interagency coordination and the previously discussed emphasis on fuel treatments and landowner education, are good ideas, they are not enough to bring firefighting costs down because they do not address the heart of the cost issue - the ongoing construction of homes in high fire hazard areas (Rasker, 2009). Furthermore, because fire-prone counties

and WUI communities are subsidized to a great extent by the federal government, they have little incentive to change the current situation by limiting development in fire-prone WUI areas. As a result, all US taxpayers bear the burden of protecting a small proportion of the total population from wildfire, at great expense. 
Rasker (2009) therefore presented 10 potential solutions to the problem that, in directly addressing costs, would also indirectly change the policies that foster low-density residential development in the WUI, thus ultimately reducing potential wildfire losses. Many of these ideas focus on economic incentives or disincentives that would help lead to increased fiscal responsibility, fairer and more equitable distribution of fire management costs, and improved homeowner and wildland firefighter safety. However, most of these would likely be unpopular due to the reduction of federal government subsidies to counties and WUI landowners, and would therefore require substantial political willpower at all levels of government to enact. They are summarized below:

1) Publish maps identifying areas with high probability of wildland fires.

Some states, such as California, Oregon, and Montana, already require this. Mapping at a national level would provide necessary baseline information for education and policy actions.

2) Increase awareness of the financial consequences of home building in fire-prone areas.

The federal government can inform local governments and WUI residents of the costs of fighting wildfires in the WUI, information which is currently lacking, for the most part. This could be done by facilitating studies of the costs of protecting homes from wildfires on a per-county basis, for instance. 
3) Redirect federal aid towards land use planning on private lands.

Several federal programs already provide assistance with fuel treatments and landowner education to local governments in high-fire risk areas. Some of this aid could be redirected to assist communities with land use planning, encouraging development away from the WUI, and offering financial incentives to communities that do this.

4) Add incentives for counties to sign firefighting cost share agreements.

"Master agreements" between federal and non-federal agencies to share firefighting costs can be difficult to implement and take years to negotiate, and there is a lack of standards and guidance for such agreements. Few counties sign them in the western US. Thus, there is a need for incentives for signing, and disincentives for not signing, these agreements. The OIG (2006) recommended Congressional clarification of the role of the US Forest Service in protecting private property, and suggested renegotiation between the Forest Service and non-Federal partners to ensure that suppression expenditures in private and WUI areas are appropriately shared (Liang et al., 2008), although such changes might not affect total suppression expenditures. 
5) Purchase or obtain easements on fire-prone lands.

Strategic land or easement purchases through various federal programs would help prevent private development in the most fire-prone areas that are at the greatest risk of imminent development. Purchases could be prioritized using the previously discussed national WUI fire hazard map.

6) Create a national fire insurance and mortgage program to apply lessons from efforts to prevent development in floodplains.

Congress could develop a national wildland fire insurance program, modeled after the National Flood Insurance Program (NFIP), that requires insurance coverage and provides disaster relief to landowners and communities in the WUI. As with NFIP, participation in this program would be contingent on adoption of local ordinances that minimize the future threat from wildfires. Homeowners building in the most fire-prone lands would be required to purchase firefighting insurance.

7) Allow insurance companies to charge higher premiums in fire-prone areas.

Currently, the insurance market is not providing disincentives to building in fire-prone areas because fire risk is being underpriced. Although insurance companies assess fire risk to homes and can cancel or fail to renew homeowner policies based on fire risk, they rarely do so, and are usually content with the homeowner taking various simple and inexpensive actions to reduce fire hazard and risk to firefighters. Some companies 
actually contract with private firefighters to create defensible space and to protect homes during wildfires. In addition, some states, including California, have Fair Access to Insurance Requirements (FAIR) programs in which subsidized insurance is offered to homeowners living in state-designated fire hazard zones when private companies refuse to insure them. All of these conditions are essentially incentives to build in highly fireprone areas. If insurance premiums were adjusted based on wildland fire risk, development in the WUI would be discouraged and thus freighting costs reduced.

8) Limit development in the wildland-urban interface with local zoning ordinances.

Local governments can regulate where future homes are built, directing them away from the most fire-prone parts of the WUI, by using planning tools, including zoning ordinances. However, zoning tends to be deeply unpopular in the rural West because it is seen as a government "taking" of private property. Hence, these tools are rarely used to limit or restrict development in the WUI. If the federal government was to stop subsidizing WUI development by shouldering most of the suppression costs of protecting homes from forest fires, then local governments would be much more likely to find ways to direct development away from the WUI, and therefore protect their budgets. Fried et al. (2008) noted that remarkable reductions in the rate of conversions from wildland to residential use have been seen in Oregon as a result of land use controls imposed in 1980. 
9) Eliminate home interest mortgage deductions for new homes in the wildland-urban interface.

Through the federal tax code, homeowners may deduct the interest on loans to buy, build, or improve a home for mortgages up to $\$ 1,000,000$ on a first or second home, a situation that encourages second homes and larger lots. Eliminating or greatly reducing the mortgage interest deduction would reduce future fire suppression costs by decreasing both the number of new homes built in the WUI and the lot size of those new homes.

10) Induce federal land managers to shift more of the cost of wildland firefighting to local governments by reducing their firefighting budgets.

Because county governments currently enjoy a firefighting subsidy from the federal and state governments, there is no financial disincentive to curtail the building of more homes on fire-prone lands. If the federal government has less money available to spend, more of the burden of protecting homes will fall on county-level jurisdictions. This, in turn, will serve as a powerful disincentive to permit more homes in the wildland-urban interface. 


\subsection{Fuel Treatments}

\subsubsection{Definition and Purpose}

Although wildfire behavior is driven in part by weather and topography, human efforts to influence fire behavior necessarily focus on hazard reduction through fuel treatments (Peterson et al., 2005). The term "fuel" refers to the live and dead surface and canopy biomass that are burned in wildland fire (Reinhardt et al., 2008). Fuel treatments are mechanical, silvicultural, or burning activities conducted by forest managers to reduce fuel loadings and continuity, or otherwise change fuel characteristics, in order to lessen fire behavior or burn severity in the fuel-altered zone (Agee et al., 2000; Agee and Skinner, 2005; NWCG, 2006). For example, the main objective of the National Fire and Fire Surrogate Study (FFS; Schwilk et al., 2009) is to alter stand conditions so that projected fire severity would result in at least 80 percent of the dominant and codominant trees surviving a wildfire under $80^{\text {th }}$ percentile fire weather conditions (Weatherspoon and McIver, 2000). This reduction in fire severity is typically accomplished by reducing surface fuels, ladder fuels, and canopy bulk density; increasing canopy base height; and providing for the retention of large, fire-resistant trees (Graham et al., 2004; Agee and Skinner, 2005). General principles aside, the objectives and prescriptions for any given fuels treatment project are always site-specific (Agee et al., 2000).

Fuel treatments are usually implemented at the stand level, but agencies are increasingly conducting landscape-level fuel modification activities (Reinhardt et al., 2008). In 
addition, fuel treatments often differ between WUI and wildland areas (Reinhardt et al., 2008; Safford et al., 2009). In the former, the focus is on protection of lives and property, achieved via the creation of safe zones for direct suppression activities based on mechanized support. WUI fuel reduction projects often emphasize mechanical treatment over prescribed fire use, and can be complicated due to multiple ownership boundaries (Schoennagel et al., 2009). In contrast, wildland fuel treatments usually take place in uninhabited areas on public lands, are more likely to incorporate prescribed fire, and are typically intended to mitigate the ecological effects of large, severe wildfires and to restore fire-prone ecosystems (Ibid.). They also facilitate indirect fire control efforts by slowing fire spread (Safford et al., 2009).

The discussion in the preceding paragraph illustrates a point about the purpose of fuel treatments; namely, what their relationship to fire management activities is, or should be. While enhancement of fire suppression or prescribed burning activities is commonly cited as a main objective of fuel treatments (e.g. Agee et al., 2000; Moghaddas, 2007), the argument has been made that this is a fundamental misunderstanding of the situation, and that the overriding goal of fuel treatments should only be to reduce fire behavior and severity in places where they have been unnaturally high (Stephens and Ruth, 2005; Reinhardt et al., 2008). In other words, according to this viewpoint, the point of fuel treatments is not to reduce fire frequency, size, spread rate, or annual area burned; nor is it to extinguish existing fires, facilitate fire suppression activities, or reduce suppression costs. This is because wildfire is an essential ecological process that should not, and indeed cannot, be permanently eliminated from the landscape (Reinhardt et al., 2008). 
The almost complete exclusion of low-intensity fire during decades of fire suppression has only guaranteed that future fires will be larger, more severe, and more uncontrollable with each passing year (although fire weather, not fuel loading, is the ultimate determining factor in the occurrence of such "megafires" [Bessie and Johnson, 1995; Graham, 2003]). It is instead more appropriate to think of fuel treatments as reducing the potential for unnaturally severe fire effects, increasing ecosystem resilience, and making wildfire more socially acceptable. This lack of clarity regarding objectives and expectations of fuel treatments has resulted in substantial confusion and misconceptions about the subject, and created unnecessary divisiveness within the fire science and management communities (Ibid.).

\subsubsection{Need}

The semiarid ponderosa pine and mixed-conifer forests of the western US were once dominated by large, fire-resistant trees and shaped by frequent low-intensity wildfire. It is estimated that prior to the $19^{\text {th }}$ century, California alone typically experienced an annual average of 1.8 million ha of wildfire, an amount far beyond what is now considered "extreme" (Stephens et al., 2007b). In these forests, productivity frequently exceeds decomposition; as a result, flammable live and dead biomass accumulates in the absence of regular fire or other removal activities, and can persist for 30 years or longer (Weatherspoon and Skinner, 1996; Stephens, 2004).

The disruption of this fire regime due to the cumulative effects of $19^{\text {th }}$ and $20^{\text {th }}$ century land use changes, including timber harvesting, livestock grazing, and fire suppression, as 
well as fluctuating climatic conditions, has resulted in denser forest canopies, a higher proportion of fire-intolerant (shade-tolerant) species, fewer large trees, and more understory ladder fuels (shrubs and small trees) than during the pre-Euroamerican era, all conditions that increase the probability of surface fires developing into crown fires (McKelvey et al., 1996; Scott and Reinhardt, 2001; Franklin and Agee, 2003; Dellasala et al., 2004; Graham et al., 2004; Agee and Skinner, 2005; Peterson et al., 2005; North et al., 2007; Littell et al., 2009; Schwilk et al., 2009). In contrast, forests typified by lowfrequency (on the order of centuries), high-intensity fire regimes and heavy fuel loadings (e.g., Rocky Mountain lodgepole pine and high-elevation spruce-fir) are unlikely to have experienced unnatural fuel buildup during the fire suppression era (Romme et al., 2004); therefore, fuel treatments in these forests cannot be justified for ecological reasons alone (Franklin and Agee, 2003; Dellasala et al., 2004).

Furthermore, highly successful, institutionalized fire suppression efforts begun in the mid-20th century and continuing today mean that wildfire now occurs less frequently in the Sierra Nevada and cover much less area than was the case prior to Euroamerican settlement - 97 to 99 percent of wildland fires are extinguished during initial attack at a size of less than 0.1 ha (Stephens and Ruth 2005; Stephens et al., 2007b). However, fires are much more likely to be large and severe when they do occur (Weatherspoon and Skinner, 1996).

Ironically, because of this institutional emphasis on fire suppression, fuels continue to accumulate and therefore fire hazard is perceived as growing more critical with every 
passing year (although it is probably most accurate to say that the interactions between land use history and climate are the primary drivers of wildfire activity [Littell et al., 2009]). Recent estimates of western US forest area at high risk of catastrophic wildfire have ranged from approximately 16 million ha on US Forest Service lands (GAO, 1999) to over 77 million ha on all public lands (Office of the President, 2002). Several studies have pointed out that large, severe wildfires have been increasing over the past several decades (Stephens, 2005; Stephens and Ruth, 2005; McKelvey and Busse, 1996; Westerling et al., 2006; Miller et al., 2009). Due to this perception that both human and natural resources are increasingly at risk from severe wildfire across the western US, the need for both fire hazard reduction and ecological restoration in western US fire-adapted conifer forests is generally considered to be urgent (GAO, 1999).

\subsubsection{Efficacy}

Although much anecdotal evidence exists showing the efficacy of fuel treatments in mitigating severe fire behavior under moderate fire weather conditions, Martinson and Omi (2008) describe fuel treatment effectiveness as being a controversial subject, noting that "despite a well-established theoretical basis for their use, scant empirical evidence currently exists on fuel treatment effectiveness for mitigating the behavior and effects of extreme wildfire events." In northern California mixed-conifer forests, fuel treatments have been observed to fail (i.e., have no effect on wildfire severity or effects) under extreme weather conditions that included high winds, high temperatures, and low relative humidity (R. Tompkins, Plumas National Forest, personal communication). Furthermore, 
because fire activity in Sierra Nevada mixed-conifer forest is becoming less fuel-limited and more climate-limited (Miller et al., 2009), it is unclear whether existing climatic trends towards warming and more intense summer drought will weaken or negate any benefits that are currently obtained from fuel treatments.

Due to sociopolitical constraints, it is not possible to experimentally burn large areas of forestland in the US; therefore, most studies evaluating fuel treatment efficacy are based on computer modeling simulations of hypothetical fires entering either real or simulated fuel treatments, with all the attendant assumptions that modeling involves and which often do not reflect real-world conditions (Carey and Schumann, 2003; Graham et al., 2004). The previously mentioned nationwide Fire and Fire Surrogate Study (FFS) uses this methodology with real-world fuel treatments under experimental conditions (Weatherspoon and McIver, 2000). However, because the assumptions used in modeling have not been validated, particularly under extreme fire weather conditions, the results of modeling experiments are best viewed as "hypotheses awaiting an empirical test" (Martinson and Omi, 2008).

Nonetheless, some information can be gleaned from situations in which, purely by chance, wildfires burned through areas that had previously received fuel treatments. As of 2008, 23 studies based on this type of situation had been published; all of them relied on post facto analysis (Martinson and Omi, 2008). Unfortunately, only five of these studies included both a statistical test and adequate control to discern a fuel treatment effect in an actual wildfire (Ibid.). The results of these five studies generally showed a decrease in 
fire severity (as measured by amount of bole char, crown scorch, or crown consumption/ mortality) in treatment areas where activity fuels (slash) had been removed, either by mechanical removal or by prescribed burning. Sites that had received prescribed fire saw the greatest reductions in severity.

It is anticipated that in 2011 the USFS Pacific Southwest Research Station will be publishing at least one paper evaluating the efficacy of fuel treatments in altering real (not modeled) wildfire behavior, as well as investigating treatment effects on stand carbon pools, using data from two dozen or more recent fires in California (M. North, USFS Pacific Southwest Research Station, personal communication).

\subsubsection{Revenue Potential}

Forest fuel treatments come in three general types: prescribed burning, mastication, and felling of trees (Barbour et al., 2007), as well as combinations thereof. Prescribed burning is generally less expensive than mechanical fuel treatments (McCandliss, 2002; Peterson et al., 2005), although when merchantable products can be sold to help offset treatment costs, net project costs can fall below those for a burning or mastication project, thus allowing for a larger area to be treated and providing an economic benefit to the local community (Barbour et al., 2007; Hartsough et al., 2008). Burning and mastication projects always sustain a net cost because no merchantable products are generated (Barbour et al., 2007). However, the costs of fuel treatment implementation are minuscule in comparison to the amounts spent on fighting wildfires, with one federal 
government estimate putting the cost of fire suppression at over ten times the cost of prescribed fire (\$1,438 ha $\mathrm{ha}^{-1}$ vs. $\$ 126 \mathrm{ha}^{-1}$, respectively) (USDA-USDI, 2003).

The cost of prescribed burning on National Forest lands in the US was found by Cleaves et al. (2000) to vary between $\$ 57$ and $\$ 551$ per ha, with costs being highest in the northern and western US, and lowest in southern and eastern forests. McCandliss (2002) cited costs ranging from $\$ 16$ to $\$ 173$ per ha for prescribed burns on the Sierra National Forest. Prescribed fire costs from six western US National Fire and Fire Surrogate Study (FFS; Schwilk et al., 2009) sites ranged from $\$ 310$ to $\$ 1,210$ per ha, although these were likely overstated because of smaller burn unit sizes and more inexperienced crews than are typically used by the federal land management agencies (Hartsough et al., 2008). Factors influencing the cost of prescribed burning include the cost of fireline installation, ignition type, mop-up requirements, potential damage from escape, smoke management, aesthetics, and safety (Cleaves and Brodie, 1990), as well as overall stand condition, fuel type, burn complexity, and season of burning (Hartsough et al., 2008).

Fuel treatment projects that involve tree felling are often expensive and controversial (North et al., 2007), and although the potential for the sale of sawlogs sometimes exists, the woody material planned for removal frequently consists of small, unmerchantable trees that cannot be sold to help cover treatment costs ${ }^{1}$ (Peterson et al., 2005; Stephens and Moghaddas, 2005c). At the five of the western US FFS sites, mechanical harvesting costs (including both thinning and mastication) ranged from $\$ 1,730$ to $\$ 5,150$ per ha

\footnotetext{
${ }^{1}$ Although this material could potentially be used as fuel to create heat and electricity in cogeneration plants, or to create cellulosic ethanol fuel, large-scale implementation is infeasible under current market conditions.
} 
(Hartsough et al., 2008). When offset by the value of merchantable products removed, costs were significantly lower than for prescribed burning; in two cases, including at Blodgett Forest in the central Sierra Nevada, a net profit of nearly $\$ 3,000$ per ha was predicted from mechanical treatments (Ibid.). However, the magnitude of this benefit is heavily influenced by the value of the products obtained. Factors influencing the cost of mechanical fuel treatments are associated with machinery used, operators, supervision and planning, site characteristics, haulage, and facilities used (Chalmers and Hartsough, no date).

Mason et al. (2006) performed a cost/benefit analysis of fuel treatments, broadened to include market and non-market considerations. They found that despite the apparently unrecoverable costs of removing unmerchantable smallwood for fire hazard reduction, the negative impacts of catastrophic crown fires on society are significantly underestimated, and the benefits provided by fuel treatments are far more substantial than commonly acknowledged. These benefits include avoidance of firefighting costs, fatalities, and property destruction, among numerous others. Typical fuel treatment costs were calculated to be approximately $\$ 1,433$ per ha, while the society-wide benefits of avoiding stand-replacing crown fire were valued as high as $\$ 4,896$ per ha (Ibid.).

\subsubsection{Policy}

Millions of hectares of forest lands in the western US contain accumulations of flammable fuel that are much higher than historical conditions (USDA-USDI, 2001a), 
and although timber harvesting, livestock grazing, and weather patterns have all played a role (Peterson et al., 2005), this situation can predominantly be attributed to the policy of total fire suppression (the "10 a.m. policy") pioneered by the US Forest Service in the early $20^{\text {th }}$ century, and adopted by other federal agencies such as the National Park Service and Bureau of Land Management (USDA-USDI, 2000; Stephens and Ruth, 2005). This policy, spurred by massive conflagrations such as 1871's Peshtigo Fire and 1910's Big Blowup, remained in place with the US Forest Service until the early 1970s, even as the National Park Service had begun using prescribed fire to restore ecosystem health in the late 1960s following the issuance of the "Leopold Report" (Stephens and Ruth, 2005). However, the use of fire as a management tool on USFS lands remained rare in subsequent decades. Even as annual fire suppression expenditures increased significantly in the last half of the $20^{\text {th }}$ century, average annual area burned increased concurrently (Ibid.).

As a result of the 1994 fire season, with its 34 fatalities and growing recognition of fire problems caused by fuel accumulation, federal fire policy was modified beginning in 1995 to recognize and embrace the role of fire as an essential ecological process (1995 Federal Fire Policy; USDA-USDI, 2001a). It is now widely recognized that the near total exclusion of small, low-intensity wildfires due to decades of highly successful fire suppression has diminished essential ecosystem processes such as nutrient cycling, soil productivity, plant succession, and overall watershed health (Dombeck et al., 2004). However, our nation's legacy of treating fire as a dangerous, destructive force has made it difficult for improved scientific knowledge to be translated into the policy arena, and as a 
result, fire suppression has remained the primary focus of wildland fire management activity (Franklin and Agee, 2003; Dombeck et al., 2004). Hence the occasional characterization of US wildland fire policy as "bipolar" (Dellasala et al., 2004).

In the late 1990s, Congress, responding to the convergence of forest health concerns, skyrocketing firefighting costs, and the increasing danger to WUI residents from uncontrolled conflagrations, asked the US Forest Service to come up with a cohesive strategy for landscape-scale fire hazard reduction (GAO, 1999). The Forest Service responded by reiterating its commitment to improving the resilience and sustainability of forests and grasslands at risk; conserving priority watersheds, species and biodiversity; reducing wildland fire costs, losses, and damages; and better ensuring public and firefighter safety (USDA-USDI, 2000). Then, in response to the record fire season of 2000, which included the Cerro Grande escaped prescribed burn that destroyed 235 homes in New Mexico (USDI National Park Service, 2001), President Clinton requested the Secretaries of Agriculture and Interior to review existing federal fire policy and prepare a national strategy to prevent the loss of life, natural resources, private property, and livelihoods in wildland and WUI areas (USDA-USDI, 2001a).

The review, while finding that the 1995 policy was still generally sound and appropriate, resulted in the creation of the National Fire Plan (NFP; USDA-USDI, 2000), which was intended to enhance response to severe wildland fires, reduce their impacts on communities, and ensure sufficient firefighting capabilities for the future. The NFP includes five key points: firefighting preparedness, rehabilitation and restoration of 
burned areas, reduction of hazardous fuels, community assistance, and accountability. Among other things, the NFP called for the development of integrated federal/state/local fuel management teams to oversee projects; finding ways to utilize traditionally nonmerchantable small diameter wood from fuel treatment projects; and committing adequate financial support to ensure projects are accomplished expeditiously (USDAUSDI, 2000).

As a consensus grew among both fire scientists and policy makers that the continuation of large-scale fire suppression would inevitably result in larger and more severe wildfires in the future, fuel treatments came to be seen as a panacea by some segments of the public (Weatherspoon and Skinner, 1996; USDA-USDI, 2000; Franklin and Agee, 2003; Reinhardt et al., 2008). Accordingly, Congress responded to the NFP by increasing funding for fuel reduction projects significantly in the early 2000s. Simultaneously, the Bush Administration promoted its Healthy Forests Initiative (HFI; Office of the President, 2002), much of which became law as the Healthy Forests Restoration Act of 2003 (HFRA, 2003). The HFRA was intended to streamline the administrative and environmental review processes and limit legal appeals in response to purported lawsuitrelated delays in the implementation of fuel treatment projects, although the assertion of excessive delays was later shown to be false (GAO, 2003).

The HFRA was widely criticized the scientific community for its failure to rely on established forest science as the basis for the fuel management directives it established; specifically, it did not consider the appropriateness of treatment across differing forest 
types and fire regimes (Franklin and Agee, 2003; Stephens and Ruth, 2005). The Act was equally deficient in its failure to address the need for comprehensive, long-term wildfire management policy in the US (Franklin and Agee, 2003; Dellasala et al., 2004). In the arena of public opinion, the HFRA was seen by some as little more than a cover for increased logging (Dellasala et al., 2004).

Furthermore, while the NFP and HFRA mandate that at least 50 percent of the funding allocated to federal fuels projects be used to protect WUI communities, according to one study, WUI and immediately adjacent areas (the "Community Protection Zone") treated under the NFP have thus far comprised only eleven percent of the total at-risk area treated in the western US (Schoennagel et al., 2009), although the federal government disputes this conclusion (USDI-USDA, 2006). Due largely to the fact that these WUI areas are predominantly non-federal property (Theobald and Romme, 2007), federal fire managers charged with implementing NFP/HFRA-specified WUI fire protection projects often find that their options are limited. However, the formation of Community Wildfire Protection Plans (CWPPs), as authorized by and defined in the HFRA, can facilitate cooperation between agencies and private landowners on fuel reduction projects; as of 2010, roughly 60 percent of 6,506 at-risk communities in the western US had a CWPP or equivalent plan in place, while an additional 24 percent were identified as being at "reduced risk" (NASF, 2010).

Extensive recommendations for improving federal forest fire policy were offered by Stephens and Ruth (2005). Their suggestions included the following: 
- explicitly place emphasis on reducing potential fire behavior and effects, instead of simply "reducing fuels";

- ensure that fuel treatments are site-specific and appropriate for the forest type in which they are applied;

- require monitoring and evaluation of treatment effectiveness, instead of pressuring managers to meet area-treated targets as an end in itself;

- increase use of the existing Wildland Fire Use Policy;

- require the creation of fire plans in all forests with hazardous fuel conditions;

- increase use of Strategically PLaced Area Treatments (SPLATs) and Defensible Fuel Profile Zones (DFPZs), while emphasizing the need for WUI homeowners to maintain defensible space around combustion-resistant homes;

- provide more detailed information about wildfires, such as amounts of land burned in low-, moderate-, and high-severity fires, and by how much these amounts deviate from desired conditions for each class;

- keep fire policies easily adaptable in the face of year-to-year uncertainties, e.g. climate variability;

- re-prioritize the relationship between fine-scale filters (e.g. the Endangered Species Act) and coarse-scale filters (e.g. overall ecosystem integrity) so that the focus is on outcomes instead of specific methods, or spatial or temporal constraints (i.e., look at the big picture);

- modify regulations to allow more prescribed burning opportunities while also considering public health; 
- invest in professional fire ecology or fuels-management positions to the same degree to which fire suppression resources have been funded;

- $\quad$ strive to encourage collaborative stewardship with projects that will benefit local communities and take advantage of adaptive management;

- encourage Congress to provide a larger federal fire suppression budget, to prevent fuel treatment funds from being taken for emergency fire suppression activities;

- use more caution on fires that escape initial attack and on "megafires", as these fires have caused numerous casualties and suppression activities on them, while very expensive, are largely ineffective.

In summary, because managing for fuels directly affects soil, water, air processes and functions, and fish and wildlife habitats, a rigid, one-size-fits-all approach to management such as that presented in the HFRA is not appropriate (Dellasala et al., 2004; Reinhardt et al., 2008). Instead, a long-term, comprehensive national forest fire policy that considers all aspects of wildfire management, not just fuels and fire suppression, is needed (Franklin and Agee, 2003; Stephens and Ruth, 2005). This policy should be based on scientific principles and data, consider the full range of ecological and social values, include adaptive management as a core principle, and should be an integral part of an overall vision for stewardship and management of the nation's forests. 


\subsubsection{Treatment Implementation and Types}

The type and sequence of fuel treatments selected for a given site depend on the amount of surface fuel present; the density of understory and midcanopy trees; long-term potential effects of fuel treatments on vegetation, soil, and wildlife; and short-term potential effects on smoke production (Peterson et al., 2005). Additional considerations include site access, what materials are to be removed versus left on site, and costs. It is important to note that because forest vegetation is constantly growing, fuel treatments must be maintained over time. A commonly cited fuel treatment lifespan is 10 to 15 years, after which a treatment's ability to reduce severe fire behavior is significantly reduced (Agee and Skinner, 2005; Battaglia et al., 2008). Prioritization of fuel treatment areas in the WUI is typically determined through the use of risk analysis techniques that identify the probabilities of severe fire in a given area and the values at risk of damage or loss from wildfire.

Both prescribed fire and mechanical thinning treatments are commonly used to modify vegetation for fire hazard reduction throughout the western US, including in Sierra Nevada mixed conifer forest (Graham et al., 2004; Peterson et al., 2005). In addition, mastication or mulching treatments have become increasingly popular due to their effectiveness at quickly increasing canopy base height in dense stands, while avoiding the drawbacks of prescribed fire (Kane et al., 2009). The various treatment types are used both separately and in combinations. 


\subsubsection{Prescribed Fire}

Prescribed fire is often used to reduce surface fuels for fire hazard reduction, as well as for ecosystem restoration in appropriate forest types, such as southwestern ponderosa pine and mixed conifer (Peterson et al., 2005). It may be used alone or in combination with other fuel treatment types. The effectiveness of prescribed fire depends on weather, initial fuel conditions, and skill of the fire manager, and it can be safely conducted only if the probability of crown fire initiation is low (Ibid.).

Prescribed fire accomplishes the aforementioned goals by reducing fuel continuity on the forest floor, thereby slowing fire spread rate, reducing fire intensity, and reducing the likelihood of fire spreading into ladder fuels and tree crowns (Peterson et al., 2005). It can also be used as a non-mechanical method of thinning unnaturally dense thickets of small trees or brush by directly killing them. This is often done in areas where mechanical treatment options are limited, such as in national parks. Thus, prescribed fire has been successfully used as a standalone treatment in Yosemite and Sequoia-Kings Canyon National Parks in the Sierra Nevada, as well as on National Forest lands, since the late 1960s (Van Wagtendonk, 2007). The Kings River Sustainable Forest Ecosystems Project, begun in 1994, is a large-scale attempt to reduce fire hazard and restore ecosystem function in westside Sierra Nevada brush and forest types using a combination of fuel treatment types, including standalone prescribed fire (McCandliss, 2002). 
Two of the four fuel treatment types in the current research involved prescribed fire: Fire Only, and Thin + Fire.

\subsection{Advantages}

In fire-adapted ecosystems such as Sierra Nevada mixed conifer forest, fire plays a crucial role in fuel consumption, plant mortality, and soil heating, which in turn affect post-fire vegetation composition, forest nutrient cycling, creation of wildlife habitat, and in strongly fire-adapted species such as giant sequoia, the spurring of regeneration (Stephenson, 1999). Fire establishes dynamic landscape mosaics that maintain ecological integrity (Reinhardt et al., 2008). Thus, fuel treatments that do not include fire may not fully achieve restoration goals in fire-prone ecosystems (Ibid.).

\subsection{Constraints}

Prescribed fire, if excessively intense, may injure or kill individual trees and clumps of trees that are not targeted for removal through crown scorch or consumption, cambial heating, or consumption of feeder roots; it may also result in soil sterilization and hydrophobicity (Peterson et al., 2005). However, the primary constraints to the use of prescribed fire have largely to do with human, not ecological, concerns. Prescribed fires create smoke that decreases air quality in local communities and contributes to greenhouse gas emissions (Ibid.); hence, one of the largest stumbling blocks to fire use can be obtaining permission from the local Air Pollution Control District (APCD; 
McCandliss, 2002). Additionally, legal protections for threatened and endangered species can limit management options (Ibid.). Furthermore, the fear of an escaped fire, such as 2000's Cerro Grande Fire which burned 235 homes in Los Alamos, New Mexico (USDI National Park Service, 2001), means that a cautious and well-planned approach is crucial to gaining the support of the public. Without this trust, such programs will ultimately fail (McCandliss, 2002; North et al., 2009b).

For these reasons, burn prescriptions are written in ways that keep fire intensities and flame lengths to the minimum levels required to achieve the project's objectives while minimizing negative impacts (McCandliss, 2002). Burns are implemented only in very narrow windows of weather conditions. Low-intensity fires that back slowly downhill with typical flame lengths of 0.5 to $1 \mathrm{~m}$ are preferred; if this is not possible, narrow striphead ignition patterns are used, such that the fire makes only small uphill runs of 15 to 30 meters before encountering a previously burned area and going out. Complete ignition within the burn perimeter is not expected, and unburned patches are common.

Although the historical burning season in the central Sierra Nevada is summer and fall, conducting prescribed burns during these seasons can be problematic (McCandliss, 2002). Air pollution in the Central Valley tends to be worst during these months, and the potential for smoke production, spot fires, and resource damage from excessively intense fire is greatest, due to high heat and low fuel moistures. Furthermore, fire staffing is at its lowest, due to fire management teams being sent elsewhere around the State and country. Finally, because conifer forest burns tend to go slowly, only covering about ha per day, 
the short-term burning windows available from APCD during this period are not adequate to achieve much in the way of results. Hence, prescribed burning in the Sierra Nevada is typically done in the late fall (North et al., 2007). However, it may be conducted any time, even in winter if conditions permit (McCandliss, 2002). Regardless of season, burns are always staffed adequately to provide for immediate fire suppression, should it become necessary, and several days of patrol are scheduled at the end of each fire to ensure no escapes occur.

It is also important to note that when using fire as a standalone treatment, multiple entries over time are required. The first burn treatment will actually increase surface fuel loading, and therefore potential wildfire behavior, as small trees killed by the fire fall over. Keifer et al. (2006), in a study of mixed conifer surface fuel loading in Yosemite National Park, found that within ten years after prescribed fire, fuel loads had returned to from 66 to 84 percent of the pre-fire total, depending on species composition and thus fire regime (e.g., fuels accumulate more quickly in ponderosa pine stands than in white fir, thus the former has a natural regime of more frequent fire). In many cases, shrubs will also begin resprouting immediately. Thus, for areas in Sierra Nevada mixed conifer which have not seen fire in a century or more, McCandliss (2002) recommends two light underburns on a site within five years, followed by maintenance burns every five to 10 years. Over time, this provides benefits including lower fire temperatures, less smoke, lower costs, and greater firefighter safety. 
It is widely believed that in the most dense stands, burning without first thinning is excessively risky (Peterson et al., 2005); thus, some debate exists as to whether the reintroduction of fire in such unnaturally dense stands should be preceded by a preliminary mechanical treatment ("structure-based restoration"; Stephenson, 1999). However, some fire researchers and managers believe that making repeated entries with fire alone is more appropriate, given that our knowledge of pre-Euroamerican forest structure is incomplete ("process-based restoration"; Ibid.).

Given the culture of risk-avoidance in federal land management agencies, and the management emphasis on achieving target numbers for area treated regardless of how appropriate or effective the treatment, it is unsurprising that mechanical fuel treatments are often preferred over prescribed fire, especially in the WUI (Schoennagel et al., 2009). However, in remote backcountry or wilderness areas, the use of fire has gradually become more accepted; over the years, this policy has gone through a series of name changes from "Let Burn" to "Prescribed Natural Fire" to "Wildland Fire Use" to the current “Appropriate Management Response” (Van Wagtendonk, 2007).

\subsubsection{Thinning/Silvicultural Treatments}

Thinning or silvicultural fuel treatments typically utilize traditional timber harvesting techniques in order to address crown fire hazard (Graham et al., 1999). This is achieved by increasing spacing between the residual tree crowns (i.e., decreasing canopy bulk density) and removing small understory trees, low branches, and tall shrubs ("ladder 
fuels") that create vertical continuity between surface fuels and the forest canopy, carrying fire into tree crowns (i.e., increasing canopy base height) (Agee and Skinner, 2005). Crown fires are unlikely to be sustained in stands thinned to canopy bulk densities below approximately $0.10 \mathrm{~kg} / \mathrm{m}^{3}$ (Agee, 1996). As a result of these actions, potential crown fire behavior may be reduced, especially in forest types that historically burned in low severity fires (Reinhardt et al., 2008). Fuel treatments in the WUI tend to rely more heavily on mechanical methods than on prescribed fire (62 percent vs. 29 percent), due to the minimized smoke production and perception of reduced risk of uncontrolled fire from mechanical treatments (Schoennagel et al., 2009).

Three of the four fuel treatment types in the current research involved thinning from below: thin and masticate, thin and pile burn, and thin and broadcast burn.

\subsection{Advantages}

As compared to prescribed fire, the advantages of fuel treatments that incorporate thinning include increased precision, insignificant air pollution emissions, a low risk of treatments leaving prescribed boundaries, and the ability to produce forest commodities, as well as the ability to ensure fire hazard reduction by removing fuels from the forest via whole-tree yarding, also known as biomassing (Peterson et al., 2005; Stephens and Moghaddas, 2005c). 


\subsection{Constraints}

Thinning-based fuel treatments increase surface fuel loading and therefore potential fire severity through breakage, handling of slash, and disruption of the forest floor (van Wagtendonk, 1996; Graham et al., 1999; Agee and Skinner, 2005). Opening the canopy through thinning activities may also result in higher midflame wind speeds, increased heating and drying of surface fuels, and increased flammable grassy and shrub fuel loading over time due to the reduced tree competition, which would tend to promote increased fire behavior (Agee et al., 2000; Peterson et al., 2005). Stephens and Moghaddas (2005c) found that most of the traditional silvicultural systems they examined (namely, all plantation treatments, overstory removal, and individual tree selection) did not effectively reduce potential fire behavior and effects, especially wildfire-induced tree mortality under high hazard and extreme hazard fire weather conditions; thinning from below, and old-growth and young-growth reserves, were more effective at reducing predicted mortality in trees up to $51 \mathrm{~cm} \mathrm{DBH}$. The effective removal of ladder and surface fuel should help minimize fire behavior and effects by reducing the fuel load and potential for fire spread (Stephens, 1998; Graham et al., 2004; Peterson et al., 2005).

Maintenance of traditional timber stocking levels may not be always be compatible with fuel treatments. Keyes and O'Hara (2002) noted that pruning, thinning from below, and heavy thinning could all be effective in reducing potential crown fire behavior. However, the heavy thinning approach, as used in fuelbreaks, would likely be incompatible with 
traditional forest management objectives (i.e., maximizing density for timber production), as the requisite reduction in canopy bulk density for fire hazard reduction would also result in significant understocking from the timber management perspective. The authors also noted that canopy bulk density is not an intuitive measurement for forest workers, and that it remains necessary to relate crown bulk density to more common and more useful stand density measures such as stand density index (SDI).

From an ecological standpoint, mechanical fuel treatments alone cannot replace the numerous ecosystem benefits that fire provides in fire-adapted ecosystems; hence, if one of the management goals is ecological restoration in a dry forest type, thinning alone is inadequate (Reinhardt et al., 2008). Additional ecological concerns that can stem from thinning treatments include soil disturbance and compaction, disruption of nutrient cycling, damage to residual trees, and enhancement of root pathogens (Stephens and Moghaddas, 2005c).

Because small, unmerchantable trees are often the main product of thinning treatments, agencies such as USFS and BLM often include some larger, merchantable trees in their treatment plans (M. North, USFS Pacific Southwest Research Station, personal communication). However, this frequently triggers lawsuits by a distrustful public who feel that the proposed project is either too intensive, or not intensive enough (Barbour et al., 2007). From an ecological perspective, the retention of large, fire-resistant trees is recommended because it increases overall ecosystem fire resilience (Franklin and Agee, 2003; Agee and Skinner, 2005), and generally speaking, large-tree removal is secondary 
to the reduction of surface fuels and thinning smaller ladder-fuel trees when considering wildfire hazard mitigation overall (North et al., 2009b). A partial solution to the question of larger-tree removal is to encourage the cutting of small-to-intermediate sized (25- to 41-cm DBH) shade-tolerant individuals that are acting as ladder fuels to even larger shade-intolerant trees (Ibid.).

\subsubsection{Mastication/Mulching/Chipping}

Mastication (also known as mulching) is an increasingly popular mechanical fuel treatment that chips shrubs, small trees, and down woody debris with a rotary cutting or shredding head mounted on an excavator, depositing the resulting woody material in a layer on the ground (USDA, 2004a). Mastication allows land managers to meet fuel treatment goals while avoiding the constraints inherent with the use of prescribed fire (Kane et al., 2009), although it may also be used as a preliminary treatment prior to prescribed burning (Glitzenstein et al., 2006; Reiner et al., 2009). Despite the growing popularity of this treatment type, current scientific knowledge on mastication is limited (Reiner et al., 2009).

Mastication treatments change fuel arrangement by lowering the vertical height of fuels, thus increasing canopy base height and decreasing canopy bulk density (Reiner et al., 2009). However, surface fuel loading, particularly in the 1- and 10-hour size classes, is increased and therefore overall site fuel loading is not reduced (Kane et al., 2006). Fuel loading effects from mastication are site-specific and highly variable, depending upon 
type of equipment used, operator experience, and site vegetation characteristics among other factors (Kane et al., 2009). Other effects of mastication may include reduced soil compaction impacts as compared to traditional mechanical treatments (due to the equipment operating on top of the chip layer), suppression of shrub and small tree regeneration, and expedited fuel decomposition (Keyes and O'Hara, 2002; Kane et al., 2006).

In addition, fuel properties including bulk density, particle shape, and surface area-tovolume ratio are significantly changed by mastication (Kane et al., 2009). Mastication reduces particle size, changes particle shape from round to irregular, and increases particle fracturing and surface area-to-volume ratio. The result is a novel fuelbed type that undergoes changes in fuel moisture more rapidly than, and has no analog among, natural or logging slash fuelbeds. Kane et al. (2009) suggest using a plot-based method to inventory 1- and 10-hour fuels instead of using traditional planar fuel transects as per Brown (1974); they suggest retaining the planar transects for 100- and 1000-hour fuels inventory.

The effects of masticated fuelbeds on fire behavior are uncertain. Opening the stand can result in increased windspeed and drying of fuels (Reiner et al., 2009), and along with the increased surface area-to-volume ratios and potentially faster desorption rates of masticated fuel particles, may contribute to faster spread rate, higher flame length, and increased fireline intensity (Kane et al., 2009). On the other hand, the compacted nature of masticated fuelbeds could potentially reduce some or all of these behaviors and effects 
(Keyes and O'Hara, 2002), although it could also result in increases in subsequent fire effects such as soil heating, mortality of residual trees, and smoke production. Knapp et al. (2006) noted greater-than-expected crown scorch, and therefore unexpectedly high tree mortality, after prescribed fire in masticated plots.

Supplemental post-mastication treatments such as prescribed burning or incorporating the chips into the soil may help mitigate these fire effects, but they involve tradeoffs. In studies from northern California, both prescribed burning and soil incorporation in masticated fuelbeds were shown to be effective at reducing fine fuels and increasing native plant species richness, but they also resulted in greater post-treatment shrub density than mastication alone due to the stimulating effects of soil disturbance and fire (Kane et al., 2006).

Glitzenstein et al. (2006) conducted a study in which in untreated plots and masticated plots were treated with prescribed fire, and fire behavior and effects were compared. Although no statistically significant difference was found between the two treatments for spread rate and flame length, roughly 80 percent of the untreated area burned, while for the masticated plots that number was around 50 percent.

Current indications are that existing standard fuel models (Anderson, 1982; Scott and Burgan, 2005), when used with fire modeling tools such as BehavePlus (Andrews, 2009), are not fully capable of accurately predicting fire behavior in masticated fuelbeds due to the novel fuelbed properties noted above (Kane et al., 2009) and also due to the fact that 
fundamental assumptions of Rothermel-based modeling tools, such as horizontal and vertical homogeneity of fuel structure, are routinely violated in real-world conditions (Glitzenstein et al., 2006). Although flame length and spread rate in masticated fuelbeds can be adequately predicted with BehavePlus, the accuracy of the predictions is heavily dependent on the fuelbed height entered (Ibid.). In the study by Knapp et al. (2006), observed post-burn crown scorch was from two to four times the amount predicted in BehavePlus.

Glitzenstein et al. (2006) concluded that chipping (mastication) of forested areas near WUI zones may reduce the threat of wildfire and smoke production, but that its use as a preliminary treatment before prescribed burning in long-unburned stands could not be justified. However, their study area was located in South Carolina, an area in which the native vegetation differs substantially from the current study area in the western US.

A different conclusion was reached by Reiner et al. (2009). By increasing surface fuels, the authors argued, mastication is likely to increase more intense fire behavior including increased potential residence time and flame depth. Masticated fuelbeds have already been seen to result in more extreme fire behavior than expected by experience fire personnel (Ibid.), thus firefighter safety is a concern with this treatment type, and forest health and potential fire behavior goals may not be met. 


\subsubsection{Landscape-Level Treatments}

While most fuel treatment projects have thus far taken place at the stand level, of late attention has increasingly been focused on landscape-level fuel treatments (Agee et al., 2000; Finney, 2001). This is due in part to recent ecological research and public input that have emphasized the need to address cumulative impacts and coordinate management across the forest landscape (Graham et al., 1999; North et al., 2009b). The purpose of fuels management at the landscape scale (thousands of hectares) is to assist in wildfire suppression and/or to reduce area burned by high intensity fire by modifying fire behavior through the strategic placement and arrangement of fuel treatments (Finney and Cohen, 2003; Graham et al., 2004; Schmidt et al., 2008).

Landscape-level fuel treatments may take the shape of fuelbreaks, defensible fuel profile zones (DFPZs), and/or strategically placed area treatments (SPLATs; Finney, 2001). Absolute standards do not exist for such treatments, thus variability in implementation is high (Agee et al., 2000). Shaded fuelbreaks in California are typically between 90 and $400 \mathrm{~m}$ wide, with residual canopy cover of approximately 40 percent (Schmidt et al., 2008). DFPZs tend to be more rapidly implemented, treat a larger portion of the landscape, and are designed with greater consideration toward strategic placement (e.g., on ridgetops) than fuelbreaks. Based on their analysis of the 2007 Angora Fire at Lake Tahoe, Safford et al. (2009) call for a minimum fuelbreak/DFPZ width of 400 to $500 \mathrm{~m}$ in 
the WUI defense zone; the current minimum requirement under the Sierra Nevada Forest Plan Amendment is $400 \mathrm{~m}$ (USDA, 2004b).

It is not possible to treat the entire portion of the landscape currently in need of fuel treatment; hence, the primary challenges of implementing landscape-level fuel treatments are to determine how much area needs to be treated and where to place, as well as how to arrange, the treatments for maximum effect (Finney, 2001). Typically, these treatments are designed to tie into natural and/or unnatural barriers to fire spread, and are implemented in easily accessible (e.g., non-wilderness) terrain (Schmidt et al., 2008). Finney (2001) demonstrated via computer simulations that SPLATs implemented in a mathematically-derived geometric arrangement (the "herringbone" design) offer maximum disruption of fire spread while minimizing the amount of area requiring treatment. However, although the herringbone pattern is optimal, it is not ecologically or economically viable in its idealized form (Reinhardt et al., 2008).

Numerous constraints affect the use of landscape fuel treatments. The costs are prohibitive (Agee and Skinner, 2005) and although anecdotal evidence supports their use, empirical evidence of their efficacy is minimal (Reinhardt et al., 2008). Furthermore, understanding of how stand-level fuel treatment effects translate to the landscape level is poor (Schmidt et al., 2008). At the landscape scale, fire behavior in individual stands may be unrelated to overall fire severity patterns (Weatherspoon and Skinner, 1996; Finney and Cohen, 2003). Finally, landscape-level treatments have been referred to as ecologically unfeasible, as they do not mimic natural landscape processes and are not 
specifically intended to increase the fire resiliency of an area, but only to slow down the fire so it can be suppressed more easily (Reinhardt et al., 2008).

\subsubsection{Implementation and Integration with Ecological Concerns}

As noted previously, fuel treatments may or may not provide ecological benefits, depending on the characteristics and condition of the ecosystem they are placed in, and the specific details of the treatment itself. Attempting to precisely recreate preEuroamerican stand structure is not a realistic, nor desirable, goal for forest managers; ongoing and irreversible land use and climatic changes make this idea impractical (Millar et al., 2007; North et al., 2007). However, one goal of effective restoration is to reestablish the conditions (structures and functions) characteristic of the evolutionary environment of an ecosystem (Falk, 1990). In the dry mixed-conifer and ponderosa pine forests of the western US, heavily overloaded with live and dead biomass from a century or more of fire exclusion and accordingly prone to uncharacteristically severe wildfire, the opportunity exists for both fuel treatment and ecological restoration objectives to be initiated with the same project, particularly if a regime of frequent, low-intensity fire can be reintroduced to the project area.

Sierra Nevada mixed conifer forests are currently substantially different than those that existed immediately prior to Euroamerican settlement (North et al., 2007). At Teakettle Experimental Forest, west of Kings Canyon National Park, pre-Euroamerican open stands of roughly 67 trees per ha, dominated by large shade-intolerant pines but featuring a 
relatively flat diameter distribution, have been replaced by dense stands ( 469 trees per ha) of small, shade-tolerant trees forming a reverse-J-shaped diameter distribution. (Density in untreated stands for the current study averaged 1068 trees per ha; treated stands averaged 367 trees per ha.)

Current USFS fuel treatment thinning prescriptions that concentrate on the removal of intermediate $(50-75 \mathrm{~cm} \mathrm{DBH})$ trees, while providing for some timber revenue, are inadequate from an ecological restoration perspective, leaving far too many small trees and removing too many of the intermediate class (North et al., 2009b). This size class is important because it comprises the next generation of large trees. For the Sierra Nevada as a whole, vegetation management activities have produced considerably more new fuels than they have eliminated, elevating the likelihood of higher-severity surface fire, and have failed to adequately address the increasing problem of live understory fuels in silvicultural or fuel-management activities (Weatherspoon and Skinner, 1996).

In order to promote ecological restoration goals while implementing fuel treatments, North et al. (2007) recommend eliminating rigid diameter-based prescriptions and removing more small trees, fewer intermediate trees, and no large trees. Stephens et al. (2007a), concur, and further note that in-stand heterogeneity alone is not enough to restore sustainability unless it includes stand structures that are resilient against highseverity fire, drought, insects, and disease. 


\subsection{Ecosystem Services}

While fuel treatments may reduce the probability of severe wildfires destroying or damaging assets considered valuable by society, these and other forest management activities may also, through their removal and/or rearrangement of vegetation and woody debris in forest stands, diminish the ability of forest ecosystems to provide valuable benefits to society (Kaufmann et al., 1994; Chen and Jim, 2008; Dicus et al., 2009). These ecosystem services include, among others, provision of clean water, stormwater control, and aquatic habitat (Nowak and Dwyer, 2000; Elliot et al., 2010), wildlife habitat (North et al., 2009b), microclimate amelioration and energy savings (Oke, 1989; Taha et

al., 1997), noise reduction (Farnham and Beimborn, 2003), recreational opportunities (Baines, 2000; McPherson and Simpson, 2002), air pollution removal (Nowak et al., 2006) and carbon (C) sequestration and storage (Ryan et al., 2010). These benefits are easily overlooked by the public, as they are intangible and can be difficult to quantify in terms of monetary value; nonetheless, such services are critically important to the welfare of society as a whole (Chen and Jim, 2008; Dicus, 2009).

\subsubsection{Carbon Sequestration and Storage}

The storage and sequestration of $\mathrm{C}$ by forests has taken on new importance in the context of atmospheric greenhouse gas accumulation and its contribution to global climate change (Myneni et al., 2001; Schimel et al., 2001; Hurtt et al., 2002; Saikku et al., 2008). Rising levels of atmospheric $\mathrm{CO}_{2}$ and other greenhouse gases are thought to contribute to 
ongoing increases in atmospheric temperatures by trapping certain wavelengths of radiation in the atmosphere (U.S. National Research Council, 1983). As trees and shrubs grow, they remove atmospheric $\mathrm{CO}_{2}$ and store carbon within their biomass; in the case of long-lived trees, this $\mathrm{C}$ can potentially be stored for hundreds of years. Dead biomass (snags, woody debris, litter, duff, and charcoal) and forest soils may also store significant amounts of C (Rowntree and Nowak, 1991; Perry, 1994). Taken together, these forest ecosystem components may form a $\mathrm{C}$ sink containing the equivalent of $15-30 \%$ of annual global fossil fuel and industrial C emissions (Myneni et al., 2001). In removing and/or burning vegetation, fuel treatments have the capacity to reduce $\mathrm{C}$ sequestration and storage, although uncertainty remains as to how, and for how long, forest management practices affect forest C fluxes (Boerner et al., 2008; Campbell et al., 2009).

In the United States, the forest $\mathrm{C}$ sink is believed to be higher at present than during the pre-Euroamerican era, due to both fire exclusion-related ingrowth and extensive regrowth following $19^{\text {th }}$ - and early $20^{\text {th }}$-century forest-clearing land uses (Hurtt et al., 2002). USFS Forest Inventory and Analysis (FIA) data for the years 2001-2005 indicates that California contains an estimated $1 \times 10^{9} \mathrm{Mg} \mathrm{C}$ in live trees and $1 \times 10^{6} \mathrm{Mg} \mathrm{C}$ in snags and downed woody debris, for a statewide average of $89.6 \mathrm{Mg} \mathrm{C}^{-1}$ (Christensen et al., 2008). Recent calculations of mean C stored in unmanaged, fire-excluded stands in Sierra Nevada mixed-conifer forest have ranged from roughly $320 \mathrm{Mg} \mathrm{C}^{-1}$ (Stephens et al., 2009b) to $426 \mathrm{Mg} \mathrm{C}^{-1}{ }^{-1}$ (North et al., 2009a). However, in this and other dry, fireadapted forest types experiencing greatly increased stem density and surface fuel loads, the $\mathrm{C}$ sink is threatened by recent, climate change-associated increases in wildfire size 
and severity (Westerling et al., 2006; Miller et al., 2009; Stephens et al., 2009b), and is predicted to decrease substantially throughout the $21^{\text {st }}$ century as regrowth slows and large, severe wildfires increase (Hurtt et al., 2002).

This increase in severe wildfire activity has led to an increased emphasis on fuel treatment implementation, especially in or near the WUI (Schoennagel et al., 2009; Mell et al., 2010). Such treatments usually emphasize the removal of small trees that have established during the fire-exclusion era (North et al., 2005). These treatments reduce the risk of stand-replacing fire, and thus substantial $\mathrm{C}$ release to the atmosphere, by decreasing surface fire intensity and the probability of crown fire initiation (Agee and Skinner, 2005). Although empirical studies are rare, such treatments appear to be effective in reducing fire intensity and severity in Sierra Nevada mixed-conifer and other forest types with historic high-frequency, low-intensity fire regimes (Carey and Schumann, 2003; Graham et al., 2004; Stephens et al., 2009a). Such canopy thinning may simultaneously significantly increase growth rates in the leave trees (Latham and Tappeiner, 2002; Skov et al., 2005), but the effects of such treatments on C dynamics in active fire regimes are not well understood (North et al., 2009a; Stephens et al., 2009b).

However, the treatment of fuels to reduce wildfire severity and effects is not without its costs to $\mathrm{C}$ storage and sequestration. Significant short-term C losses may occur through the removal or fire-induced mortality of trees; consumption of downed woody debris, forest floor materials, and understory vegetation; and fossil fuel emissions from mechanical equipment used during treatment implementation (Wiedinmyer and Neff, 
2007; Finkral and Evans, 2008; Campbell et al., 2009; Hurteau and North, 2009; North et al., 2009a). North et al. (2009a) and Stephens et al. (2009b) reported that treatments incorporating mechanical thinning resulted in the greatest immediate reductions in livetree $\mathrm{C}$ storage, with overstory thinning removing the greatest amounts of $\mathrm{C}$ (North et al., 2009a).

These forest management-related $\mathrm{C}$ losses have resulted in restrictive $\mathrm{C}$ accounting policies such as the California Climate Action Registry guidelines (CCAR, 2007), which require that any trees harvested be counted as immediate $\mathrm{C}$ losses, thus penalizing landowners and land managers for undertaking fuel treatments and other management projects designed to improve long-term forest health, resilience to wildfire, and ironically, C storage (Hurteau et al., 2008). ${ }^{2}$ Compounding the situation, wildfire losses are considered to be "uncontrollable" and are not counted against landowners or managers; after a stand-replacing fire, the baseline $\mathrm{C}$ stock is simply recalculated for the disturbed site (Hurteau and North, 2009). This failure to acknowledge the threat of catastrophic $\mathrm{C}$ release from wildfire "amounts to a perverse incentive to increase fire risk through continued fire suppression" (Hurteau et al., 2008). Indeed, Stephens et al. (2009b) found that under modeled conditions, $90 \%$ of the live-tree C pool in untreated stands had a high $(>75 \%)$ chance of being killed in a severe wildfire. A better solution would be to remove the penalty for fuel treatment-related emissions, include $\mathrm{C}$ released from wildfires in the accounting guidelines as recommended by the IPCC (2006), and

\footnotetext{
${ }^{2} 2011$ update: the most recent CCAR Forest Sector Protocol, Version 3.2 (CCAR, 2010) allows for C stored in wood products to be counted towards overall project storage; i.e., it is no longer a penalty.
} 
account for $\mathrm{C}$ stored over the long term in wood products originating at the treatment site (Finkral and Evans, 2008; Stephens et al., 2009b).

Moreover, the underlying assumption that unmanaged, fire-excluded stands store the most C (Hurtt et al., 2002) may not hold true in all cases (Hurteau and North, 2010; Hurteau et al., 2010). Despite the fact that stem densities throughout Sierra Nevada mixed-conifer forests exceed their historic range of variability (Skinner and Chang, 1996), the total forest $\mathrm{C}$ sink may have actually decreased instead of increased during the fire exclusion era, due to heavy logging that has removed the largest trees, which store the most $\mathrm{C}$ (Fellows and Goulden, 2008). Thus, despite findings that forest $\mathrm{C}$ dynamics appear to be essentially unaffected by forest management activities over the long term (Campbell et al., 2009), with C sequestration in prescribed-burned and thinned stands completely recovering to pre-treatment levels within seven years (Hurteau and North, 2010), the harvest of large, old trees results in a net loss of $\mathrm{CO}_{2}$ to the atmosphere in spite of the higher growth and $\mathrm{C}$ sequestration rates of the young trees that replace them (Harmon et al., 1990).

Whether or not the lifespan of a given fuel treatment outlasts the $\mathrm{C}$ recovery period is dependent upon site-specific factors; however, based on their research in the central Sierra Nevada, Hurteau and North (2010) reported that total C emissions from prescribed fire are likely to be sequestered by tree and shrub growth within a period of time that is shorter than the historic mean fire return interval. If this is true, the wildfire risk reduction and ecological benefits of prescribed fire could offset treatment-associated $\mathrm{C}$ emissions to 
the atmosphere. Overall, the temporary reduction in forest $\mathrm{C}$ sequestration and storage that results from fuel treatment implementation is a small price to pay for avoiding standreplacing wildfire and its disruption of long-term C stock stability (Hurteau and North, 2010; Hurteau et al., 2010).

\subsubsection{Air Pollution Removal}

While trees and shrubs can contribute to the formation of ozone $\left(\mathrm{O}_{3}\right)$ by emitting volatile organic compounds (VOCs) into the atmosphere, they also remove significant amounts of air pollutants through gas uptake and interception of airborne particles, consequently improving environmental quality and human health (Smith, 1990; Nowak et al., 2006). Because one of the primary factors affecting the uptake of atmospheric $\mathrm{C}$ is leaf area (Nowak and Dwyer, 2007), fuel treatments have the potential to reduce this ecosystem benefit through the removal or burning of vegetation.

\subsection{The Central Sierra Nevada}

The Sierra Nevada mountain range lies almost entirely within California (with a small portion in Nevada) and trends north-northwest to south-southeast, stretching approximately $650 \mathrm{~km}$ from Fredonyer Pass in the north to Tehachapi Pass in the south (Miles and Goudey, 1997). The range averages approximately $80 \mathrm{~km}$ wide and rises gently from the west on long ridges to elevations exceeding 4,300 m above sea level before dropping off abruptly at its eastern escarpment. Sampling for this study took place 
in the central Sierra Nevada, an area bounded roughly by Carson Pass on the north and the Kings River on the south.

The region's climate is Mediterranean, with warm, dry summers and cold, wet winters. Temperatures range from approximately 24 to $58 \mathrm{C}(40$ to $96 \mathrm{~F})$ in summer and 4 to $36 \mathrm{C}$ (10 to $60 \mathrm{~F}$ ) in winter (Allen, 2005). At Cherry Valley Dam, located in the middle of the study area at $1451 \mathrm{~m}$ elevation, the January mean minimum temperature for the period 1955-2009 is $-1.9 \mathrm{C}$ and the July mean maximum temperature is $30.6 \mathrm{C}$ (WRCC, 2009). Precipitation averages $1194.8 \mathrm{~mm}$ per year; average annual snowfall is $2933.7 \mathrm{~mm}$.

Soils in the Sierra Nevada mixed conifer belt are varied, and are typically derived from Mesozoic granitic, Paleozoic sedimentary and volcanic rocks, and Cenozoic volcanic rocks (Allen, 2005). Soils are deep to shallow, and fissures in granitic parent material often support forest growth, even where soil development is otherwise minimal.

The Sierra Nevada mixed conifer forest type is an assemblage of conifer and hardwood species forming a multilayered forest that dominates the western middle elevation slopes of the Sierra Nevada and occupies at least 1.8 million ha in California (Allen, 2005). The forest type contains six main tree species: ponderosa pine (Pinus ponderosa), sugar pine (Pinus lambertiana), Douglas-fir (Pseudotsuga menziesii), white fir (Abies concolor), incense-cedar (Libocedrus decurrens), and California black oak (Quercus kelloggii), along with numerous other tree and shrub species, and has been heavily influenced by disturbances including wildfire and logging. 
Fire ignited by lightning and Native Americans was common in the Sierra Nevada prior to extensive fire suppression efforts beginning in the early $20^{\text {th }}$ century (McKelvey et al., 1996). Pre-Euroamerican fire return intervals in Sierra Nevada mixed conifer forest have consistently been estimated at less than 20 years (Skinner and Chang, 1996; Stephens and Collins, 2004; North et al., 2005; Stephens et al., 2007b).

This frequent, low-intensity fire regime is thought to have contributed to fire adaptations such as thick, protective bark, fire-resistant buds and twigs, and fire-stimulated flowering, sprouting, seed release and/or germination in local tree and plant species (Skinner and Chang, 1996). Furthermore, the frequent occurrence of low-intensity fire across the landscape is now recognized as necessary to the overall diversity and health of these forests, as it leads to the creation of a mosaic or patchwork of age classes, successional stages, and vegetation types (Skinner and Chang, 1996), thus reducing the chances of a single catastrophic disturbance critically damaging the entire ecosystem.

Modern fire return intervals in the Sierra Nevada are now estimated to exceed PreEuroamerican intervals by one or two orders of magnitude; for instance, the fire return interval in pine-dominated mixed conifer forest is estimated to have increased from 15 to 185 years in the $20^{\text {th }}$ century (McKelvey et al., 1996). In fir-dominated mixed conifer forest, the estimated increase is from 12 to 644 years. 


\subsection{Computer Models}

\subsubsection{Fire Behavior Modeling}

Predicting wildfire behavior and effects is an essential fire management task (Scott and Burgan, 2005), yet the difficulties and costs involved in igniting forest land for the purpose of controlled experimentation (Stephens and Moghaddas, 2005) mean that despite their limitations, mathematical computer models have increasingly been used to simulate wildfire behavior and effects (van Wagtendonk, 1996; Stephens, 1998; Miller and Urban, 2000; Martinson and Omi, 2008).

Some of the most commonly used fire behavior modeling tools include BehavePlus (Andrews et al., 2008; Andrews, 2009), NEXUS (Scott, 1999), the Fire and Fuels Extension to the Forest Vegetation Simulator (FFE-FVS; Reinhardt and Crookston, 2003), FARSITE (Finney, 1998), and FlamMap (Finney, 2003). The surface fire components of these models are generally based on Rothermel's (1972) surface fire spread equations, while the crown fire modeling tools are typically based on Rothermel's (1991) crown fire spread equations and Van Wagner's (1977) crown fire transition equations.

Because fire simulation models are simplifications of reality and are based on numerous assumptions, the results they give can be questionable (van Wagtendonk, 1996) and 
conflicting (Scott, 2006). Major assumptions of fire modeling include uniform terrain, homogeneous fuels, surface fire spread in an elliptical shape, simplified weather and wind inputs, and a lack of extreme behavior such as fire whirls, plume-dominated fires, or fire-induced weather (Ibid.). Such assumptions are routinely violated in real-world conditions (Glitzenstein et al., 2006).

Fire modeling tools are driven in part by fuelbed inputs such as load, bulk density, fuel particle size, heat content, and moisture of extinction (Scott and Burgan, 2005). Three important input variables for assessing crown fire potential are available canopy fuel load (ACFL), canopy bulk density (CBD), and canopy base height (CBH) (Scott and Reinhardt, 2001).

- ACFL is defined as the mass of available canopy fuel per unit of ground area (Scott, 1999). Available canopy fuel is that which burns in the short period of active flaming in the canopy. Canopy fuel availability is often estimated as the foliage plus a fraction of the $0-1 / 4$ inch live branchwood.

- $\mathrm{CBD}$ is the mass of available canopy fuel per unit canopy volume, usually expressed in kilograms per cubic meter (Scott and Reinhardt, 2001). In FFE-FVS, CBD is defined as the maximum 4.5-m deep running mean of canopy bulk density for layers $0.3 \mathrm{~m}$ thick.

- $\mathrm{CBH}$, as computed in FFE-FVS, is the lowest height above the ground at which there is sufficient canopy fuel to propagate fire vertically through the canopy; the threshold value is arbitrarily set at $\left(0.011 \mathrm{~kg} / \mathrm{m}^{3}\right)$ (Ibid.). 
To facilitate fire behavior and effects calculations in the various modeling systems, fuel models are used. Fuel models (Anderson, 1982; Scott and Burgan, 2005) are generic estimates of fuel loading and size class distribution by vegetation type (e.g. grass, shrub, timber, slash) that can be used when stand-specific fuel loading data (for instance, from planar fuel transects [Brown, 1974; Brown et al., 1982]) is not available. In addition, canopy fuel loading inputs may be estimated using stereo photo guides (Scott and Reinhardt, 2005). If stand-specific fuel loading data obtained from field sampling is available, custom fuel models can be created and used as model inputs. However, caution is necessary; for instance, the novel fuelbed properties resulting from mechanical mastication treatments appear not to lend themselves very well to modeling with the current suite of modeling tools or standard fuel models (Knapp, 2006; Glitzenstein et al., 2006; Kane et al., 2009).

Typical fire behavior model outputs include fireline intensity (Byram, 1959), flame length, rate of spread, and heat per unit area (van Wagtendonk, 1996). In 2001, Scott and Reinhardt linked existing surface, crown, and crown fire transition models to come up with two new indices of crown fire hazard - torching index (TI) and crowning index (CI). These indices calculate the 6.1-m wind speeds at which torching (passive crown fire) and crowning (active crown fire) can be expected to initiate, given that other necessary conditions such as fuel moisture and topography are adequate (Scott and Reinhardt, 2001). TI is highly sensitive to $\mathrm{CBH}$, and predicted $\mathrm{CBH}$ often fluctuates dramatically 
(for example, in FFE-FVS), causing unrealistic, erratic behavior in predicted TI (Crookston and Reinhardt, 2004 in Rebain, 2009).

Thanks to ongoing technological advances, fire behavior modeling studies have become more commonplace since the mid-1990s. This research has frequently indicated that a combination of mechanical thinning and prescribed burning is more effective at reducing potential fire behavior in unnaturally dense forests than other methods of fuel treatment (e.g. van Wagtendonk, 1996; Stephens, 1998). Selected studies that involved fire simulation modeling are summarized below.

\section{1) van Wagtendonk (1996)}

Using FARSITE with Yosemite National Park mixed conifer forest data, van Wagtendonk found that fireline intensity, flame length, and heat per unit area were reduced most by two of the eight treatment types simulated - prescribed burn, and biomassing and prescribed burn. These were the only two scenarios in which torching and spotting did not occur. The prescribed burn treatment also resulted in the lowest surface rate of fire spread. Fire behavior effects were most severe in treatments that did not reduce, or increased, surface fuels; and in those that opened up the canopy, due to reduced fuel moisture from sun exposure and increased wind speeds. As expected, fire behavior was more severe under the $95^{\text {th }}$ percentile weather scenario than under the $75^{\text {th }}$ percentile scenario. 


\section{2) Stephens, 1998}

As with van Wagtendonk (1996), this study used FARSITE to examine the effects of fuel treatments in mixed conifer forest within Yosemite National Park, this time with 12

different fuel treatments. The results were similar: the prescribed burn, thinning and biomassing followed by prescribed burn, and salvage or group selection with slash and landscape fuel treatments resulted in the lowest average fireline intensities, heat per unit area, rate of spread, area burned, and scorch height under both weather scenarios.

\section{3) Miller and Urban, 2000}

Miller and Urban developed a forest gap model for Sierra Nevada forests, the FACET Model (FM), to investigate how Sierra Nevada forests might respond to three hypothetical management strategies for reintroducing fire after 100 years of exclusion, as determined from changes in basal area and species composition. Their model integrated climate, fire, and forest dynamics, and was implemented as a grid of small model plots or cells, allowing for spatial heterogeneity in a variety of forest and fuel parameters. In each of the three management scenarios (impose a natural fire regime immediately, after two prescribed burns, or after thinning all trees $<35 \mathrm{~cm} \mathrm{DBH}$ ), the percentage of basal area from large trees (> $60 \mathrm{~cm} \mathrm{DBH}$ ) returned to presuppression levels of $70-80 \%$ by the end of the simulation. All three scenarios also reduced the amount of basal area in firesensitive species, incense-cedar at lower elevations and white fir at higher elevations. The harvest scenario induced the highest mortality and quickly restored total basal area, large 
tree basal area percentage, and percent similarity of forest composition to presuppression conditions. Prescribed fire was somewhat less effective, and natural fire regime alone was least effective.

4) Knapp et al., 2006

Knapp et al. used BehavePlus with standard fuel models to predict fire behavior and effects in masticated fuelbeds at several northern California treatment sites, then burned the sites and compared the actual results to the modeled ones. While flame length and rate of spread were adequately predicted with BehavePlus, actual scorch height measured on the residual trees was substantially greater than predicted by BehavePlus, and is thought to have led to post-fire tree mortality that was significantly higher than had been expected.

5) Ager et al., 2007

The authors used FFE-FVS and PPE-FVS (the Parallel Processing Extension to FVS) to simulate five forest management scenarios in a northeastern Oregon WUI area to determine treatment rates over time, evaluate density management prescriptions for reducing fire hazard, and look at long-term treatment effects on fire behavior, forest structure, and species composition. Of the five treatments, the repeated thin and burn treatment was most effective at raising canopy base height and reducing canopy bulk density, and therefore preventing extreme fire behavior. The repeated thin treatment was 
also successful at reducing stand-level potential crown fire behavior and associated mortality. Thinning and burning only once caused temporary reductions in forest density, but because of heavy regeneration, the benefits were lost after a period of 20 to 40 years. Overall, the simulations indicated that thinning to meet stand density goals on the entire landscape would reduce fire-caused mortality, increase the area of old forests with singlestory structure, and partially change species composition to favor earlier seral species like ponderosa pine and western larch.

6) Strom and Fulé, 2007

The authors sampled seven pairs of treated-untreated stands on the Apache-Sitgreaves National Forest in May to August of 2004, two years after the Rodeo-Chediski fire. The treatment type was non-commercial thinning for fuel reduction followed by piling and burning of slash. FVS was used to simulate stand development for each treated and untreated site for a 100-year period. Two regeneration scenarios were used.

Treated areas were strongly associated with lower tree mortality when compared to untreated areas, and fire behavior as indicated by bole char height was less extreme than in untreated areas. Additionally, FVS modeling indicated that differences between treated and untreated areas will likely persist for at least the next several decades in terms of overall forest structure characteristics (density, basal area, and quadratic mean diameter). The modeling also predicted that treated areas would contain more ponderosa pine over the coming decades than the untreated areas, which would see greater proportions of hardwoods and junipers establish. 


\section{7) Schmidt et al., 2008}

Schmidt et al. used standard fuel models in NEXUS and BehavePlus to simulate pre- and post-treatment stand-level fire behavior in a southern Cascades (northern California) mixed conifer forest under three fire weather scenarios, and then used FARSITE to simulate landscape-level wildfire behavior in both untreated and treated forest landscapes. Forest inventory and surface fuel loading data were gathered at National Fire and Fire Surrogate Study (FFS) plots; canopy fuel loading was estimated with FFE-FVS.

At the stand level, the mechanical plus burn treatment was the most effective of four treatment types at reducing surface and crown fire behavior. This treatment was best at increasing canopy base height and reducing canopy bulk density and canopy cover, and it nearly equaled the effectiveness of the burn only treatment in reduction of surface fuel loading, while being likely to remain effective for a longer time than the burn only treatment. The mechanical plus burn treatment also reduced basal area and density, and increased quadratic mean diameter, by the greatest amount of any treatment.

At the landscape level, treatment type, amount, and arrangement were all found to be important. Overall, the most effective scenario at reducing both total area burned and area burned at high intensity was the burn only treatment in combination with a larger treatment area (20 or 27 percent of the landscape, as opposed to 10 percent) and a treatment arrangement based on Finney's optimal SPLATs design. For each spatial 
arrangement, type of treatment, and proportion of area treated, area burned at high intensity increased as fire weather became more extreme.

8) Dicus et al., 2009

The authors used NEXUS and FlamMap to predict potential fire behavior in an eastern Sierra Nevada WUI area at the stand and landscape levels, respectively. The three vegetation types studied were pinyon-juniper woodland, sagebrush shrubland, and annual grassland occupying previously burned pinyon-juniper stands. Shrublands demonstrated the highest rates of spread and flame lengths, except at wind speeds exceeding $25 \mathrm{~km} / \mathrm{hr}$, when fire in the pinyon-juniper stands transitioned to crown fire. The authors note that although full compliance with State of California defensible space requirements might well save some local homes in the event of a wildfire, at a landscape level such compliance would be unlikely to have an effect on fire size and behavior, due to the low population density in the area.

\subsubsection{Fire Behavior and Climate Change}

The Fourth Assessment Report of the Intergovernmental Panel on Climate Change (IPCC, 2007) predicts continuing atmospheric accumulation of greenhouse gases such as $\mathrm{CO}_{2}$ and $\mathrm{CH}_{4}$, and resultant temperature increases of about $0.2 \mathrm{C}$ per decade, along with ongoing changes to sea level, ocean acidity, wind patterns, precipitation, extreme weather events, and ice distribution. These atmospheric conditions are thought to be correlated 
with recent increases in fire duration, length of fire season, and frequency of large wildfires in the western US due to the effects of increased spring and summer temperatures, reduced annual precipitation and snowpack depth, and an earlier spring snowmelt (Westerling et al., 2006). However, although modeling tools such as FFE-FVS enable the user to predict fuel treatment effects on fire behavior and carbon sequestration/storage decades into the future, this approach is fraught with uncertainty due to the unknown effects of future climatic fluctuations (Millar et al., 2007). 


\subsection{A Comparison of Fuel Reduction Treatment Effects on Simulated Fire Behavior in Mixed-Conifer Forests of the Central Sierra Nevada Mountains}

\subsection{Introduction}

The mixed-conifer and ponderosa pine forests of the western United States, once shaped by frequent, low-intensity wildfire (Stephens and Collins, 2004) and dominated by large, fire-resistant trees (Weatherspoon and Skinner, 1996), have undergone significant changes in forest structure, species composition, and fuel loading due to the cumulative effects of $19^{\text {th }}$ and $20^{\text {th }}$ century land use changes and climatic trends (McKelvey et al., 1996; Graham et al., 2004; Agee and Skinner, 2005; Schwilk et al., 2009). In these semiarid forests, productivity often exceeds decomposition; as a result, live and dead biomass accumulates in the absence of fire (Weatherspoon and Skinner, 1996). The historically unprecedented buildup of live and dead biomass now existing in these forests, influenced by decades of timber harvesting, livestock grazing, and fire suppression interacting with changes in moisture availability and temperature, is a major contributor to recent increases in the severity of wildfire (McKelvey and Busse, 1996; Gruell, 2001; Allen et al., 2002; Stephens, 2005; Miller et al., 2009; Crimmins et al., 2011). Ironically, the ongoing emphasis on wildland fire suppression exacerbates the problem by allowing fuels to continue accumulating, assuring the future occurrence of large, severe fires (Weatherspoon and Skinner, 1996). 
Furthermore, climatic changes such as increased spring and summer temperatures and earlier spring snowmelt have been correlated with recent trends of increased large wildfire frequency, longer wildfire durations, and longer wildfire seasons in the western US (Westerling et al., 2006). These trends are predicted to continue throughout western North America, partly in response to climate change-induced shifts in vegetation distribution (Fried et al., 2004; Westerling et al., 2009).

Simultaneously, lives and property are increasingly at risk from wildfire as the wildlandurban interface (WUI) continues to expand (Radeloff et al., 2005; Theobald and Romme, 2007; Fried et al., 2008; Westerling and Bryant, 2008). The WUI has been defined as any location "where humans and their development meet or intermix with wildland fuel" (USDA-USDI, 2001b). During the 1990s, the WUI in California increased by $8.7 \%$ to occupy over 2.8 million hectares (Hammer et al., 2007). The mixed-conifer forests of the Sierra Nevada abut hundreds of WUI communities (USDA-USDI, 2001b; FRAP, 2010).

During the period 2003 to 2009, an annual average of 3 million ha and 1,435 homes burned in the US, although these numbers were strongly influenced by the 2003 and 2007 fires in southern California (NIFC, 2010a; NIFC, 2010b; NOAA, 2010). The overall effect of the ecological and demographic changes described above, and the implication for the future, are that human and natural resources will continue to be at risk of wildfirecaused damage and destruction in the western US (Fried et al., 2008; Mell et al., 2010). Furthermore, Westerling and Bryant (2008) predicted that over the next several decades, climate change could result in additional, significant increases in wildfire-related 
property damages in WUI areas proximate to major metropolitan areas throughout California, including in the Sierra Nevada foothills northeast of Sacramento.

Defending these resources has become extremely costly; recent federal wildland fire suppression costs have been estimated at $\$ 1$ billion (Liang et al., 2008) to $\$ 3$ billion annually (Rasker, 2009). The cost in human lives has been high as well: an average of 12 civilians and 21 wildland firefighters have died annually in wildfires within and outside of the WUI over the past decade (Rasker, 2009; NOAA, 2010). Such costs and losses are projected to continue rising as more of the WUI is developed (Gude et al., 2009; Bryant and Westerling, 2009).

Although wildfire behavior is driven in part by topography and climate/weather, human efforts to influence fire behavior necessarily focus on hazard reduction through fuel treatments (Peterson et al., 2005). Fuel treatments consist of mechanical and prescribed fire activities that manipulate or remove fuels to reduce fire behavior and/or severity (NWCG, 2006), and promote more fire-resilient forest conditions by reducing the loading and continuity of live and dead forest fuels (Agee and Skinner, 2005). These treatments typically try to reduce surface, ladder, and canopy fuels, increase canopy base height, and provide for the retention of large, fire-resistant trees (Graham et al., 2004; Agee and Skinner, 2005). If implemented properly, fuel treatments may double as ecological restoration activities in this forest type (North et al., 2009). 
The need for fuel treatments in some western US forests, including those of the lower-tomiddle elevation Sierra Nevada, is generally acknowledged to be urgent (Weatherspoon and Skinner, 1996; Weatherspoon, 2000; GAO, 2003; Agee and Skinner, 2005). WUI fuel treatments tend to be more intensive, and therefore more expensive, than wildland fuel treatments (Safford et al., 2009). While fuel treatments can be costly and difficult to implement due to conflicts between management objectives, the regulatory process, and public expectations (McCandliss, 2002; Dicus and Scott, 2006; North et al., 2007), the benefits provided by fuel treatments (including avoidance of firefighting costs, fatalities, and property destruction) are far more substantial than commonly acknowledged, by one estimate reaching nearly $\$ 5,000 \mathrm{ha}^{-1}$ (Mason et al., 2006).

Currently, empirical evidence regarding the effectiveness of fuel treatments in attenuating severe wildfire behavior and effects is somewhat limited (Pollet and Omi, 2002; Martinson and Omi, 2008), and what little evidence is available tends to focus on wildland settings rather than the WUI (Safford et al., 2009). The difficulties and costs involved in igniting forest stands for the purpose of controlled experimentation (Stephens and Moghaddas, 2005a) mean that computer models have increasingly been used to simulate fire behavior and effects (van Wagtendonk, 1996; Stephens, 1998; Miller and Urban, 2000; Dicus, 2009; Dicus et al., 2009). However, the national Fire and Fire Surrogate Study (FFS; Weatherspoon, 2000; McIver et al., 2009), a research network of long-term, multidisciplinary experiments investigating fuel treatment protocols in historic frequent, low-intensity fire regimes, provides a current example of experimental fire science in the US (Schwilk et al., 2009). 
The objective of the current research is to evaluate how differing fuel treatment types in a Sierra Nevada mixed-conifer forest WUI affect various surface and canopy fuel properties, and how these changes subsequently impact potential fire behavior. This work focuses most specifically on the wildland portion of the WUI, forestlands through which wildfire approaches urbanized areas. It does not address fuel and fire behavior characteristics of the urbanized part of the WUI, in which the ignitability of homes and their immediate surroundings is thought to be the primary driver of fire hazard (Cohen, 2000; Mell et al., 2010).

\subsection{Methods}

\subsubsection{Site Description}

Sampling took place in mixed-conifer forest stands in California's central Sierra Nevada Mountains, between roughly 1067 and 1890 meters elevation above sea level, across a latitudinal distance of approximately $130 \mathrm{~km}$, or roughly between Arnold (Calaveras County) and Bass Lake (Madera County; see Figure 3.1). Old-growth stands were not sampled. The Sierra Nevada mixed-conifer forest type is characterized by six main tree species: ponderosa pine (Pinus ponderosa Dougl. ex Laws.), sugar pine (Pinus lambertiana Dougl.), Douglas-fir (Pseudotsuga menziesii [Mirb.] Franco), white fir (Abies concolor [Gord. \& Glend.] Lindl. ex Hildebr.), incense-cedar (Libocedrus decurrens Torr.), and California black oak (Quercus kelloggii Newb.); over 100 species of grasses, forbs, and shrubs make up the understory for this forest type (Allen, 2005). At 
higher elevation sites, ponderosa pine was replaced by Jeffrey pine (Pinus jeffreyi Grev. $\&$ Balf.). Soils in the Sierra Nevada mixed-conifer belt are varied, and are typically derived from Mesozoic granitic, Paleozoic sedimentary and volcanic, and Cenozoic volcanic rocks (Allen, 2005). Soils are deep to shallow, and fissures in granitic parent material often support forest growth, even where soil development is otherwise minimal.



Figure 3.1. Study region - the central Sierra Nevada; stars indicate sampling sites. 
The area's climate is Mediterranean, with warm, dry summers and cold, wet winters. At Cherry Valley Dam, located roughly in the middle of the study area at $1451 \mathrm{~m}$ elevation, the January mean minimum temperature for the period $1955-2009$ is $-1.9{ }^{\circ} \mathrm{C}$ and the July mean maximum temperature is $30.6^{\circ} \mathrm{C}$. Rainfall averages $1194.8 \mathrm{~mm}$ annually; average annual snowfall is $2933.7 \mathrm{~mm}$ (WRCC, 2009).

\subsubsection{Treatment Types and Field Measurements}

Field sampling took place between June and October 2008 in WUI areas managed by the US Department of Agriculture, Forest Service (USFS; Sierra and Stanislaus National Forests) and the US Department of Interior, National Park Service (NPS; Yosemite National Park). The fuel treatment types investigated included thin and masticate (hereafter, "Masticate"), thin and pile burn ("Pile Burn"), thin and broadcast burn ("Thin + Fire"), and broadcast burn only ("Fire Only"; Table 3.1). "Masticate" refers to a fuels management method in which a tracked vehicle carrying a rotary blade or drum is used to shred or chop live and dead fuels, depositing the debris on the ground (USDA, 2004a; Kane et al., 2009). At the Pile Burn sites, the boles, tops, and limbs of all cut trees were piled and burned. Thin + Fire sites received a thin followed by prescribed fire, and Fire Only sites received prescribed burning alone. At both USFS and NPS sites, the treatments involving thinning had typically been implemented in two phases spanning from one to eight years; for each site, field sampling occurred within four years of the final treatment phase. 
Treatments on US Forest Service lands were guided by the Sierra Nevada Forest Plan Amendment (SNFPA; USDA, 2004a) and the California Spotted Owl (CASPO) interim guidelines (Verner et al., 1992). The SNFPA requires that at least $50 \%$ of initial fuel treatment work in the Sierra Nevada should take place in the WUI until the WUI is sufficiently treated (Safford et al., 2009); the CASPO guidelines call for the thinning of all trees between 25.4 and $76.2 \mathrm{~cm}$ diameter at breast height $(\mathrm{DBH} ; 1.37 \mathrm{~m})$ while retaining at least $40 \%$ canopy cover or $40 \%$ basal area, whichever is more conservative. In contrast to the USFS sites, the NPS stands had received a light thin from below to 15.2 cm DBH (I. Hirschfield, Yosemite National Park, personal communication).

Table 3.1. Fuel treatment types, locations, and dates of implementation.

\begin{tabular}{llll} 
Treatment type & Project name & Project location & Date(s) treated \\
\hline Thin \& masticate ("Masticate") & Progeny & Sierra NF & Thinned 2000, masticated 2005-06 \\
& Gorf & Sierra NF & Thinned 1999, masticated 2007 \\
& Sonny Mdws & Sierra NF & Thinned 2006, masticated 2008 \\
Thin \& pile burn & Highway 41 & Yosemite NP & Thinned 2004, piles burned 2004-05 \\
("Pile Burn") & Hodgdon Mdw & Yosemite NP & Thinned 2003, piles burned 2003-04 \\
Thin \& burn ("Thin + Fire") & Bee Hart & Stanislaus NF & Thinned 1999-2001, burned 2007 \\
& Upper Cow Mdw & Stanislaus NF & Thinned 2001, burned 2008 \\
& Irish & Stanislaus NF & Thinned 2000, burned 2008 \\
Burn only ("Fire Only") & Big Creek & Yosemite NP & Burned 2004 \\
& Highway 41 & Yosemite NP & Burned 2007 \\
& Irish & Stanislaus NF & Burned 2008 \\
\hline
\end{tabular}

Each of the four fuel treatment types originally consisted of three replications, giving a sampling design of $n=12$ experimental units (treatment $\times$ site combinations) $)^{3}$. Due to time and resource constraints, it was not possible to sample the same inventory plots

\footnotetext{
${ }^{3}$ The term "experimental units" is used throughout, even though this was not a true controlled experiment.
} 
before and after fuel treatment implementation; instead, at each experimental unit three treatment plots and two nearby untreated (proxy control) plots were sampled. Fixed plot size was 0.08 ha. At two sites, the existence of differing but adjacent treatment types allowed the use of a single set of control plots for comparison; thus, the total number of plots sampled equaled 56 instead of 60 . After the conclusion of field work, but prior to the statistical analysis, one Pile \& Burn site was removed from the study due to data quality problems stemming from poorly matched untreated and treated plots.

Plot selection was assisted by USFS and NPS personnel familiar with the treatment sites. To minimize variability between plots at each experimental unit, stand characteristics such as slope, aspect, elevation, soil productivity, untreated composition, and stand age were held constant to the extent possible. Variability between experimental units was not controlled except that mixed-conifer stands on west-to-southwest aspects were used throughout the study.

Plots were randomly installed at least $25 \mathrm{~m}$ from the nearest road or other treatment boundary in a location that was determined to be "representative" of the condition being sampled. Once an acceptable area was found, plot center was located by randomly spinning the compass dial and taking three paces on the azimuth indicated. Anomalous areas such as riparian areas or unburned patches within a broadcast burn perimeter were avoided. 
At each plot, three $15 \mathrm{~m}$ planar intercept fuel transects (Brown, 1974; Lutes et al., 2006) were installed at azimuths of $360^{\circ}, 120^{\circ}$, and $240^{\circ}$ in order to obtain surface fuel loading by timelag size class, percent cover live and dead woody and herbaceous vegetation, fuelbed depth, and litter and duff depth.

In addition, at each plot species, diameter, height, and height to live crown base were recorded for all live trees greater than $2.5 \mathrm{~cm}$ DBH. Due to time constraints, dense thickets of suppressed trees were sometimes grouped, with several trees being measured and the average values being applied to the entire group (e.g., " 20 white firs, DBH $10 \mathrm{~cm}$, height to live crown $1.2 \mathrm{~m}$, total height $5.5 \mathrm{~m}$ "). Due to time constraints, standing dead trees were not measured; however, unusual levels of mortality were not noted at any of the sampling sites, an observation supported by USFS Forest Inventory \& Analysis (FIA) data for the Stanislaus and Sierra National Forests (K. Waddell, FIA, personal communication).

Each plot contained a 0.0004 ha regeneration plot centered $4 \mathrm{~m}$ from plot center at an azimuth of 90 degrees; all seedlings that germinated from seed were tallied by species. GPS coordinates were recorded at each plot center, and photographs were taken in each of the four cardinal directions from plot center. 


\subsubsection{Fuels and Fire Behavior Calculations}

Surface fuel loading and depth characteristics were calculated with JFiremon (formerly FIREMON; Lutes et al., 2006). Down woody debris (DWD) outputs included 1-hr (0$0.64 \mathrm{~cm}), 10-\mathrm{hr}(0.64-2.54 \mathrm{~cm})$, and 100-hr $(2.54-7.62 \mathrm{~cm})$ surface fuel loading $\left(\mathrm{Mg} \mathrm{ha}^{-}\right.$ $\left.{ }^{1}\right)$; 1000-hr $(>7.62 \mathrm{~cm})$ loading $\left(\mathrm{Mg} \mathrm{ha}^{-1}\right)$; litter and duff loading $\left(\mathrm{Mg} \mathrm{ha}^{-1}\right)$; total woody surface fuel loading $\left(\mathrm{Mg} \mathrm{ha}^{-1}\right)$; litter and duff depth $(\mathrm{cm})$; and fuelbed depth $(\mathrm{m})$. Onethrough 100-hr fuels are referred to collectively as fine woody debris (FWD), while 1000-hr fuels are referred to as coarse woody debris (CWD). Total woody surface fuel loading refers to FWD, CWD, litter, and duff loads combined. Outputs for live and dead woody and herbaceous vegetation included percent cover, average height (m), and biomass $\left(\mathrm{Mg} \mathrm{ha}^{-1}\right)$. Herbaceous vegetation was encountered so infrequently that it was ultimately removed from the statistical analysis.

Basic stand structural characteristics (basal area $\left[\mathrm{m}^{2} \mathrm{ha}^{-1}\right]$; canopy cover [\%]; trees ha ${ }^{-1}$; quadratic mean diameter [QMD; cm]; stand height [average height of the 40 tallest trees; $\mathrm{m}]$ ) and canopy fuel loading variables (canopy base height $[\mathrm{CBH} ; \mathrm{m}]$; canopy bulk density $\left.\left[\mathrm{CBD} ; \mathrm{kg} \mathrm{m}^{-3}\right]\right)$, were calculated with the Western Sierra variant of the Fire and Fuels Extension to the Forest Vegetation Simulator (WSVAR FFE-FVS; Reinhardt and Crookston, 2003; Rebain, 2009). Due to the fact that FFE-FVS does not provide available canopy fuel loading (ACFL), a required canopy fuel input for NEXUS 2.0 fire modeling software (Scott, 1999), live foliage biomass $\left(\mathrm{Mg} \mathrm{ha}^{-1}\right)$ from the FFE-FVS All Fuels Report was substituted (Brown and Johnston, 1976; E. Reinhardt, Missoula Fire Sciences 
Laboratory, personal communication). The substitution meant that the fraction of 0.0 to $0.6 \mathrm{~cm}$ branchwood typically included as part of ACFL was not part of these fire behavior calculations.

Modeling of potential fire behavior was conducted with NEXUS 2.0, which combines Rothermel's (1972) surface fire spread equations and Van Wagner's (1977) crown fire initiation equations in order to simulate stand-level fire spread and intensity (Scott and Reinhardt, 2001). Custom surface fuel models were created in BehavePlus Version 4.0.0 (Andrews, 2009; Andrews et al., 2008). Based on site conditions and experience, custom fuel models were initialized from standard fuel model TL5 (Scott and Burgan, 2005) and then adjusted using mean JFiremon surface fuel loading outputs specific to each combination of experimental unit and condition (untreated or treated). In all custom fuel models, litter load was added to the 1-hr fuel load. For the Masticate sites, 1-hr fuel surface area-to-volume $\left(\mathrm{SA} \mathrm{V}^{-1}\right)$ ratio was modified from the default $6,562 \mathrm{~m}^{2} \mathrm{~m}^{-3}(2,000$ $\left.\mathrm{ft}^{2} \mathrm{ft}^{-3}\right)$ to $8,202 \mathrm{~m}^{2} \mathrm{~m}^{-3}\left(2,500 \mathrm{ft}^{2} \mathrm{ft}^{-3}\right)$ to better reflect the characteristics of this novel fuelbed type (M. Battaglia, USFS Rocky Mountain Research Station, personal communication).

Archival $50^{\text {th }}$ percentile and $90^{\text {th }}$ percentile fire weather data from 13 weather stations in the study area was then obtained using FireFamily Plus 4 (Bradshaw and McCormick, 2000) and averaged into sets of moderate hazard and high hazard fire weather values, respectively, for fire behavior modeling (Table 3.2). Additionally, the $6.1 \mathrm{~m}(20 \mathrm{ft}), 10$ minute average open windspeeds derived from FireFamily Plus were modified to 
represent average gust speed for each weather percentile, because this provides a more realistic interpretation of potentially hazardous wind conditions on the fireline (NOAA, 2008; see Ager et al., 2007). The effect of this modification was that $90^{\text {th }}$ percentile wind speeds in this study are similar to $97.5^{\text {th }}$ percentile ("extreme hazard") wind speeds used in other Sierra Nevada fuels and fire behavior studies (e.g., Stephens and Moghaddas, 2005a; Schmidt et al., 2008).

For NEXUS modeling purposes, foliar moisture content (FMC) was held constant at the default value of $100 \%$, as the range of old-foliage FMC values for most species straddles 100\%, and site-specific FMC data were not available (Scott and Reinhardt, 2001). Slope was held constant at $20 \%$ in NEXUS, as this was close to the average value across all plots. Wind direction was upslope and a wind reduction factor of 0.3 was used. These inputs were then used in conjunction with the custom fuel models from BehavePlus to obtain potential fire behavior outputs including flame length $(\mathrm{m})$, rate of spread $\left(\mathrm{km} \mathrm{hr}^{-1}\right)$, fireline intensity $\left(\mathrm{kW} \mathrm{m}^{-1}\right)$, torching index $\left(\mathrm{km} \mathrm{hr}^{-1}\right)$, and crowning index $\left(\mathrm{km} \mathrm{hr}^{-1}\right)$.

Table 3.2. Average fire weather values used in NEXUS 2.0 for two weather conditions.

\begin{tabular}{lcc} 
Input & $\begin{array}{c}\text { 50th } \\
\text { Percentile }\end{array}$ & $\begin{array}{c}90 \text { th } \\
\text { Percentile }\end{array}$ \\
\hline Average 6.1 m gust speed $\left(\mathrm{km} \mathrm{hr}^{-1}\right)$ & 25.8 & 32.2 \\
Temperature $\left({ }^{\circ} \mathrm{C}\right)$ & 28.9 & 33.3 \\
RH $(\%)$ & 22 & 12 \\
Fuel moisture $(\%)$ & & \\
1-hr & 5 & 3 \\
10-hr & 5 & 3 \\
100-hr & 10 & 6 \\
Live woody vegetation & 73 & 66 \\
Live herbaceous vegetation & 48 & 30 \\
\hline
\end{tabular}




\subsubsection{Statistical Analysis}

For all statistical analyses, the experimental unit was treatment type $\times$ site combination. For each of the four treatment types, $n=3$, with the exception of Pile Burn, for which $n=$ 2 (thus, total $n=11$ ). Data from the two untreated and three treated plots per experimental unit were averaged into untreated and treated "stands", respectively, for each response variable. Two different statistical analyses were then conducted on the percent difference between untreated and treated stands for each response variable. This type of analysis is sometimes referred to as "percent change"; because this was not a true before and after study, the term "percent difference" is used here. The analysis of percent difference was chosen because this type of analysis may help control the confounding effects of treatment age and site, by allowing for equal assessment of effects across all sites without regard for differences in overall fuel loading between sites (H. Smith, California Polytechnic State University, personal communication). Minitab 15.1.30.0 (Minitab, 2007) was used for all statistical analyses.

The first type of analysis was used to evaluate variation between treatment types; thus, a general linear model (GLM) analysis was performed on percent difference for each response variable in order to determine whether significant differences existed between treatment means $(\alpha=0.10)$. Due to the range of treatment ages ( $0-4$ years), time since treatment was added as a covariate. The covariate ultimately proved not to affect the outcome of significance/non-significance for any of the variables tested; therefore, in order to use the simplest model possible, it was dropped from the analysis. If at least one 
significant difference between treatment means was indicated in the GLM analysis, a Tukey's Honestly Significant Difference (HSD) test was used to evaluate which specific treatment types were significantly different from the others $(\alpha=0.10)$.

The second type of analysis was used to assess whether treated stands varied significantly from untreated stands. To that end, a one-way analysis of variance (ANOVA) was used to generate $90 \%$ confidence intervals in order to determine whether the percent difference between untreated and treated stands was significantly different than zero $(\alpha=0.10)$ for a given response variable.

In some cases, an untreated (proxy control) stand had a value of zero for a response variable (i.e., was non-stocked) while the corresponding treated stand had a nonzero value, resulting in a division-by-zero error in the percent difference calculations. To allow for the calculation of percent difference, the zero value was replaced by a placeholder value that was no greater than one-quarter the amount of the smallest nonzero value for the response variable across all untreated stands (McDonald, 2009).

Although the ANOVA assumption of independent experimental units was consistently met, the assumptions of normally distributed data and homoscedasticity were not always met. When the data did not meet these assumptions, square root and log base 10 transformations were tried (McDonald, 2009) and the statistical tests were repeated. When the transformations did not correct the violation(s), the tests were repeated with the 
most extreme observation omitted to check for any different outcomes (H. Smith, California Polytechnic State University, personal communication).

\subsection{Results}

Two types of tables are provided in each of the Results subsections. The first type of table shows mean absolute values for each response variable per condition (untreated or treated) and treatment type; these mean values were not included in the statistical analysis, are provided for reference purposes only, and should not be compared directly to the statistical analysis tables that follow them in each section. The second type of table shows 1) mean percent difference between untreated and stands for each response variable; 2) the significance of the difference, if any, as indicated by $90 \%$ confidence intervals; 3) whether significant differences exist between treatment means, as determined by GLM analysis; and 4) which treatment means were different from the others, based on Tukey pairwise comparisons. The included bar charts reflect GLM and pairwise comparison results; due to space constraints, they do not show the confidence interval results.

\subsubsection{Stand Structural and Fuel Loading Characteristics}

Mean FFE-FVS and JFiremon outputs for stand structural and fuel loading characteristics in untreated stands are presented in Table 3.3; values for treated stands are shown in Table 3.4. Statistical analysis results are shown in Table 3.5. 
Table 3.3. Mean (standard error) stand structural and fuel loading characteristics in untreated stands.

\begin{tabular}{|c|c|c|c|c|}
\hline Response & Masticate & Pile Burn & Thin + Fire & Fire Only \\
\hline \multicolumn{5}{|l|}{ Stand structure } \\
\hline Basal area $\left(\mathrm{m}^{2} \mathrm{ha}^{-1}\right)$ & $49.8(6.4)$ & $96.1(46.3)$ & $52.5(0.8)$ & $64.1(7.9)$ \\
\hline Canopy cover $(\%)$ & $69(4.7)$ & $72(11.0)$ & $61(2.7)$ & $73(6.1)$ \\
\hline Trees ha ${ }^{-1}$ & $1659.8(430.9)$ & $1263.4(398.9)$ & $742.6(23.1)$ & $1140.3(233.9)$ \\
\hline Quadratic mean diameter $(\mathrm{cm})$ & $20.7(3.5)$ & $30.1(2.9)$ & $30.0(0.8)$ & $27.2(1.5)$ \\
\hline Stand height $(\mathrm{m})$ & $27.7(0.5)$ & $34.9(7.8)$ & $27.6(0.5)$ & $26.6(0.8)$ \\
\hline \multicolumn{5}{|l|}{ Woody debris } \\
\hline 1-hr fuels $\left(\mathrm{Mg} \mathrm{ha}^{-1}\right)$ & $1.2(0.6)$ & $1.2(0.6)$ & $0.9(0.2)$ & $1.1(0.3)$ \\
\hline 10-hr fuels $\left(\mathrm{Mg} \mathrm{ha}^{-1}\right)$ & $7.6(2.0)$ & $7.3(2.4)$ & $2.4(0.4)$ & $7.6(1.1)$ \\
\hline 100-hr fuels $\left(\mathrm{Mg} \mathrm{ha}^{-1}\right)$ & $6.2(0.6)$ & $11.4(7.8)$ & $2.2(0.7)$ & $10.7(4.7)$ \\
\hline 1- to 100 -hr fuels $\left(\mathrm{Mg} \mathrm{ha}^{-1}\right)$ & $15.0(2.2)$ & $20.0(10.8)$ & $5.5(0.5)$ & $19.4(5.8)$ \\
\hline 1000-hr fuels $\left(\mathrm{Mg} \mathrm{ha}^{-1}\right)$ & $43.5(15.6)$ & $83.7(34.2)$ & $15.8(1.6)$ & $45.0(36.6)$ \\
\hline Litter load $\left(\mathrm{Mg} \mathrm{ha}^{-1}\right)$ & $27.4(6.7)$ & $35.4(11.9)$ & $26.4(2.0)$ & $32.5(7.4)$ \\
\hline Duff load $\left(\mathrm{Mg} \mathrm{ha}^{-1}\right)$ & $43.6(7.7)$ & $75.4(8.0)$ & $65.1(8.6)$ & $51.4(8.9)$ \\
\hline Total woody surface fuels $\left(\mathrm{Mg} \mathrm{ha}^{-1}\right)$ & $129.5(10.8)$ & $214.5(48.9)$ & $112.8(11.7)$ & $148.3(57.5)$ \\
\hline Fuelbed depth (m) & $0.15(0.02)$ & $0.17(0.08)$ & $0.12(0.02)$ & $0.16(0.04)$ \\
\hline \multicolumn{5}{|l|}{ Shrub and canopy fuels } \\
\hline Live shrub cover $(\%)$ & $46.3(18.3)$ & $16.4(10.5)$ & $29.5(20.1)$ & $24.2(9.4)$ \\
\hline Dead shrub cover $(\%)$ & $6.1(4.1)$ & $0.8(0.8)$ & $5.2(2.6)$ & $5.0(2.6)$ \\
\hline Live shrub load $\left(\mathrm{Mg} \mathrm{ha}^{-1}\right)$ & $12.1(5.5)$ & $2.8(1.9)$ & $4.0(1.4)$ & $2.5(0.8)$ \\
\hline Dead shrub load $\left(\mathrm{Mg} \mathrm{ha}^{-1}\right)$ & $1.2(0.8)$ & $0.1(0.1)$ & $0.2(0.1)$ & $1.0(0.6)$ \\
\hline Shrub height (m) & $1.02(0.26)$ & $0.45(0.12)$ & $0.35(0.10)$ & $0.44(0.06)$ \\
\hline Canopy bulk density $\left(\mathrm{kg} \mathrm{m}^{-3}\right)$ & $0.116(0.024)$ & $0.115(0.004)$ & $0.099(0.019)$ & $0.108(0.007)$ \\
\hline Canopy base height (m) & $0.9(0.2)$ & $0.6(0.0)$ & $0.6(0.0)$ & $1.1(0.3)$ \\
\hline
\end{tabular}


Table 3.4. Mean (standard error) stand structural and fuel loading characteristics in treated stands.

\begin{tabular}{|c|c|c|c|c|}
\hline Response & Masticate & Pile Burn & Thin + Fire & Fire Only \\
\hline \multicolumn{5}{|l|}{ Stand structure } \\
\hline Basal area $\left(\mathrm{m}^{2} \mathrm{ha}^{-1}\right)$ & $54.5(5.1)$ & $70.8(10.2)$ & $55.7(3.2)$ & $51.8(2.8)$ \\
\hline Canopy cover (\%) & $51(1.7)$ & $62(6.5)$ & $50(3.2)$ & $53(3.2)$ \\
\hline Trees ha ${ }^{-1}$ & $320.3(55.4)$ & $539.7(95.1)$ & $182.8(10.8)$ & $350.7(96.0)$ \\
\hline Quadratic mean diameter $(\mathrm{cm})$ & $47.2(3.6)$ & $41.5(6.7)$ & $62.5(2.2)$ & $45.9(6.8)$ \\
\hline Stand height (m) & $35.3(0.1)$ & $34.1(2.7)$ & $32.4(1.2)$ & $29.6(1.2)$ \\
\hline \multicolumn{5}{|l|}{ Woody debris } \\
\hline 1-hr fuels $\left(\mathrm{Mg} \mathrm{ha}^{-1}\right)$ & $1.3(0.4)$ & $0.5(0.2)$ & $0.1(0.1)$ & $0.2(0.1)$ \\
\hline 10-hr fuels $\left(\mathrm{Mg} \mathrm{ha}^{-1}\right)$ & $11.2(1.8)$ & $3.1(0.2)$ & $1.2(0.4)$ & $1.9(0.7)$ \\
\hline 100-hr fuels $\left(\mathrm{Mg} \mathrm{ha}^{-1}\right)$ & $12.1(2.0)$ & $2.1(1.9)$ & $2.5(1.0)$ & $4.0(1.5)$ \\
\hline 1- to 100 -hr fuels $\left(\mathrm{Mg} \mathrm{ha}^{-1}\right)$ & $24.6(3.1)$ & $5.7(1.9)$ & $3.7(1.4)$ & $6.0(1.8)$ \\
\hline 1000-hr fuels ( $\left.\mathrm{Mg} \mathrm{ha}^{-1}\right)$ & $25.7(19.1)$ & $46.7(5.0)$ & $19.4(10.3)$ & $22.1(7.8)$ \\
\hline Litter load $\left(\mathrm{Mg} \mathrm{ha}^{-1}\right)$ & $23.5(3.7)$ & $15.2(4.5)$ & $8.5(2.7)$ & $9.1(2.6)$ \\
\hline Duff load (Mg ha $\left.{ }^{-1}\right)$ & $26.9(6.7)$ & $45.7(3.8)$ & $7.5(6.7)$ & $10.3(9.2)$ \\
\hline Total woody surface fuels $\left(\mathrm{Mg} \mathrm{ha}^{-1}\right)$ & $100.6(16.2)$ & $113.4(7.6)$ & $39.1(17.2)$ & $47.5(21.1)$ \\
\hline Fuelbed depth (m) & $0.11(0.01)$ & $0.09(0.03)$ & $0.03(0.01)$ & $0.06(0.00)$ \\
\hline \multicolumn{5}{|l|}{ Shrub and canopy fuels } \\
\hline Live shrub cover $(\%)$ & $14.5(6.2)$ & $5.5(3.4)$ & $7.5(6.2)$ & $26.4(17.6)$ \\
\hline Dead shrub cover $(\%)$ & $0.5(0.3)$ & $0.1(0.1)$ & $8.5(7.7)$ & $2.0(0.9)$ \\
\hline Live shrub load $\left(\mathrm{Mg} \mathrm{ha}^{-1}\right)$ & $0.9(0.4)$ & $0.4(0.3)$ & $0.3(0.2)$ & $1.4(0.9)$ \\
\hline Dead shrub load $\left(\mathrm{Mg} \mathrm{ha}^{-1}\right)$ & $0.0(0.0)$ & $0.0(0.0)$ & $0.3(0.3)$ & $0.1(0.1)$ \\
\hline Shrub height (m) & $0.23(0.06)$ & $0.15(0.06)$ & $0.13(0.05)$ & $0.25(0.03)$ \\
\hline Canopy bulk density $\left(\mathrm{kg} \mathrm{m}^{-3}\right)$ & $0.049(0.007)$ & $0.094(0.002)$ & $0.049(0.007)$ & $0.064(0.022)$ \\
\hline Canopy base height (m) & $2.4(1.1)$ & $3.4(0.9)$ & $7.7(2.0)$ & $7.0(2.3)$ \\
\hline
\end{tabular}

\subsubsection{Stand Structural Characteristics}

The GLM analysis found significant differences in mean percent difference between treatments only for trees $\mathrm{ha}^{-1}$ (Table 3.5; Figure 3.2); subsequent Tukey's HSD tests indicated that the Masticate and Thin + Fire treatments reduced trees ha ${ }^{-1}$ significantly more than did the Pile Burn treatment. However, 90\% confidence intervals generated with a one-way ANOVA showed that, compared to untreated stands, all four treatment 
types significantly reduced trees $\mathrm{ha}^{-1}$ (Table 3.5). In addition, canopy cover was significantly decreased and QMD significantly increased by all treatments except Pile Burn. Stand height was significantly increased by the Masticate treatment.

Table 3.5. Mean percent difference between untreated and treated stands, general linear model pvalue $(\alpha=0.10)$, and standard error for stand structural and fuel loading characteristics.

\begin{tabular}{|c|c|c|c|c|c|c|}
\hline Response & Masticate & Pile Burn & Thin + Fire & Fire Only & $p$ & SE \\
\hline \multicolumn{7}{|l|}{ Stand structure } \\
\hline Basal area $^{a}$ & 10.9 & 2.6 & 6.4 & -15.3 & 0.827 & 36.5 \\
\hline Canopy cover ${ }^{\mathrm{a}}$ & $-25.6(-)$ & -11.1 & $-17.3(-)$ & $-26.5(-)$ & 0.650 & 15.1 \\
\hline Trees ha ${ }^{-1}$ & $-78.3(-) \mathrm{a}$ & $-55.2(-) b$ & $-75.3(-) \mathrm{a}$ & $-70.0(-) \mathrm{ab}$ & 0.039 & 7.0 \\
\hline Quadratic mean diameter & $141.3(+)$ & 41.5 & $109.0(+)$ & $68.2(+)$ & 0.187 & 48.5 \\
\hline Stand height ${ }^{\mathrm{a}}$ & $27.2(+)$ & 4.8 & 17.5 & 11.6 & 0.623 & 19.3 \\
\hline \multicolumn{7}{|l|}{ Woody debris } \\
\hline 1-hr fuels & $78.8(+) \mathrm{a}$ & $-43.8 a b$ & $-93.3(-) b$ & $-84.7(-) a b$ & 0.088 & 75.7 \\
\hline $10-$ hr fuels $^{\mathrm{b}}$ & $86.8(+) \mathrm{a}$ & $-53.0 \mathrm{ab}$ & $-43.4 \mathrm{ab}$ & $-76.1 b$ & 0.082 & 75.8 \\
\hline 100-hr fuels & $95.6(+) \mathrm{a}$ & $-86.4(-) b$ & $1.9 \mathrm{~b}$ & $-47.5(-) b$ & 0.006 & 40.0 \\
\hline 1 - to 100 -hr fuels & $72.3(+) \mathrm{a}$ & $-66.9(-) b$ & $-36.1 b$ & $-66.5(-) b$ & 0.017 & 42.3 \\
\hline 1000-hr fuels & -16.7 & -36.0 & 35.5 & 125.1 & 0.546 & 135.4 \\
\hline Litter load & $-10.2 \mathrm{a}$ & $-56.3(-) b$ & $-68.8(-) b$ & $-68.5(-) b$ & 0.007 & 15.6 \\
\hline Duff load & $-35.1(-)$ & $-39.2(-)$ & $-86.8(-)$ & $-72.5(-)$ & 0.198 & 29.6 \\
\hline Total woody surface fuels & -19.1 & -45.1 & $-62.8(-)$ & $-55.1(-)$ & 0.488 & 34.8 \\
\hline Fuelbed depth & $-25.4(-) \mathrm{a}$ & $-36.8(-)$ ab & $-68.6(-) b$ & $-57.1(-) \mathrm{ab}$ & 0.100 & 18.9 \\
\hline \multicolumn{7}{|l|}{ Shrub and canopy fuels } \\
\hline Live shrub cover & -17.2 & -65.6 & $-81.2(-)$ & -13.9 & 0.600 & 70.6 \\
\hline Dead shrub cover ${ }^{c}$ & 39.1 & -88.5 & -46.2 & -17.1 & 0.719 & 112.9 \\
\hline Live shrub load ${ }^{\mathrm{b}}$ & $-60.9(-)$ & $-89.4(-)$ & $-95.5(-)$ & $-47.1(-)$ & 0.274 & 42.2 \\
\hline Dead shrub load ${ }^{c, d}$ & -95.8 & -82.5 & -20.7 & -33.1 & 0.805 & 14.1 \\
\hline Shrub height & $-69.3(-)$ & $-67.3(-)$ & $-59.7(-)$ & $-43.3(-)$ & 0.519 & 22.0 \\
\hline Canopy bulk density & $-51.9(-)$ & -18.3 & $-48.1(-)$ & $-42.1(-)$ & 0.399 & 21.2 \\
\hline Canopy base height & 147.2 & 450.0 & $1166.7(+)$ & $758.3(+)$ & 0.231 & 19.8 \\
\hline
\end{tabular}

Symbols $(+$ or -$)$ following mean values indicate a significant $(\alpha=0.10)$ increase or decrease in comparison to untreated stands. Differing letters following mean values in a row indicate a significant $(\alpha=0.10)$ difference between treatment means. A lack of symbols or letters indicates a lack of significant treatment effects.

${ }^{a}$ Variable could not be made to meet the ANOVA assumption of equal variances.

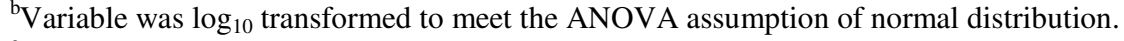

${ }^{\mathrm{c}}$ Variable had an extreme observation removed.

${ }^{\mathrm{d}}$ Variable could not be made to meet the ANOVA assumption of normal distribution. 




Figure 3.2. Mean percent difference and standard error between untreated and treated stands for basic stand characteristics; significant differences between treatment means $(p<0.10)$ are indicated by differing letters.

Bars depict mean percent increase or decrease in treatment stand response variables in comparison to untreated stands.

\subsubsection{Woody Debris Characteristics}

The GLM analysis indicated significant differences between treatment means for 1-hr fuels, 10-hr fuels, 100-hr fuels, 1- to 100-hr fuels, litter loading, and fuelbed depth. Specific differences between treatments, as identified by Tukey's HSD tests, are reported in Table 3.5 and Figures 3.3 and 3.4.

Ninety percent confidence intervals showed that the Fire Only treatment significantly reduced FWD loading in all size classes except 10-hr fuels, compared to the untreated stands (Table 3.5). Pile Burn significantly reduced 100-hr and 1- to 100-hr fuels, while Thin + Fire significantly reduced $1-\mathrm{hr}$ fuels. In contrast to the other treatments, the 
Masticate treatment significantly increased FWD loading in all size classes. Significant fuel reductions were found for litter loading (Pile Burn, Thin + Fire, Fire Only), total woody surface fuel loading (Thin + Fire, Fire Only), and duff loading and fuelbed depth (all treatment types). Significant results were not found for 1000-hr fuels.

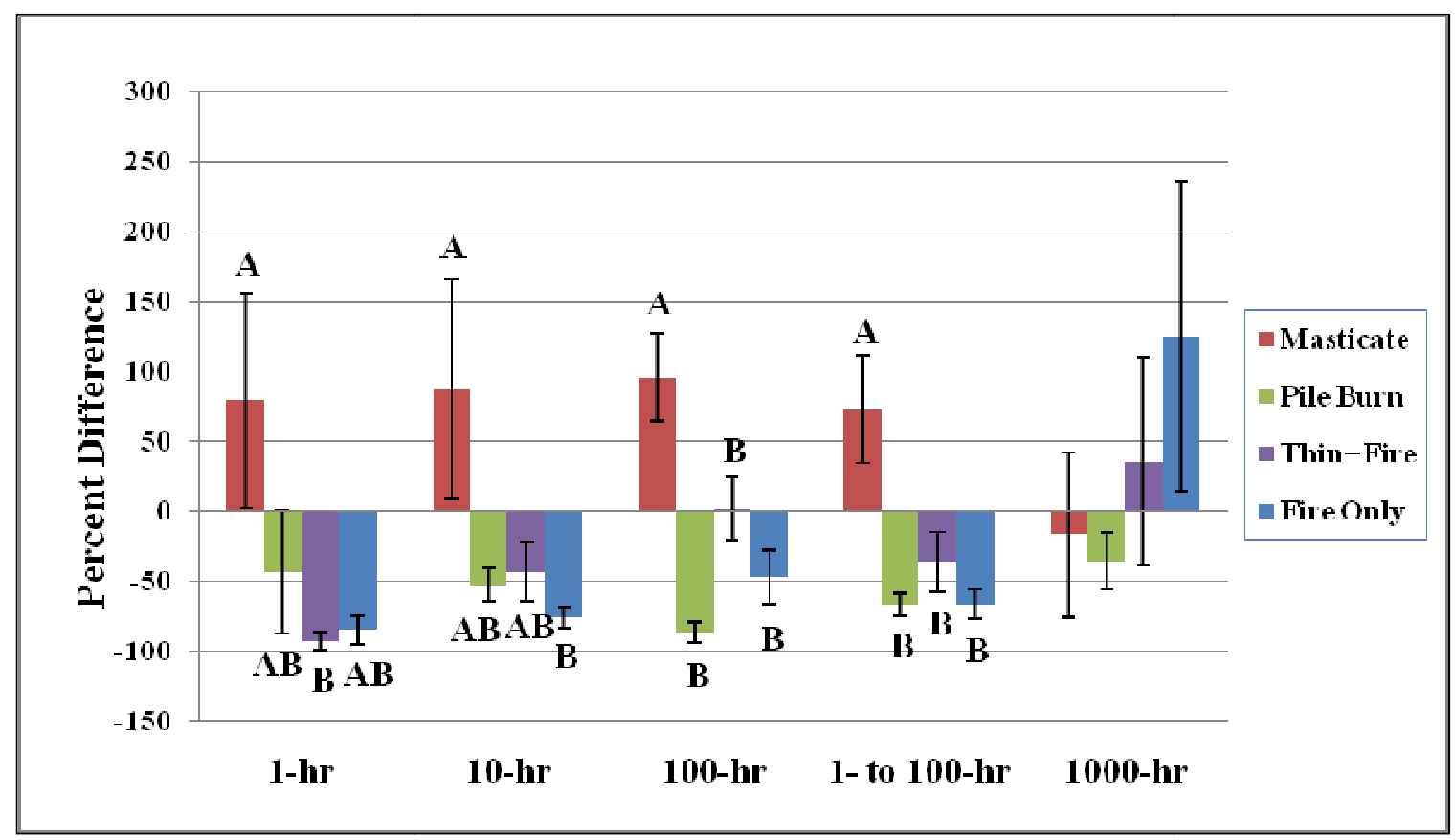

Figure 3.3. Mean percent difference and standard error between untreated and treated stands for 1through 1000-hr surface fuel loads; significant differences between treatment means $(p<0.10)$ are indicated by differing letters.

Bars depict mean percent increase or decrease in treatment stand response variables in comparison to untreated stands. 


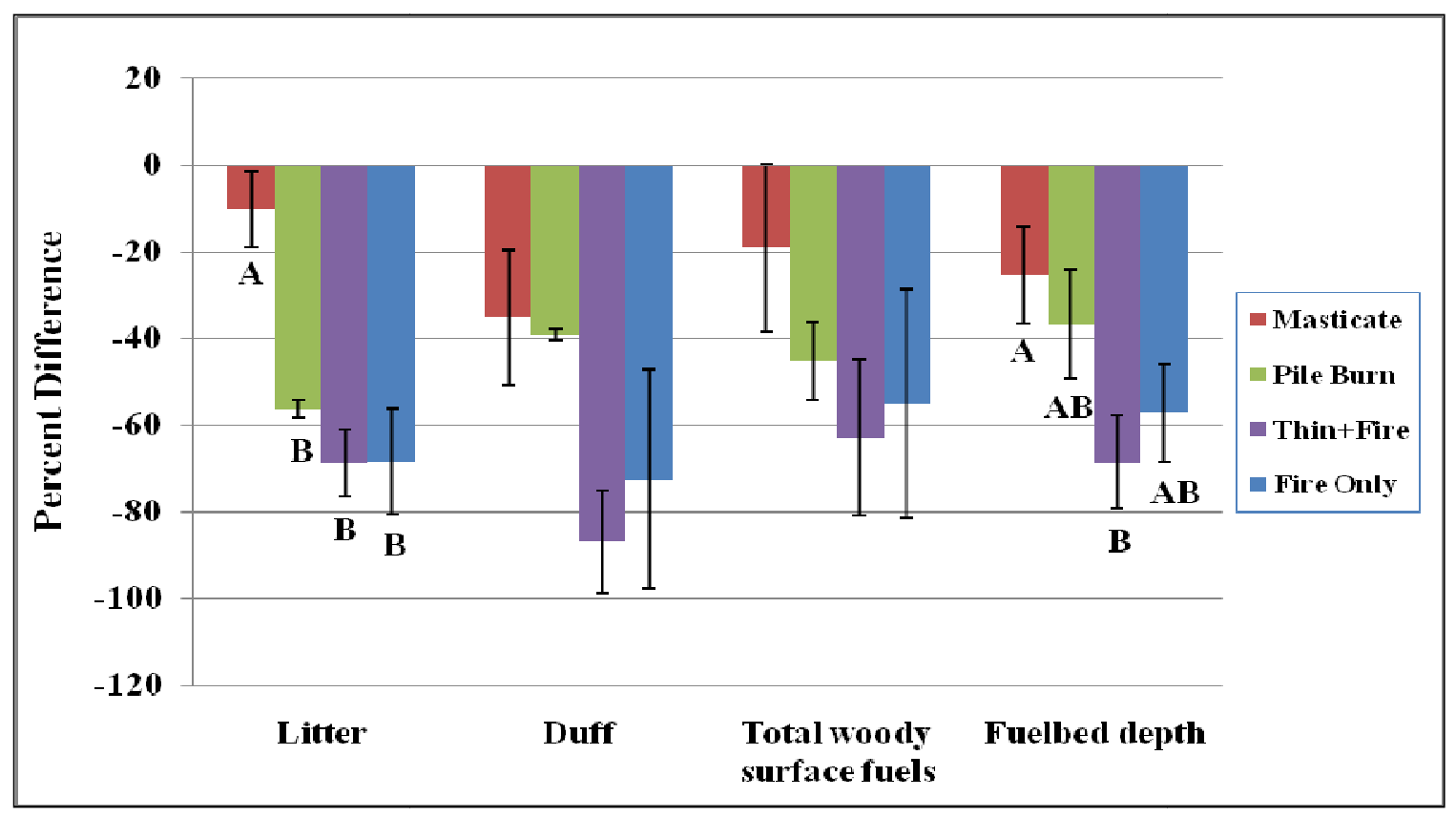

Figure 3.4. Mean percent difference and standard error between untreated and treated stands for various woody surface fuel loads and fuelbed depth; significant differences between treatment means $(p<0.10)$ are indicated by differing letters.

Bars depict mean percent increase or decrease in treatment stand response variables in comparison to untreated stands.

\subsubsection{Shrub and Canopy Fuels}

The GLM analysis of shrub and canopy fuels did not find any significant differences between treatments. The $90 \%$ confidence intervals indicated that all treatment types significantly decreased shrub height and live shrub loading (Table 3.5). The Thin + Fire treatment significantly decreased live shrub cover as well. Compared to untreated stands, canopy bulk density was significantly reduced by all treatment types except Pile Burn, while Fire Only and Thin + Fire significantly increased canopy base height. 


\subsubsection{Potential Fire Behavior}

Mean NEXUS fire behavior outputs for untreated and treated stands under $50^{\text {th }}$ and $90^{\text {th }}$ percentile weather conditions are shown in Table 3.6. The GLM analysis did not find significant differences between treatment means for any of the potential fire behavior outputs under either specific fire weather scenario (Table 3.7; Figures 3.5 and 3.6). Torching index (TI; the windspeed required for transition from surface fire to passive crown fire) could not be displayed on the charts due to the magnitude of the percent difference values. 
Table 3.6. Mean (standard error) potential fire behavior under $50^{\text {th }}$ and $90^{\text {th }}$ percentile weather conditions in untreated and treated stands.

Untreated stands

\begin{tabular}{lcccc}
\hline \multicolumn{1}{c}{$50^{\text {th }}$ percentile } & Masticate & Pile Burn & Thin + Fire & Fire Only \\
\hline Fire type & $67 \% \mathrm{~S}, 33 \% \mathrm{P}$ & $100 \% \mathrm{P}$ & $33 \% \mathrm{~S}, 67 \% \mathrm{P}$ & $33 \% \mathrm{~S}, 67 \% \mathrm{P}$ \\
Spread rate $\left(\mathrm{m} \mathrm{min}^{-1}\right)$ & $4.7(3.7)$ & $13.9(0.9)$ & $13.1(1.9)$ & $12.5(0.9)$ \\
Fireline intensity $\left(\mathrm{kW} \mathrm{m}^{-1}\right)$ & $657.3(582.6)$ & $3766.5(1823.5)$ & $3375.7(1669.3)$ & $2159.0(1725.1)$ \\
Flame length $(\mathrm{m})$ & $1.3(0.8)$ & $4.8(2.0)$ & $4.1(1.8)$ & $3.1(1.9)$ \\
Torching index $\left(\mathrm{km} \mathrm{hr}^{-1}\right)$ & $57.3(37.0)$ & $11.4(11.4)$ & $8.5(8.5)$ & $20.2(10.7)$ \\
Crowning index $\left(\mathrm{km} \mathrm{hr}^{-1}\right)$ & $36.1(5.0)$ & $34.8(0.8)$ & $41.4(7.4)$ & $36.6(1.9)$
\end{tabular}

\begin{tabular}{lcccc}
\hline \multicolumn{1}{c}{ 90th percentile } & Masticate & Pile Burn & Thin + Fire & Fire Only \\
\cline { 1 - 4 } Fire type & $33 \% \mathrm{~S}, 33 \% \mathrm{P}$ & $100 \% \mathrm{~A}$ & $33 \% \mathrm{~S}, 67 \% \mathrm{~A}$ & $33 \% \mathrm{P}, 33 \% \mathrm{~A}$, \\
Spread rate $\left(\mathrm{m} \mathrm{min}^{-1}\right)$ & $33 \% \mathrm{~A}$ & & & $33 \% \mathrm{C}$ \\
Fireline intensity $\left(\mathrm{kW} \mathrm{m}^{-1}\right)$ & $18.2(8.8)$ & $28.3(0.0)$ & $23.8(4.5)$ & $27.6(0.7)$ \\
Flame length $(\mathrm{m})$ & $6962.0(3684.7)$ & 19793.5 & 11373.3 & 14987.7 \\
Torching index $\left(\mathrm{km} \mathrm{hr}^{-1}\right)$ & $7.8(4.1)$ & $1378.5)$ & $(5653.7)$ & $(2151.1)$ \\
Crowning index $\left(\mathrm{km} \mathrm{hr}^{-1}\right)$ & $46.3(30.5)$ & $10.5(0.9)$ & $11.9(5.7)$ & $15.5(2.2)$ \\
& $31.6(4.5)$ & $30.4(0.7)$ & $36.0(6.5)$ & $32.5(1.7)$
\end{tabular}

Treated stands

\begin{tabular}{lcccc}
\hline \multicolumn{1}{c}{$50^{\text {th }}$ percentile } & Masticate & Pile Burn & Thin + Fire & Fire Only \\
\hline Fire type & $100 \% \mathrm{~S}$ & $100 \% \mathrm{~S}$ & $100 \% \mathrm{~S}$ & $100 \% \mathrm{~S}$ \\
Spread rate $\left(\mathrm{m} \mathrm{min}^{-1}\right)$ & $2.0(0.8)$ & $3.5(0.4)$ & $0.9(0.7)$ & $5.9(2.6)$ \\
Fireline intensity $\left(\mathrm{kW} \mathrm{m}^{-1}\right)$ & $39.3(26.8)$ & $287.5(150.5)$ & $12.3(9.0)$ & $72.0(28.0)$ \\
Flame length $(\mathrm{m})$ & $0.3(0.1)$ & $1.0(0.3)$ & $0.2(0.1)$ & $0.5(0.1)$ \\
Torching index $\left(\mathrm{km} \mathrm{hr}^{-1}\right)$ & $144.6(78.4)$ & $59.6(4.5)$ & $1654.8(672.4)$ & $206.0(123.4)$ \\
Crowning index $\left(\mathrm{km} \mathrm{hr}^{-1}\right)$ & $66.6(8.0)$ & $40.5(0.5)$ & $66.7(6.9)$ & $60.6(12.2)$ \\
& & & & \\
\multicolumn{1}{c}{ 90th percentile } & Masticate & Pile Burn & Thin + Fire & Fire Only \\
\hline Fire type & $100 \% \mathrm{~S}$ & $100 \% \mathrm{~S}$ & $100 \% \mathrm{~S}$ & $67 \% \mathrm{~S}, 33 \% \mathrm{C}$ \\
Spread rate $\left(\mathrm{m} \mathrm{min}^{-1}\right)$ & $3.4(1.4)$ & $6.2(1.2)$ & $1.6(1.3)$ & $19.4(4.7)$ \\
Fireline intensity $\left(\mathrm{kW} \mathrm{m}^{-1}\right)$ & $78.7(55.3)$ & $560.5(267.5)$ & $25.0(19.7)$ & $3552.7(3350.6)$ \\
Flame length $(\mathrm{m})$ & $0.5(0.2)$ & $1.4(0.3)$ & $0.3(0.1)$ & $4.8(3.9)$ \\
Torching index $\left(\mathrm{km} \mathrm{hr}^{-1}\right)$ & $123.3(68.4)$ & $48.4(1.5)$ & $1315.2(524.5)$ & $175.0(101.5)$ \\
Crowning index $\left(\mathrm{km} \mathrm{hr}^{-1}\right)$ & $58.6(7.1)$ & $35.4(0.4)$ & $58.6(6.1)$ & $53.2(10.8)$ \\
\hline
\end{tabular}

For fire type, $\mathrm{S}=$ surface fire, $\mathrm{P}=$ passive crown fire, $\mathrm{A}=$ active crown fire, $\mathrm{C}=$ conditional crown fire. 
Ninety percent confidence intervals identified at least one significant effect on predicted fire behavior for each treatment type as compared to untreated stands (Table 3.7). Significant results were not found for spread rate or fireline intensity under either fire weather scenario; however, predicted flame length in treated stands was significantly lower than in untreated stands in the Pile Burn and Thin + Fire treatments, under both weather scenarios. Fire Only significantly reduced flame length only under $90^{\text {th }}$ percentile conditions. The confidence intervals additionally indicated a significant increase in TI by the Thin + Fire treatment, while crowning index $(\mathrm{CI}$; the windspeed required for transition from passive crown fire to active crown fire) was significantly increased by all treatments except Pile Burn.

Because existing fuel models (Anderson, 1982; Scott and Burgan, 2005) are thought to be inadequate for use with the compact fuelbeds characteristic of mastication (Knapp et al., 2006; Kane et al., 2009), thus raising questions regarding the validity of fire modeling outputs in such fuelbeds, the potential fire behavior data were analyzed a second time with the Masticate treatment removed. (Please refer to pp. 63-65 for further discussion of this issue). The results are displayed in Table 3.8. Comparing Tables 3.7 and 3.8, one can see that removing the Masticate treatment from the statistical analysis resulted in findings of statistical significance (from the $90 \%$ confidence intervals) for mean reduction in spread rate and fireline intensity for all remaining treatment types under both weather scenarios. In addition, the reduction of flame length by the Fire Only treatment under the 50th percentile weather scenario became significant. Furthermore, a significant difference between treatment types was found for spread rate under 90th percentile weather: Thin + 
Fire was found to reduce spread rate significantly more than Fire Only. The initial torching index and crowning index results were unaffected by the removal of the Masticate treatment.

Figures 3.7 and 3.8 show fuel treatment effects on flame length under both weather scenarios as compared against an idealized untreated stand (averaged from all untreated stands). The charts indicate that all treatment types would be effective at keeping flame length low until wind speeds of approximately $41 \mathrm{~km} \mathrm{hr}^{-1}\left(50^{\text {th }}\right.$ percentile conditions $)$ or $35 \mathrm{~km} \mathrm{hr}^{-1}\left(90^{\text {th }}\right.$ percentile conditions) were experienced. Thin + Fire had the greatest impact on predicted flame length, and on fire behavior overall, significantly decreasing flame length and increasing TI and CI under both weather scenarios. 
Table 3.7. Mean percent difference between untreated and treated stands, general linear model pvalue $(\alpha=0.10)$, and standard error for potential fire behavior under $50^{\text {th }}$ and $90^{\text {th }}$ percentile weather conditions.

\begin{tabular}{|c|c|c|c|c|c|c|}
\hline 50th percentile & & & & & & \\
\hline Response & Masticate & Pile Burn & Thin + Fire & Fire Only & $p$ & SE \\
\hline Spread rate $^{a}$ & 156.7 & -75.0 & -91.0 & -49.9 & 0.250 & 150.8 \\
\hline Fireline intensity & 17.5 & -92.6 & -72.9 & -64.7 & 0.528 & 86.7 \\
\hline Flame length & -23.8 & $-77.9(-)$ & $-65.0(-)$ & -54.9 & 0.724 & 55.9 \\
\hline Torching inde $\mathrm{x}^{\mathrm{a}}$ & 666.1 & 3220.8 & $154187.0(+)$ & 15133.1 & 0.214 & 73688.0 \\
\hline Crowning index & $99.4(+)$ & 16.4 & $66.1(+)$ & $63.6(+)$ & 0.549 & 60.1 \\
\hline \multicolumn{7}{|l|}{ 90th percentile } \\
\hline Response & Masticate & Pile Burn & Thin + Fire & Fire Only & $p$ & SE \\
\hline Spread rate $^{\mathrm{a}}$ & 108.4 & -78.1 & -89.9 & -29.8 & 0.394 & 183.5 \\
\hline Fireline intensity ${ }^{\mathrm{b}}$ & 7.2 & -97.1 & -67.7 & -80.5 & 0.804 & 104.3 \\
\hline Flame length & -42.0 & $-92.7(-)$ & $-66.1(-)$ & $-73.1(-)$ & 0.833 & 61.9 \\
\hline Torching inde $\mathrm{x}^{\mathrm{a}}$ & 732.4 & 2512.3 & $121937.6(+)$ & 12647.6 & 0.218 & 58278.0 \\
\hline Crowning index & $101.4(+)$ & 16.5 & $66.8(+)$ & $64.1(+)$ & 0.551 & 61.7 \\
\hline
\end{tabular}

Symbols $(+$ or -$)$ following mean values indicate a significant $(\alpha=0.10)$ increase or decrease in comparison to untreated stands. A lack of symbols indicates a lack of significant treatment effects.

${ }^{a}$ Variable was $\log _{10}$ transformed to meet the ANOVA assumption of normal distribution.

${ }^{\mathrm{b}}$ Variable was square root transformed to meet the ANOVA assumption of normal distribution.

Table 3.8. Mean percent difference between untreated and treated stands, general linear model pvalue $(\alpha=0.10)$, and standard error for potential fire behavior under $50^{\text {th }}$ and $90^{\text {th }}$ percentile weather conditions, with the Masticate treatment type removed.

\begin{tabular}{|c|c|c|c|c|c|}
\hline 50th percentile & & & & & \\
\hline Response & Pile Burn & Thin + Fire & Fire Only & $p$ & SE \\
\hline Spread rate & $-75.0(-)$ & $-91.0(-)$ & $-49.9(-)$ & 0.290 & 28.3 \\
\hline Fireline intensity & $-92.6(-)$ & $-72.9(-)$ & $-64.7(-)$ & 0.802 & 45.3 \\
\hline Flame length & $-77.9(-)$ & $-65.0(-)$ & $-54.9(-)$ & 0.870 & 47.2 \\
\hline Torching index & 3220.8 & $154187.0(+)$ & 15133.1 & 0.171 & 87185.6 \\
\hline Crowning index & 16.4 & $66.1(+)$ & $63.6(+)$ & 0.351 & 36.9 \\
\hline \multicolumn{6}{|l|}{ 90th percentile } \\
\hline Response & Pile Burn & Thin + Fire & Fire Only & $p$ & SE \\
\hline Spread rate & $-78.1(-)$ ab & $-89.9(-) b$ & $-29.8(-) \mathrm{a}$ & 0.035 & 20.5 \\
\hline Fireline intensity & $-97.1(-)$ & $-67.7(-)$ & $-80.5(-)$ & 0.743 & 40.6 \\
\hline Flame length & $-92.7(-)$ & $-66.1(-)$ & $-73.1(-)$ & 0.794 & 42.6 \\
\hline Torching index & 2512.3 & $121937.6(+)$ & 12647.6 & 0.173 & 68951.4 \\
\hline Crowning index & 16.5 & $66.8(+)$ & $64.1(+)$ & 0.352 & 37.3 \\
\hline
\end{tabular}

Symbols $(+$ or -$)$ following mean values indicate a significant $(\alpha=0.10)$ increase or decrease in comparison to untreated stands. A lack of symbols indicates a lack of significant treatment effects. 


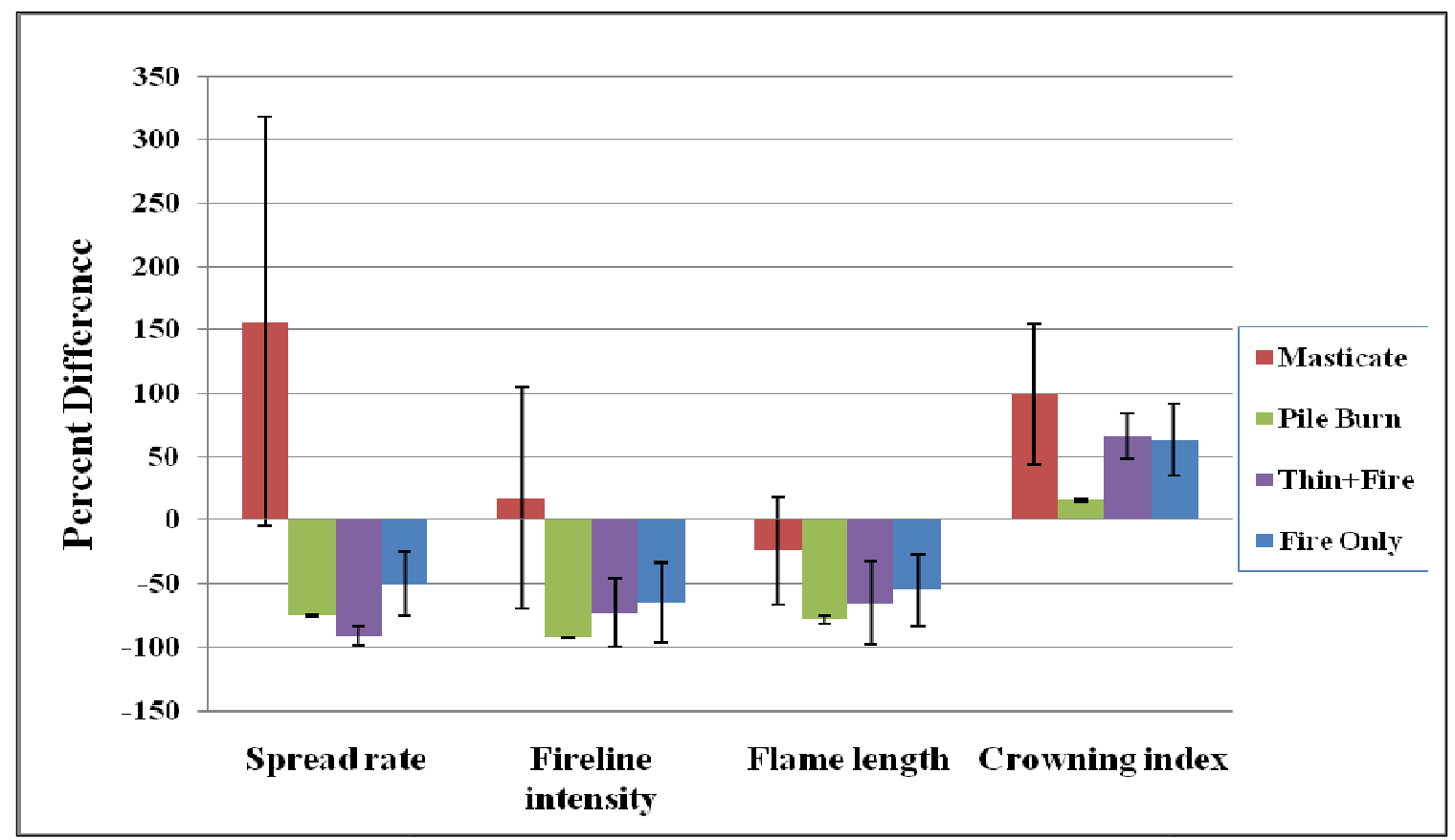

Figure 3.5. Mean percent difference and standard error between untreated and treated stands for potential fire behavior characteristics under $5^{\text {th }}$ percentile fire weather conditions; significant differences between treatment means $(p<0.10)$ are indicated by differing letters.

Bars depict mean percent increase or decrease in treatment stand response variables in comparison to untreated stands. Spread rate: the rate at which a head fire travels through surface or crown fuels

Fireline intensity: the heat energy release per unit time from a 1-meter wide section of the fuel bed extending from the front to the rear of the flaming zone; a function of spread rate and heat per unit area

Flame length: length of flames as measured from midway in the active flaming combustion zone to the average tip of the flames; calculated from fireline intensity

Crowning index: the open windspeed (wind speed at $6.1 \mathrm{~m}$ above ground level) at which active crown fire is possible 


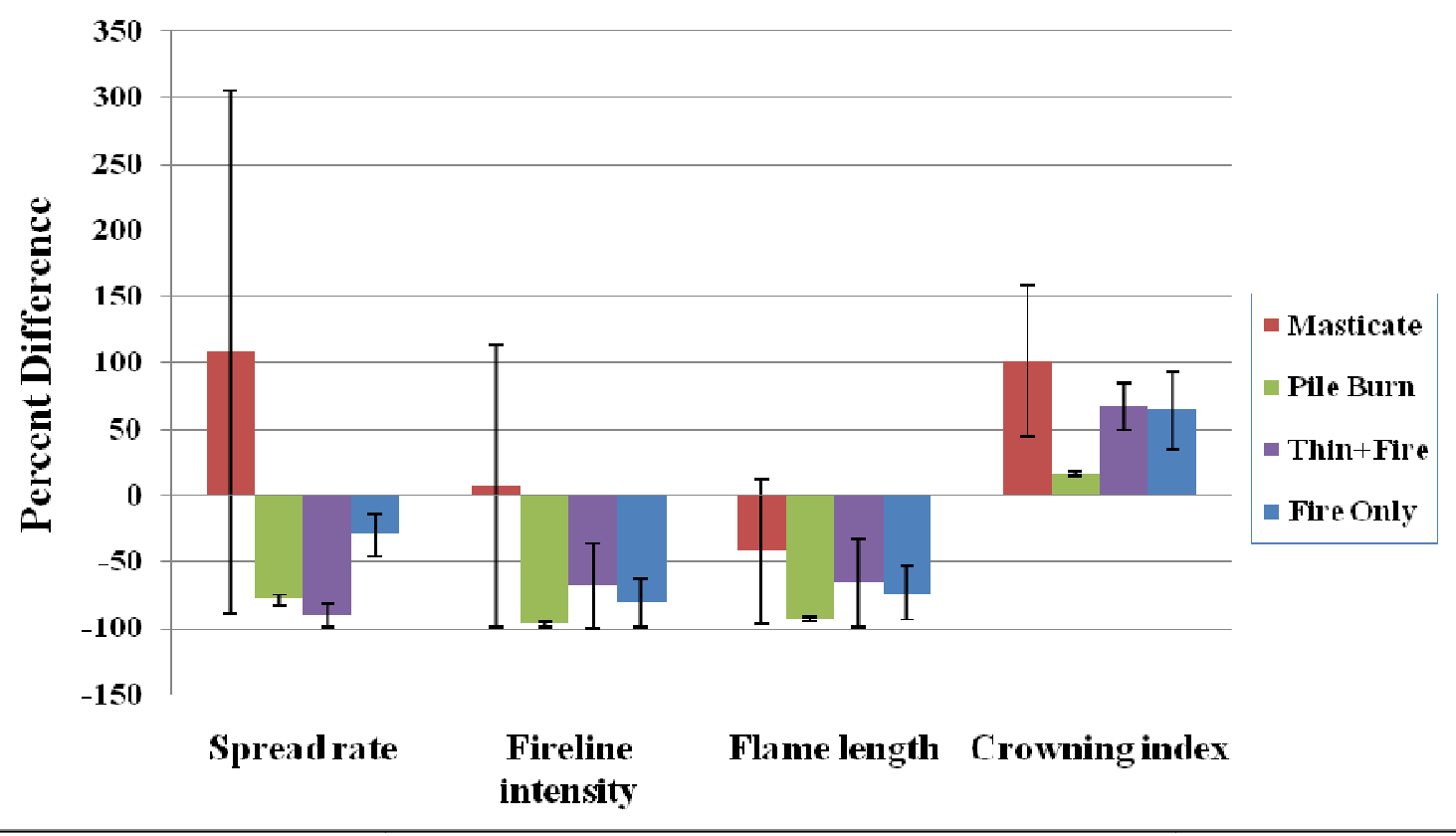

Figure 3.6. Mean percent difference and standard error between untreated and treated stands for potential fire behavior characteristics under $90^{\text {th }}$ percentile fire weather conditions; significant differences between treatment means $(p<0.10)$ are indicated by differing letters.

Bars depict mean percent increase or decrease in treatment stand response variables in comparison to untreated stands. Spread rate: the rate at which a head fire travels through surface or crown fuels

Fireline intensity: the heat energy release per unit time from a 1-meter wide section of the fuel bed extending from the front to the rear of the flaming zone; a function of spread rate and heat per unit area

Flame length: length of flames as measured from midway in the active flaming combustion zone to the average tip of the flames; calculated from fireline intensity

Crowning index: the open windspeed (wind speed at $6.1 \mathrm{~m}$ above ground level) at which active crown fire is possible 


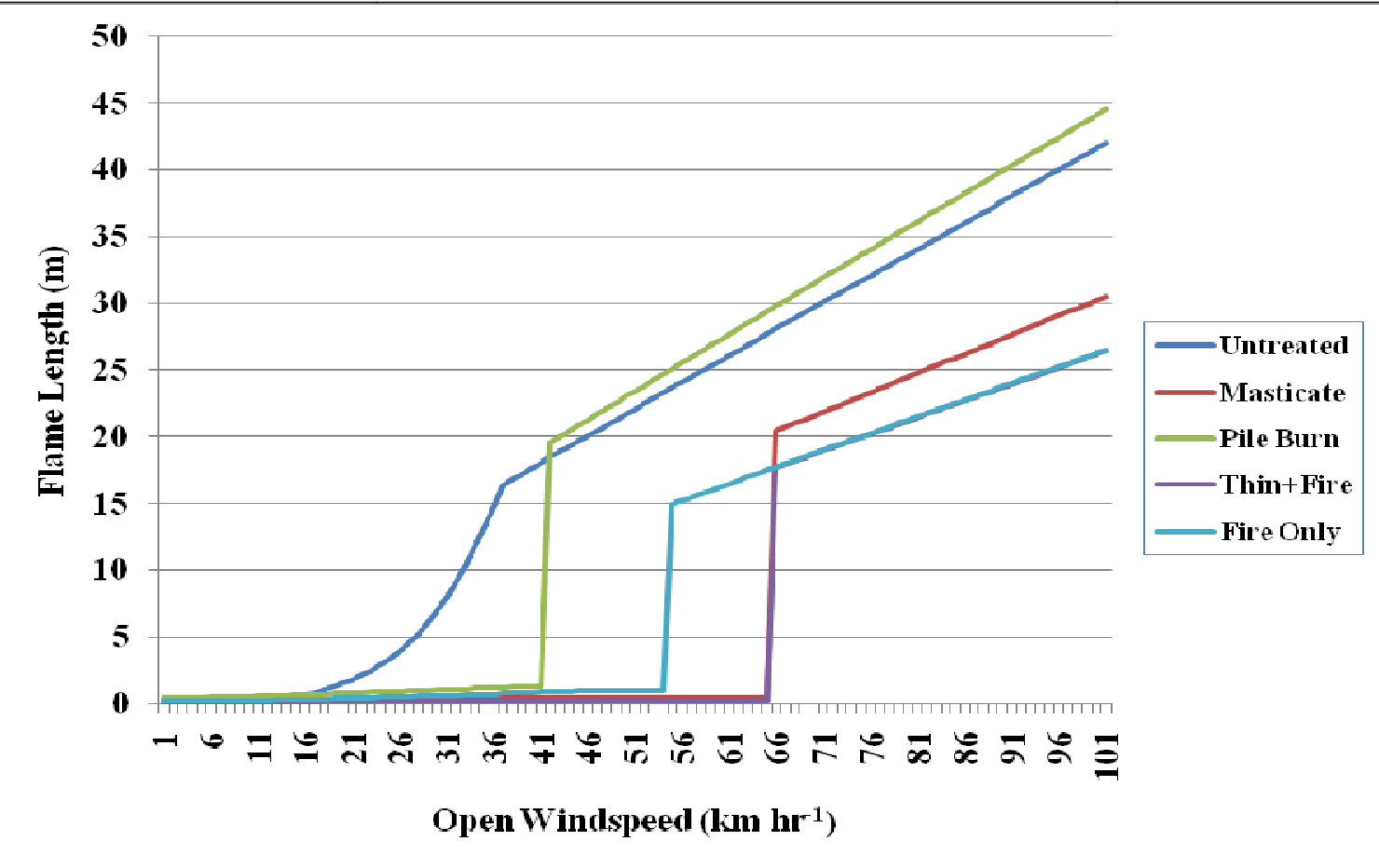

Figure 3.7. Fuel treatment effects on flame length under $50^{\text {th }}$ percentile fire weather conditions.

Flame length: length of flames as measured from midway in the active flaming combustion zone to the average tip of the flames; calculated from fireline intensity

Open windspeed: the wind speed at $6.1 \mathrm{~m}$ above ground level 


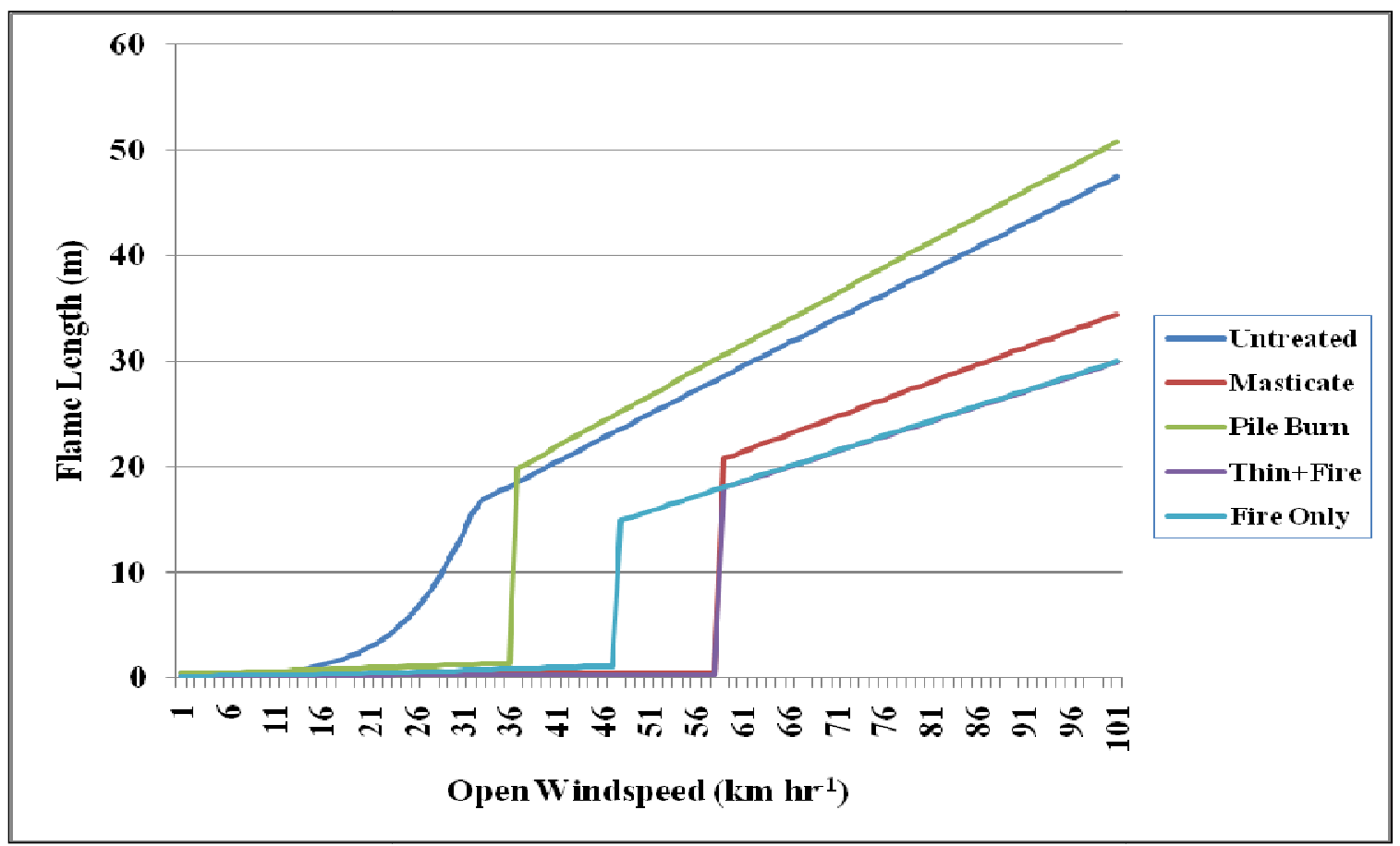

Figure 3.8. Fuel treatment effects on flame length under $90^{\text {th }}$ percentile fire weather conditions.

Flame length: length of flames as measured from midway in the active flaming combustion zone to the average tip of the flames; calculated from fireline intensity

Open windspeed: the wind speed at $6.1 \mathrm{~m}$ above ground level

\subsection{Discussion}

Fuel treatments are typically designed to lessen wildfire severity and effects by reducing surface fuels, raising canopy base height, reducing canopy bulk density, and retaining large, fire-resistant trees (Agee and Skinner, 2005). Despite widespread misconceptions, fuel treatments are not properly intended to prevent fire from occurring; nor should they be implemented to facilitate fire suppression activities (Reinhardt et al., 2008). Duration of fuel treatment effectiveness depends on the treatment type and factors that affect productivity, including forest type, fire regime, climate, and soils (Graham et al., 2004; Skinner, 2005); in the dry mixed-conifer forests of the Sierra Nevada, where the rate of 
productivity exceeds the rate of decomposition (Weatherspoon and Skinner, 1996), treatment effects typically last between 5 and 20 years (Stephens et al., 2009a). The implementation of any given fuel treatment is site-specific and inevitably involves certain tradeoffs (Stephens and Moghaddas, 2005a).

Treatments involving broadcast burning are most likely to effectively reduce surface fuels and thus surface fire intensity while also restoring a critical ecosystem function, and under some circumstances they may also reduce ladder fuels and canopy bulk density, especially as regards smaller trees (Peterson et al., 2005). Nonetheless, they can be difficult to implement due to public concerns over smoke production and the risk of escaped fire, and multiple entries are often required within a decade, compounding these difficulties (McCandliss, 2002).

In contrast, mechanical treatments are generally more effective at thinning out dense forest canopies and allow for greater precision (i.e., targeting certain stand components but not others) than prescribed fire (Stephens and Moghaddas, 2005a). Furthermore, because the risk of unintended treatment effects (such as escaped fire) is perceived as being lower with mechanical treatments than with prescribed burning, mechanical treatments are often preferred in the WUI (Schoennagel et al., 2009). However, because mechanical treatments commonly increase surface fuel loading, follow-up treatments such as prescribed fire or pile burning are often required in order to mitigate the elevated fire hazard resulting from the initial treatment (Graham et al., 2004). Fuel treatments that combine mechanical methods with prescribed fire have typically been found to be most 
effective at creating a fire-resilient forest structure (fewer but larger-diameter trees), reducing surface fuels, and increasing understory species richness in dry, mixed-conifer forest stands such as those of the central Sierra Nevada (Schwilk et al., 2009).

Basic stand structural characteristics are targeted in fuel treatments in order to reduce ladder fuels and canopy bulk density, thus limiting the chance of crown fire initiation and spread (Agee and Skinner, 2005). In the current study, all treatments except Pile Burn significantly reduced canopy cover and increased diameter (QMD), while trees $\mathrm{ha}^{-1}$ was significantly reduced by all four treatment types (Table 3.5). The fact that Fire Only significantly affected canopy cover and QMD is somewhat unexpected, given that similar studies (Stephens and Moghaddas, 2005a; North et al., 2007; Schmidt et al., 2008) did not report such effects. Conversely, in the current study the Pile Burn treatment, which might reasonably be expected to have significant effects on canopy cover and QMD, did not. This is probably because all Pile Burn sites for this study were located within Yosemite National Park, where basal area in untreated stands was substantially higher than on USFS lands in this study (Table 3.3), and where a much lower thinning intensity was applied than at the other mechanical treatment sites. The fact that only the Masticate treatment significantly affected stand height likely stems from the extreme density of small trees that was encountered in the untreated stands for this treatment type.

Surface fuel components, including DWD and live and dead vegetation, contribute to flame length and passive crown fire initiation (i.e., torching; Van Wagner, 1977). DWD fuels were most effectively reduced by the Fire Only treatment (Table 3.5), although Pile 
Burn and Thin + Fire resulted in some reductions as well. In contrast to FWD results from similar, recent studies (Stephens and Moghaddas, 2005a; Schmidt et al., 2008), Thin + Fire significantly reduced only $1-\mathrm{hr}$ fuels. This lack of significant change may be attributable to the fact that mean FWD loading in the untreated stands for Thin + Fire was substantially lower than in the other untreated stands (Table 3.3). The significant reductions in 100-hr and 1- to 100-hr fuels seen with the Pile Burn treatment may be partly attributable to one of the sampling sites being located near a campground. Firewood collection by campers at this site may have decreased fuel loading in one or more of these size classes.

Fuel loading effects from mastication are site-specific and can be highly variable, depending upon type of equipment used, operator experience, and site vegetation characteristics among other factors (D. Tolmie, Sierra National Forest, personal communication). Masticated fuelbeds are generally more compact than natural or slash fuelbeds, thus potentially moderating fire behavior due to the reduction in fuelbed depth (Glitzenstein et al., 2006). However, mastication also increases FWD loading, as a result of the conversion of vertical fuels to surface fuels (Reiner et al., 2009; Stephens et al., 2009a). Kane et al. (2009) noted that because the arrangement and physical properties of masticated particles differ substantially from those found in natural or logging slash fuelbeds, the use of planar surface fuel transects (Brown, 1974) may not provide an accurate inventory of 1- and 10-hr fuels in masticated fuelbeds. 
In the current study, the Masticate treatment significantly reduced duff loading and fuelbed depth, but increased FWD loading in all size classes (Table 3.5); these results generally mirror earlier research (Stephens and Moghaddas, 2005a; Kobziar et al., 2009). Although the compact quality of masticated fuelbeds may decrease surface fire spread rate (Glitzenstein et al., 2006), the increased surface fuel loading may contribute to increased fire intensity, residence time, and chance of crown fire initiation, leading to increased tree mortality through torching or girdling (Knapp et al., 2006; Kobziar et al., 2009). With the exception of significantly improved crowning index values, the mastication treatment was not found to have statistically significant effects on predicted fire behavior in the current study.

Thousand-hour fuels (i.e., CWD) can contribute to smoke production and crown fire initiation (Stephens et al., 2005b), although they are not usually considered to contribute to surface fire spread (Rothermel, 1972). While little is known about Sierra Nevada mixed-conifer CWD dynamics prior to the fire exclusion era, CWD is important from an ecological standpoint, as it contributes to nutrient cycling, decomposition and respiration, tree regeneration, biodiversity, and wildlife habitat (Harmon et al., 1986). Treatments involving prescribed fire in the Sierra Nevada have been shown to reduce rotten 1000-hr fuels while simultaneously recruiting new, sound 1000-hr fuels by creating snags that fall within a few years (Innes et al., 2006). In the current study, 1000-hr fuels were not significantly affected by any treatment type. 
Shrubs are commonly targeted in fuel treatments due to their ability to carry fire into low tree crowns and their contribution to overall fire intensity. Because shrubs are easily killed by fire, long-term fire suppression has likely increased shrub loading and cover in Sierra Nevada mixed-conifer forests, as compared to the pre-suppression era (McCandliss, 2002). Thus, the observed treatment reductions in shrub cover, loading, and height (Table 3.5) were not unexpected.

Canopy fuel characteristics include canopy base height (CBH) and canopy bulk density (CBD), which influence the initiation of passive (torching) and active (tree-to-tree) crown fire, respectively (Scott and Reinhardt, 2001). Pruning or removal of trees with lowhanging branches reduces the probability of torching by increasing $\mathrm{CBH}$, while the potential for active crown fire is mitigated by decreasing CBD through reductions in stand density (Graham et al., 2004). The removal of trees that have low crowns and are in a position to carry fire into the crowns of taller trees (i.e., ladder fuels) thus reduces fire hazard by changing both $\mathrm{CBH}$ and CBD. In the current study, similarly to the results found by Stephens and Moghaddas (2005a) and Schmidt et al. (2008), the Thin + Fire treatment effectively reduced $\mathrm{CBD}$ and increased $\mathrm{CBH}$, while a mechanical-only treatment (here, Masticate) significantly reduced CBD (Table 3.5). However, in contrast to the findings of the aforementioned studies, the Masticate treatment did not significantly increase $\mathrm{CBH}$, while Fire Only did significantly affect both variables. Pile Burn did not have significant effects on either variable, again reflecting the low-intensity treatment applied by the National Park Service. 
Fuel treatment effectiveness is commonly assessed using predictive fire modeling tools such as NEXUS 2.0 (Scott, 1999) to calculate fire behavior outputs including rate of spread, fireline intensity, and flame length (Vaillant et al., 2009), as well as torching index (TI) and crowning index (CI; Scott and Reinhardt, 2001). While modeling software can provide useful information to fire managers, model outputs are based on assumptions of constant, homogeneous values for weather, topography, and fuel (Rothermel, 1972) that are rarely, if ever, found in nature. Thus, fire modeling results should be interpreted with caution. This is particularly true as regards mastication; existing fuel models (Anderson, 1982; Scott and Burgan, 2005) are thought to be inadequate for use with the compact fuelbeds characteristic of this relatively new treatment type (Knapp et al., 2006; Kane et al., 2009).

The current analysis found significant treatment effects on flame length, TI, and CI when compared to untreated stands, but did not find significant results for spread rate or fireline intensity (Table 3.7) (except when the Masticate treatment was removed from the analysis; see pp. 125-126 and Table 3.8). The absence of significant effects on spread rate and fireline intensity is at odds with the results reported by Stephens and Moghaddas (2005a). Their Mechanical Only treatment was found to significantly increase both of these variables under moderate $\left(80^{\text {th }}\right.$ percentile) and high $\left(90^{\text {th }}\right.$ percentile) fire hazard scenarios, while Mechanical \& Fire and Fire Only significantly reduced them. Under extreme weather conditions $\left(97.5^{\text {th }}\right.$ percentile), all three of their treatment types reduced spread rate and fireline intensity. 
Flame length is based on, and can be considered a proxy for, fireline intensity, which itself is computed from surface rate of spread (Rothermel, 1972) and heat per unit area from surface fuels (Andrews, 2009). NEXUS predicted significant reductions in flame length by Pile Burn and Thin + Fire under $50^{\text {th }}$ percentile conditions, while under $90^{\text {th }}$ percentile conditions, all treatments except Masticate reduced this variable (Table 3.7). The significant reductions in surface fuel loading reported earlier, such as with total woody surface fuels (Thin + Fire, Fire Only), fuelbed depth (all treatments), and live shrub loading (all treatments), likely contributed to the predicted reductions in flame length.

Torching index (TI) is the windspeed required in order for torching (i.e., passive crown fire) to occur (Scott and Reinhardt, 2001). Thus, higher TI is a desirable fuel treatment outcome, as it indicates a decreased likelihood that windspeeds capable of causing torching will be reached. The $90 \%$ confidence interval analysis found that only the Thin + Fire treatment significantly affected TI (Table 3.7). However, the extreme variability in the statistical analysis results may be overshadowing substantial changes induced by the other treatment types. For instance, under high hazard $\left(90^{\text {th }}\right.$ percentile $)$ fire weather conditions, Pile Burn increased TI by over 2,500\% and Fire Only increased it by over $12,600 \%$ (Table 3.6), yet neither one was found to be statistically significant, likely because Thin + Fire increased TI by an order of magnitude over Fire Only (a nearly $122,000 \%$ increase). Even the comparatively meager $732 \%$ increase in TI from Masticate would probably be considered a success by fire and fuels managers. In contrast to TI, crowning index $(\mathrm{CI})$, the windspeed required in order for active crown fire to occur, 
showed much lower variability across treatment types. All treatment types except Pile Burn were associated with a significant increase in CI; as with TI, this is a favorable treatment outcome.

An examination of fire type outputs (Table 3.6) shows that under both weather scenarios, NEXUS predicted diminished fire behavior in all treatment stands, as compared to their untreated counterparts. Fire type changed from various combinations of surface and crown fire in the untreated stands to surface fire alone in seven of eight instances. The sole exception was the Fire Only treatment under $90^{\text {th }}$ percentile weather conditions. In this case, $100 \%$ crown fire in the untreated stands (33\% each of passive, active, and conditional crown fire) changed to $67 \%$ surface fire and $33 \%$ conditional crown fire in the treated stands. The finding of $33 \%$ conditional crown fire indicates that the fuel treatment raised TI above the $90^{\text {th }}$ percentile windspeed in all three treated stands, but CI was raised above this windspeed in only two of the three treated stands. Thus, in the stand with conditional crown fire, torching would not occur, but an active crown fire entering the stand could propagate through the canopy.

Finally, as noted above, existing fuel models (Anderson, 1982; Scott and Burgan, 2005) are thought to be inadequate for use with the compact fuelbeds characteristic of mastication (Knapp et al., 2006; Kane et al., 2009), raising questions regarding the validity of fire modeling outputs in such fuelbeds (please see pp. 63-65 for further discussion of this issue). Because of this concern, subsequent to the statistical analysis of the full data set, the data were analyzed a second time with the Masticate treatment 
removed. As a result, the observed mean reductions in spread rate and fireline intensity became statistically significant for all remaining treatment types under both weather scenarios, as did reduction of flame length by the Fire Only treatment under the 50th percentile weather scenario. Thin + Fire was found to reduce spread rate significantly more than Fire Only. These results may be due in part to the fact that one of the three Masticate replications in particular was characterized by substantial outliers; thus, the removal of the treatment reduced the violation of ANOVA assumptions, specifically, the assumption of normally distributed data.

In general, notably fewer significant changes in forest structural characteristics and canopy fuel loading were seen with the National Park Service's lightly-thinned Pile Burn treatment than on the USFS Masticate and Thin + Fire sites, and yet Pile Burn reduced predicted fire behavior roughly on a par with the Masticate and Fire Only treatments (Table 3.7); only Thin + Fire was clearly superior in this regard. This illustrates that land use agencies' differing management methods may still result in similar outcomes when the overall goal of reduced fire severity and effects is the same.

\subsection{Conclusions}

The juxtaposition of unnaturally high, flammable fuel loads and expanding human population and infrastructure in forested WUI areas throughout the western US is increasingly perceived as an urgent situation, leading to a renewed emphasis on the

planning and implementation of fuel treatments (GAO, 1999). Research on fire 
characteristics in the complex live and dead fuelbeds of the WUI has been steadily been increasing over the past decade (Weise and Wotton, 2010), and although further study is needed (Martinson and Omi, 2008; Mell et al., 2010), current indications are that fuel treatments involving mechanical methods, prescribed fire, or some combination of the two can be effective at reducing severe wildfire behavior and effects, particularly in historically frequent, low-intensity, mixed-conifer fire regimes such as those of the central Sierra Nevada (van Wagtendonk, 1996; Stephens, 1998; Weatherspoon and Skinner, 1996; Stephens et al., 2009a; Ager et al., 2010; Moghaddas et al., 2010). The result is a significant net benefit to society in the form of catastrophic wildfire avoided (Mason et al., 2006). However, even when fuel treatments appear to succeed in reducing wildfire severity, numerous homes in the WUI may still be destroyed by fire (Murphy et al., 2007). While this situation is in part a result of extreme fire weather overwhelming firefighting resources, elevated fire hazard on individual property owners' lots can play a critical role as well. Near-structure vegetation and home construction characteristics are frequently the determining factors in whether or not a given home ignites during a wildfire (Cohen, 2000).

The results obtained in this study should be interpreted with caution. Variability between experimental units was high, sample size was small, and despite best efforts, the accuracy of a true before-and-after study could not be achieved. In addition, computer simulation output is heavily dependent on assumptions of fuelbed homogeneity which often do not reflect real-world conditions. Nonetheless, trends evident in the current study generally reflect findings from other mixed-conifer fuel and fire behavior studies in the region 
(Stephens and Moghaddas, 2005a; Ritchie et al., 2007; Schmidt et al., 2008; Kobziar et al.., 2009; Reiner et al., 2009; Schwilk et al., 2009; Stephens et al., 2009a). These trends were most consistent with other research for treatments combining mechanical thinning with prescribed fire, and include significant fuel treatment-related reductions in trees $\mathrm{ha}^{-1}$, canopy cover, $\mathrm{CBD}$, and predicted flame length, as well as significant increases in $\mathrm{CBH}$ and predicted TI and CI.

Looking to the future, short- and long-term management goals that guide fire and fuels managers must be informed by the best available scientific research into the efficacy and ecological effects of fuel treatments at both stand and landscape scales (Stephens and Moghaddas, 2005a; Ager et al., 2007; Finney et al., 2007; North et al., 2009b). As an example, the CASPO thinning guidelines (Verner et al., 1992) currently used in USFS fire hazard reduction projects throughout the Sierra Nevada, although effective at reducing canopy bulk density and therefore the probability of active crown fire, do not approximate historical forest structure or composition, leading to concerns over longterm ecological integrity (North et al., 2007; North et al., 2009b). However, attempts to rigidly recreate forest ecosystem structures and functions that existed in the preEuroamerican era are likely to be unrealistic in the face of challenges such as invasive species, climate change, and growth of the WUI (Millar et al., 2007). Future fire hazard mitigation initiatives should emphasize the use of adaptive management and the adoption of a risk-based framework for fire management, while additionally focusing on reduction of greenhouse gas emissions, reintroduction of fire as an ecosystem process, and a reevaluation of urban growth policies in the WUI (Moritz and Stephens, 2008). 


\subsection{A Comparison of Fuel Reduction Treatment Effects on Ecosystem Services in Mixed-Conifer Forests of the Central Sierra Nevada Mountains}

\subsection{Introduction}

The mixed-conifer and ponderosa pine forests of the western United States, once shaped by frequent, low-intensity wildfire and dominated by large, fire-resistant trees, have undergone significant changes in forest structure, species composition, and fuel loading due to the cumulative effects of $19^{\text {th }}$ and $20^{\text {th }}$ century land use changes and climatic trends (McKelvey et al., 1996; Graham et al., 2004; Agee and Skinner, 2005; Schwilk et al., 2009). In these semiarid forests, productivity often exceeds decomposition; as a result, live and dead biomass accumulates in the absence of fire (Weatherspoon and Skinner, 1996). The historically unprecedented buildup of live and dead biomass now existing in these forests, influenced by decades of timber harvesting, livestock grazing, and fire suppression interacting with changes in moisture availability and temperature, is a major contributor to recent increases in the severity of wildfire (McKelvey and Busse, 1996; Gruell, 2001; Allen et al., 2002; Stephens, 2005; Miller et al., 2009; Crimmins et al., 2011).

Furthermore, climatic changes such as increased spring and summer temperatures and earlier spring snowmelt have been correlated with recent trends of increased large wildfire frequency, longer wildfire durations, and longer wildfire seasons in the western US (Westerling et al., 2006). These trends are predicted to continue throughout western 
North America, partly in response to climate change-induced shifts in vegetation distribution (Fried et al., 2004; Westerling et al., 2009).

Simultaneously, lives and property are increasingly at risk from wildfire as the wildlandurban interface (WUI) continues to expand (Radeloff et al., 2005; Fried et al., 2008; Westerling and Bryant, 2008). The WUI has been defined as any location "where humans and their development meet or intermix with wildland fuel" (USDA-USDI, 2001b). During the 1990s, the WUI in California increased by $8.7 \%$ to occupy over 2.8 million hectares (Hammer et al., 2007). The mixed-conifer forests of the Sierra Nevada abut hundreds of WUI communities (USDA-USDI, 2001b; FRAP, 2010).

Although wildfire behavior is driven in part by weather and topography, human efforts to influence fire behavior necessarily focus on hazard reduction through fuel treatments (Peterson et al., 2005). Fuel treatments consist of mechanical and prescribed fire activities that manipulate or remove fuels to reduce fire behavior and/or severity (NWCG, 2006), and promote more fire-resilient forest conditions by reducing the loading and continuity of live and dead forest fuels (Agee and Skinner, 2005). The need for fuel treatments in some western US forests, including those of the lower-to-middle elevation Sierra Nevada, is generally acknowledged to be urgent (Weatherspoon and Skinner, 1996; Weatherspoon, 2000; GAO, 2003; Agee and Skinner, 2005).

However, while fuel treatments may reduce the probability of severe wildfires destroying or damaging assets considered valuable by society, these and other forest management 
activities may also, through their removal and/or rearrangement of vegetation and woody debris in forest stands, diminish the ability of forest ecosystems to provide valuable benefits to society (Kaufmann et al., 1994; Chen and Jim, 2008; Dicus et al., 2009). These ecosystem services include, among others, provision of clean water, stormwater control, and aquatic habitat (Nowak and Dwyer, 2000; Elliot et al., 2010), wildlife habitat (North et al., 2009b), microclimate amelioration and energy savings (Oke, 1989; Taha et al., 1997), noise reduction (Farnham and Beimborn, 2003), and recreational opportunities (Baines, 2000; McPherson and Simpson, 2002). These benefits are easily overlooked by the public, as they are intangible and can be difficult to quantify in terms of monetary value; nonetheless, such services are critically important to the welfare of society as a whole (Chen and Jim, 2008; Dicus, 2009). In the present research, we take a closer look at two additional ecosystem services, air pollution removal and carbon (C) sequestration and storage.

While trees and shrubs can contribute to the formation of ozone $\left(\mathrm{O}_{3}\right)$ by emitting volatile organic compounds (VOCs) into the atmosphere, they also remove significant amounts of air pollutants through gas uptake and interception of airborne particles, consequently improving environmental quality and human health (Smith, 1990; Nowak et al., 2006). Because one of the primary factors affecting the uptake of atmospheric $\mathrm{C}$ is leaf area (Nowak and Dwyer, 2007), fuel treatments have the potential to reduce this ecosystem benefit through the removal or burning of vegetation. 
The storage and sequestration of $\mathrm{C}$ by forests has taken on new importance in the context of atmospheric greenhouse gas accumulation and its contribution to global climate change (Myneni et al., 2001; Schimel et al., 2001; Hurtt et al., 2002). Rising levels of atmospheric $\mathrm{CO}_{2}$ and other greenhouse gases are thought to contribute to ongoing increases in atmospheric temperatures by trapping certain wavelengths of radiation in the atmosphere (U.S. National Research Council, 1983). As trees and shrubs grow, they remove atmospheric $\mathrm{CO}_{2}$ and store carbon within their biomass; dead biomass (snags, woody debris, litter, and duff) and forest soils may also store significant amounts of C (Rowntree and Nowak, 1991; Perry, 1994). Taken together, these forest ecosystem components may form a $\mathrm{C}$ sink containing the equivalent of $15-30 \%$ of annual global fossil fuel and industrial C emissions (Myneni et al., 2001). In removing and/or burning vegetation, fuel treatments have the capacity to reduce $\mathrm{C}$ sequestration and storage, although uncertainty remains as to how, and for how long, forest management practices affect forest C fluxes (Boerner et al., 2008; Campbell et al., 2009).

The objective of the current research is to evaluate how differing fuel treatment types (Fire Only, Thin + Fire, Pile Burn, and Masticate) in a Sierra Nevada mixed-conifer forest WUI affect two ecosystem services provided by forests: air pollution removal, and tree-based $\mathrm{C}$ sequestration and storage. We investigated only the immediate, as opposed to long-term, effects of fuel treatments on these variables. This work focuses most specifically on the wildland portion of the WUI, forestlands through which wildfire approaches urbanized areas. Predicted long-term fuel treatment effects on varying forest C pools in Sierra Nevada mixed-conifer forest are discussed in North et al. (2009b). For 
discussion of $\mathrm{C}$ emissions from fuel treatment implementation and wood product processing, refer to Finkral and Evans (2008), North et al. (2009b), and Stephens et al. (2009b).

\subsection{Methods}

\subsubsection{Site Description}

Sampling took place in mixed-conifer forest stands in California's central Sierra Nevada Mountains, between roughly 1067 and 1890 meters elevation above sea level, across a latitudinal distance of approximately $130 \mathrm{~km}$, or roughly between Arnold (Calaveras County) and Bass Lake (Madera County; see Figure 4.1). Old-growth stands were not sampled. The Sierra Nevada mixed-conifer forest type is characterized by six main tree species: ponderosa pine (Pinus ponderosa Dougl. ex Laws.), sugar pine (Pinus lambertiana Dougl.), Douglas-fir (Pseudotsuga menziesii [Mirb.] Franco), white fir (Abies concolor [Gord. \& Glend.] Lindl. ex Hildebr.), incense-cedar (Libocedrus decurrens Torr.), and California black oak (Quercus kelloggii Newb.); over 100 species

of grasses, forbs, and shrubs make up the understory for this forest type (Allen, 2005). At higher elevation sites, ponderosa pine was replaced by Jeffrey pine (Pinus jeffreyi Grev. \& Balf.). Soils in the Sierra Nevada mixed-conifer belt are varied, and are typically derived from Mesozoic granitic, Paleozoic sedimentary and volcanic, and Cenozoic volcanic rocks (Allen, 2005). Soils are deep to shallow, and fissures in granitic parent material often support forest growth, even where soil development is otherwise minimal. 


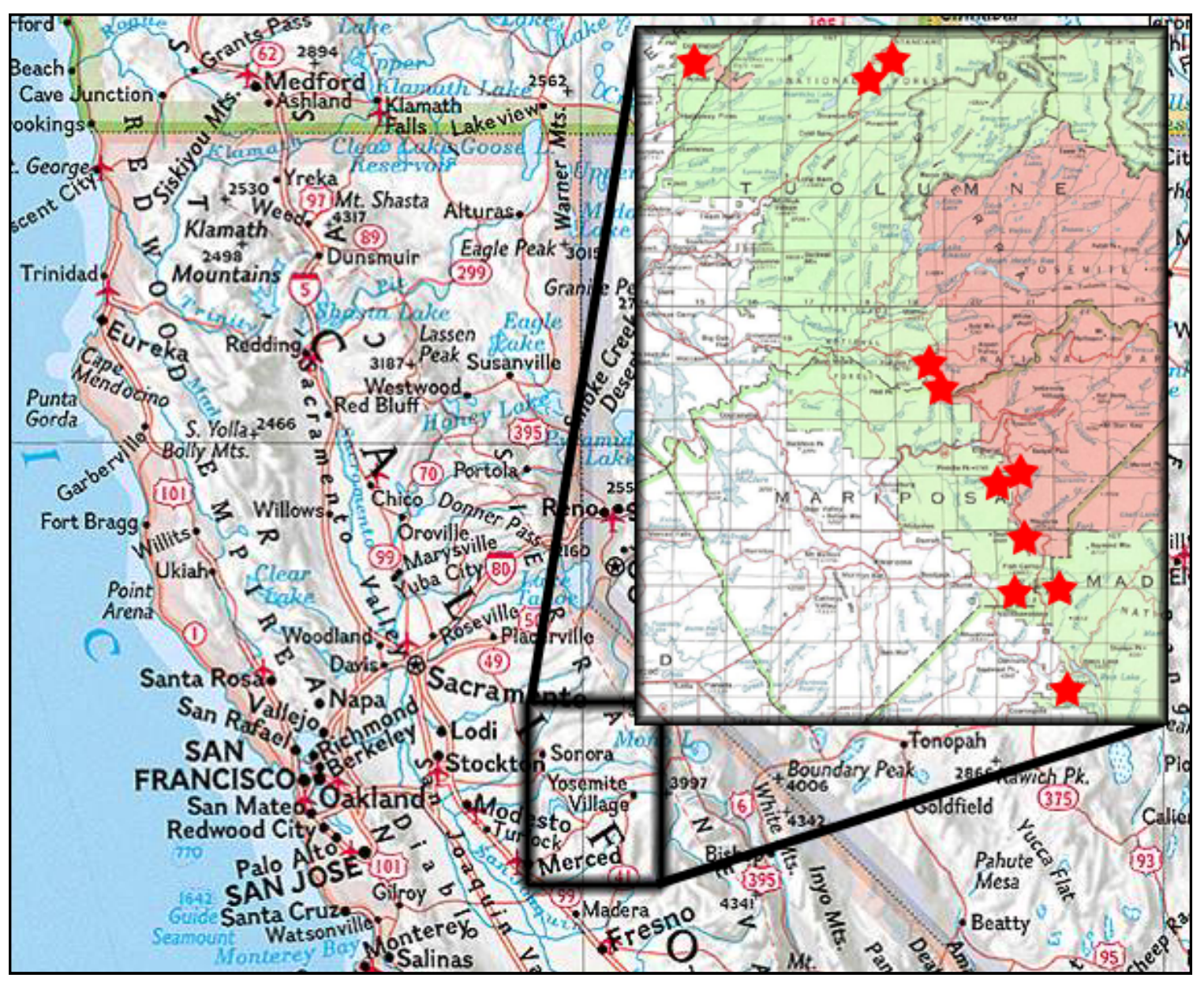

Figure 4.1. Study region - the central Sierra Nevada; stars indicate sampling sites.

The area's climate is Mediterranean, with warm, dry summers and cold, wet winters. At Cherry Valley Dam, located roughly in the middle of the study area at $1451 \mathrm{~m}$ elevation, the January mean minimum temperature for the period $1955-2009$ is $-1.9{ }^{\circ} \mathrm{C}$ and the July mean maximum temperature is $30.6^{\circ} \mathrm{C}$. Rainfall averages $1194.8 \mathrm{~mm}$ annually; average annual snowfall is $2933.7 \mathrm{~mm}$ (WRCC, 2009). 


\subsubsection{Field Measurements}

Field sampling took place between June and October 2008 in WUI areas managed by the US Department of Agriculture, Forest Service (USFS; Sierra and Stanislaus National Forests) and the US Department of Interior, National Park Service (NPS; Yosemite National Park). The fuel treatment types investigated included thin and masticate (hereafter, "Masticate"), thin and pile burn ("Pile Burn"), thin and broadcast burn ("Thin + Fire"), and broadcast burn only ("Fire Only"; Table 4.1). "Masticate" refers to a fuels management method in which a tracked vehicle carrying a rotary blade or drum is used to shred or chop live and dead fuels, depositing the debris on the ground (USDA, 2004a; Kane et al., 2009). At the Pile Burn sites, the boles, tops, and limbs of all cut trees were piled and burned. Thin + Fire sites received a thin followed by prescribed fire, and Fire Only sites received prescribed burning alone. At both USFS and NPS sites, the treatments involving thinning had typically been implemented in two phases spanning from one to eight years; for each site, field sampling occurred within four years of the final treatment phase.

Treatments on US Forest Service lands were guided by the Sierra Nevada Forest Plan Amendment (SNFPA; USDA, 2004a) and the California Spotted Owl (CASPO) interim guidelines (Verner et al., 1992). The SNFPA requires that at least $50 \%$ of initial fuel treatment work in the Sierra Nevada should take place in the WUI until the WUI is sufficiently treated (Safford et al., 2009); the CASPO guidelines call for the thinning of all trees between 25.4 and $76.2 \mathrm{~cm}$ diameter at breast height $(\mathrm{DBH} ; 1.37 \mathrm{~m})$ while 
retaining at least $40 \%$ canopy cover or $40 \%$ basal area, whichever is more conservative. In contrast to the USFS sites, the NPS stands had received a light thin from below to 15.2 cm DBH (I. Hirschfield, Yosemite National Park, personal communication).

Table 4.1. Fuel treatment types, locations, and dates of implementation.

\begin{tabular}{llll} 
Treatment type & Project name & Project location & Date(s) treated \\
\hline $\begin{array}{l}\text { Thin \& masticate } \\
\text { ("Masticate") }\end{array}$ & Progeny & Sierra NF & Thinned 2000, masticated 2005-06 \\
& Gorf & Sierra NF & Thinned 1999, masticated 2007 \\
& Sonny Mdws & Sierra NF & Thinned 2006, masticated 2008 \\
\hline $\begin{array}{l}\text { Thin \& pile burn } \\
\text { ("Pile Burn") }\end{array}$ & Highway 41 & Yosemite NP & Thinned 2004, piles burned 2004-05 \\
& Hodgdon Mdw & Yosemite NP & Thinned 2003, piles burned 2003-04 \\
\hline Thin \& burn & Bee Hart & Stanislaus NF & Thinned 1999-2001, burned 2007 \\
("Thin + Fire") & Upper Cow & Stanislaus NF & Thinned 2001, burned 2008 \\
& Mdw & Stanislaus NF & Thinned 2000, burned 2008 \\
& Irish & Yosemite NP & Burned 2004 \\
& Big Creek & Yosemite NP & Burned 2007 \\
\hline Burn only ("Fire Only") & Highway 41 & Stanislaus NF & Burned 2008 \\
& Irish & & \\
& & &
\end{tabular}

Each of the four fuel treatment types originally consisted of three replications, giving a sampling design of $n=12$ experimental units (treatment $\times$ site combinations) ${ }^{4}$. Due to time and resource constraints, it was not possible to sample the same inventory plots before and after fuel treatment implementation; instead, at each experimental unit three treatment plots and two nearby untreated (proxy control) plots were sampled. Fixed plot size was 0.08 ha. At two sites, the existence of differing but adjacent treatment types allowed the use of a single set of control plots for comparison; thus, the total number of plots sampled equaled 56 instead of 60 . After the conclusion of field work, but prior to

\footnotetext{
${ }^{4}$ The term "experimental units" is used throughout, even though this was not a true controlled experiment.
} 
the statistical analysis, one Pile \& Burn site was removed from the study due to data quality problems stemming from poorly matched untreated and treated plots.

Plot selection was assisted by USFS and NPS personnel familiar with the treatment sites. To minimize variability between plots at each experimental unit, stand characteristics such as slope, aspect, elevation, soil productivity, untreated composition, and stand age were held constant to the extent possible. Variability between experimental units was not controlled except that mixed-conifer stands on west-to-southwest aspects were used throughout the study.

Plots were randomly installed at least $25 \mathrm{~m}$ from the nearest road or other treatment boundary in a location that was determined to be "representative" of the condition being sampled. Once an acceptable area was found, plot center was located by randomly spinning the compass dial and taking three paces on the azimuth indicated. Anomalous areas such as riparian areas or unburned patches within a broadcast burn perimeter were avoided.

In addition, at each plot species, diameter, height, and height to live crown base were recorded for all live trees greater than $2.5 \mathrm{~cm}$ DBH. Due to time constraints, dense thickets of suppressed trees were sometimes grouped, with several trees being measured and the average values being applied to the entire group (e.g., "20 white firs, DBH $10 \mathrm{~cm}$, height to live crown $1.2 \mathrm{~m}$, total height $5.5 \mathrm{~m}$ "). Standing dead trees were not measured; unusual levels of mortality were not noted at any of the sampling sites, an observation 
supported by USFS Forest Inventory \& Analysis (FIA) data for the Stanislaus and Sierra National Forests (K. Waddell, FIA, personal communication).

Each plot contained a 0.0004 ha regeneration plot centered $4 \mathrm{~m}$ from plot center at an azimuth of 90 degrees; all seedlings that germinated from seed were tallied by species. GPS coordinates were recorded at each plot center, and photographs were taken in each of the four cardinal directions from plot center.

\subsubsection{Ecosystem Services Calculations}

Stand-level leaf area, air pollution removal, and $\mathrm{C}$ storage and sequestration for inventory year 2008 were calculated with the USFS Northern Research Station's i-Tree Eco program, Version 3.0.9 (formerly known as UFORE; Nowak and Crane, 2000). Eco uses forest inventory data in combination with local hourly air pollution and meteorological data to quantify urban forest structure and environmental effects.

Eco calculates dry deposition of air pollution (i.e., deposition during non-precipitation periods) to trees based on tree-cover data, hourly NCDC weather data, and U.S. Environmental Protection Agency (EPA) pollution-concentration monitoring data (UFORE Methods, no date). For carbon monoxide $(\mathrm{CO})$, ozone $\left(\mathrm{O}_{3}\right)$, nitrogen dioxide $\left(\mathrm{NO}_{2}\right)$, and sulfur dioxide $\left(\mathrm{SO}_{2}\right)$, Eco calculates hourly dry deposition. For particulate matter less than 10 microns in diameter $\left(\mathrm{PM}_{10}\right)$, the model calculates daily deposition. First, tree-cover data is calculated using tree and shrub leaf area index (LAI) and percent 
evergreen tree and shrub leaf area. Pollutant flux is then calculated as the product of the deposition velocity and the pollutant concentration. Finally, average hourly pollutant flux is multiplied by total tree canopy coverage to estimate total hourly pollutant removal.

Stand C storage and sequestration are calculated in Eco by using forest inventory data in combination with allometric equations from the scientific literature to estimate whole-tree (aboveground plus belowground) biomass for each inventoried tree; tree biomass is then multiplied by 0.5 to derive the amount of $\mathrm{C}$ stored (Nowak and Crane, 2000). Gross annual $\mathrm{C}$ sequestration is estimated by adding average diameter growth from the appropriate genera and diameter classes to the existing tree diameter (year $x$ ) to estimate tree diameter in year $x+1$; for trees in forest stands, average DBH growth was estimated at $0.38 \mathrm{~cm} \mathrm{yr}^{-1}$ (UFORE Methods, no date). Other forest $\mathrm{C}$ pools, such as down woody debris, litter, and duff, cannot be included in the Eco calculations. Eco does allow for the inclusion of shrubs for air pollution removal calculations (although not $\mathrm{C}$ storage or sequestration), but only live tree data was provided to i-Tree for use in the Eco calculations for the current study.

Required Eco inputs that were not sampled in the field were derived from other sources. Crown width for each tree was calculated using the Western Sierra variant of the Fire and Fuels Extension to the Forest Vegetation Simulator (WSVAR FFE-FVS; Reinhardt and Crookston, 2003; Rebain, 2009). Percent crown missing, percent dieback, and crown light exposure data for the Sierra and Stanislaus National Forests were obtained from Karen Waddell of the USFS Pacific Northwest Regional Forest Inventory and Analysis 
(FIA) office. Averaged Sierra and Stanislaus National Forest FIA data were used for the Yosemite National Park stands.

For comparison purposes, the Carbon Reports feature in FFE-FVS was also used to calculate stand-level live-tree C storage. Similarly to Eco, FFE-FVS uses inventory data in combination with allometric equations to calculate tree biomass, and then converts the biomass to units of $\mathrm{C}$ by multiplying by 0.5 (Penman et al., 2003). Biomass prediction equations by Jenkins and others (2003) were used in order to allow for direct comparisons of this work to prior Sierra Nevada mixed-conifer C studies (e.g., North et al., 2009a; Stephens et al., 2009b). The FFE-FVS aboveground and belowground livetree $\mathrm{C}$ storage outputs were subsequently added together to allow for a direct comparison with the Eco C storage results. Stephens et al. (2009b) noted that because the FFE default equations are species-specific (unlike the Jenkins and others [2003]) equations, which are grouped by genus), using the default equations would be preferable; however, the default equations are not available for all species.

\subsubsection{Statistical Analysis}

For all statistical analyses, the experimental unit was treatment type $\times$ site combination. For each of the four treatment types, $n=3$, with the exception of Pile Burn, for which $n=$ 2 (thus, total $n=11$ ). Data from the two untreated and three treated plots per experimental unit were averaged into untreated and treated "stands", respectively, for each response variable. Two different types of statistical analysis were then conducted on 
the percent difference between untreated and treated stands for each response variable. This type of analysis is sometimes referred to as "percent change"; because this was not a true before and after study, the term "percent difference" is used here. The analysis of percent difference was chosen because this type of analysis may help control the confounding effects of treatment age and site (H. Smith, California Polytechnic State University, personal communication). Minitab 15.1.30.0 (Minitab, 2007) was used for all statistical analyses.

The first type of analysis was used to evaluate variation between treatment types; thus, a general linear model (GLM) analysis was performed on percent difference for each response variable in order to determine whether significant differences existed between treatment means $(\alpha=0.10)$. Due to the range of treatment ages $(0-4$ years $)$, time since treatment was added as a covariate. The covariate ultimately proved not to affect the outcome of significance/non-significance for any of the variables tested; therefore, in order to use the simplest model possible, it was dropped from the analysis. If at least one significant difference between treatment means was indicated in the GLM analysis, a Tukey's Honestly Significant Difference (HSD) test was used to evaluate which specific treatment types were significantly different from the others $(\alpha=0.10)$.

The second type of analysis was used to assess whether treated stands varied significantly from untreated stands. To that end, a one-way analysis of variance (ANOVA) was used to generate $90 \%$ confidence intervals in order to determine whether the percent difference 
between untreated and treated stands was significantly different than zero $(\alpha=0.10)$ for a given response variable.

In some cases, an untreated stand had a value of zero for a response variable while the corresponding treated stand had a nonzero value, resulting in a division-by-zero error in the percent difference calculations. To allow for the calculation of percent difference, the zero value was replaced by a placeholder value that was no greater than one-quarter the amount of the smallest nonzero value for the response variable across all untreated stands (McDonald, 2009).

Although the ANOVA assumption of independent experimental units was consistently met, the assumptions of normally distributed data and homoscedasticity were not always met. When the data did not meet these assumptions, square root and log base 10 transformations were tried (McDonald, 2009) and the statistical tests were repeated. When the transformations did not correct the violation(s), the tests were repeated with the most extreme observation omitted to check for any different outcomes $(H$. Smith, California Polytechnic State University, personal communication).

\subsection{Results}

Two results tables are provided below. Table 4.2 shows mean absolute values for each response variable per condition (untreated or treated) and treatment type; these mean values were not included in the statistical analysis and are provided for reference 
purposes only. Table 4.3 shows mean percent difference between untreated and stands for each response variable, the significance of the difference (if any) as indicated by $90 \%$ confidence intervals, and GLM p-value and standard error.

\subsubsection{Leaf Area and Air Pollution Removal}

Mean i-Tree Eco outputs for leaf area, removal of five pollutants $\left(\mathrm{CO}, \mathrm{O}_{3}, \mathrm{NO}_{2}, \mathrm{SO}_{2}\right.$, and $\mathrm{PM}_{10}$ ), and total hourly pollutant removal in untreated and treated stands are presented in Table 4.2. Neither the GLM analysis nor the ANOVA-generated 90\% confidence intervals found significant treatment effects (Table 4.3; Figure 4.2). Because percent difference results for $\mathrm{CO}, \mathrm{O}_{3}, \mathrm{NO}_{2}$, and $\mathrm{SO}_{2}$ were identical, they are grouped together as one response variable in Table 4.3 and Figure 4.2. 
Table 4.2. Mean (standard error) air pollution removal, live-tree $\mathrm{C}$ sequestration, and live-tree $\mathrm{C}$ storage in untreated and treated stands.

\begin{tabular}{|c|c|c|c|c|}
\hline Untreated Stands & & & & \\
\hline Response & Masticate & Pile Burn & Thin + Fire & Fire Only \\
\hline \multicolumn{5}{|l|}{ Airborne Pollutant Removal } \\
\hline Leaf area $\left(\mathrm{m}^{2} \mathrm{ha}^{-1}\right)$ & $\begin{array}{l}62518.7 \\
(5224.1)\end{array}$ & $\begin{array}{c}85065.4 \\
(27087.7)\end{array}$ & $\begin{array}{l}53641.7 \\
(2674.6)\end{array}$ & $\begin{array}{l}71726.8 \\
(8698.9)\end{array}$ \\
\hline $\mathrm{CO}\left(\mathrm{kg} \mathrm{ha}^{-1}\right)$ & $3.0(0.3)$ & $3.8(1.5)$ & $2.0(0.2)$ & $3.0(0.5)$ \\
\hline $\mathrm{O}_{3}\left(\mathrm{~kg} \mathrm{ha}^{-1}\right)$ & $79.0(7.0)$ & $100.8(39.7)$ & $52.5(5.8)$ & $78.8(12.4)$ \\
\hline $\mathrm{NO}_{2}\left(\mathrm{~kg} \mathrm{ha}^{-1}\right)$ & $18.8(1.7)$ & $24.0(9.5)$ & $12.5(1.4)$ & $18.8(2.9)$ \\
\hline $\mathrm{SO}_{2}\left(\mathrm{~kg} \mathrm{ha}^{-1}\right)$ & $3.8(0.3)$ & $4.8(1.9)$ & $2.5(0.3)$ & $3.8(0.6)$ \\
\hline $\mathrm{PM}_{10}\left(\mathrm{~kg} \mathrm{ha}^{-1}\right)$ & $74.1(6.8)$ & $96.9(30.3)$ & $62.2(1.2)$ & $85.1(10.9)$ \\
\hline Total pollutant removal $\left(\mathrm{kg} \mathrm{ha}^{-1}\right)$ & $178.7(16.1)$ & $230.3(82.9)$ & $131.7(8.9)$ & $189.5(27.1)$ \\
\hline \multicolumn{5}{|l|}{ C Sequestration and Storage } \\
\hline $\begin{array}{l}\text { Live-tree C sequestration }\left(\mathrm{Mg} \mathrm{ha}^{-1}\right. \\
\left.\mathrm{yr}^{-1}\right)^{\mathrm{a}}\end{array}$ & $2.6(0.2)$ & $4.0(1.6)$ & $2.3(0.0)$ & $3.1(0.5)$ \\
\hline Live-tree $\mathrm{C}$ storage $\left(\mathrm{Mg} \mathrm{ha}^{-1}\right)^{\mathrm{b}}$ & $123.4(14.6)$ & $263.7(138.1)$ & $138.4(13.4)$ & $179.6(27.1)$ \\
\hline Live-tree $\mathrm{C}$ storage $\left(\mathrm{Mg} \mathrm{ha}^{-1}\right)^{\mathrm{c}}$ & $178.1(28.7)$ & $331.6(146.8)$ & $199.4(12.2)$ & $241.8(30.1)$ \\
\hline \multicolumn{5}{|l|}{ Treated Stands } \\
\hline Response & Masticate & Pile Burn & Thin + Fire & Fire Only \\
\hline \multicolumn{5}{|l|}{ Airborne Pollutant Removal } \\
\hline Leaf area $\left(\mathrm{m}^{2} \mathrm{ha}^{-1}\right)$ & $\begin{array}{l}41892.1 \\
(3533.7)\end{array}$ & $\begin{array}{l}62830.5 \\
(6045.3)\end{array}$ & $\begin{array}{l}40666.2 \\
(1911.4)\end{array}$ & $\begin{array}{l}42876.7 \\
(3432.3)\end{array}$ \\
\hline $\mathrm{CO}\left(\mathrm{kg} \mathrm{ha}^{-1}\right)$ & $1.8(0.2)$ & $2.7(0.0)$ & $1.4(0.2)$ & $1.6(0.1)$ \\
\hline $\mathrm{O}_{3}\left(\mathrm{~kg} \mathrm{ha}^{-1}\right)$ & $46.7(5.5)$ & $72.1(0.6)$ & $37.2(4.8)$ & $43.0(2.2)$ \\
\hline $\mathrm{NO}_{2}\left(\mathrm{~kg} \mathrm{ha}^{-1}\right)$ & $11.1(1.3)$ & $17.2(0.1)$ & $8.9(1.1)$ & $10.2(0.5)$ \\
\hline $\mathrm{SO}_{2}\left(\mathrm{~kg} \mathrm{ha}^{-1}\right)$ & $2.2(0.3)$ & $3.5(0.0)$ & $1.8(0.2)$ & $2.1(0.1)$ \\
\hline $\mathrm{PM}_{10}\left(\mathrm{~kg} \mathrm{ha}^{-1}\right)$ & $48.3(3.6)$ & $71.1(8.1)$ & $47.2(2.3)$ & $50.4(4.4)$ \\
\hline Total pollutant removal $\left(\mathrm{kg} \mathrm{ha}^{-1}\right)$ & $110.1(10.8)$ & $166.5(8.9)$ & $96.5(7.5)$ & $107.3(6.9)$ \\
\hline \multicolumn{5}{|l|}{ C Sequestration and Storage } \\
\hline $\begin{array}{l}\text { Live-tree C sequestration }\left(\mathrm{Mg} \mathrm{ha}^{-1}\right. \\
\left.\mathrm{yr}^{-1}\right)^{\mathrm{a}}\end{array}$ & $1.9(0.1)$ & $2.8(0.3)$ & $1.6(0.0)$ & $1.9(0.1)$ \\
\hline Live-tree $\mathrm{C}$ storage $\left(\mathrm{Mg} \mathrm{ha}^{-1}\right)^{\mathrm{b}}$ & $151.0(8.6)$ & $180.5(36.9)$ & $146.9(8.1)$ & $142.4(7.2)$ \\
\hline Live-tree $\mathrm{C}$ storage $\left(\mathrm{Mg} \mathrm{ha}^{-1}\right)^{\mathrm{c}}$ & $198.8(15.0)$ & $238.0(47.5)$ & $229.9(23.4)$ & $197.6(19.4)$ \\
\hline
\end{tabular}


Table 4.3. Mean percent difference between untreated and treated stands, general linear model pvalue $(\alpha=0.10)$, and standard error for air pollution removal, $C$ sequestration, and $C$ storage.

\begin{tabular}{lcccccc} 
Response & Masticate & Pile Burn & Thin + Fire & Fire Only & $p$ & SE \\
\hline \multicolumn{1}{c}{ Airborne Pollutant Removal } & & & & & & \\
Leaf area $^{\mathrm{a}}$ & 2.9 & 27.0 & 13.9 & -9.5 & 0.621 & 31.1 \\
$\mathrm{CO}_{\mathrm{O}} \mathrm{O}_{3}, \mathrm{NO}_{2}, \mathrm{SO}_{2}{ }^{\mathrm{b}}$ & -8.5 & 27.3 & 5.9 & -15.4 & 0.582 & 32.6 \\
$\mathrm{PM}_{10}{ }^{\mathrm{a}}$ & 0.5 & 26.5 & 13.7 & -10.2 & 0.617 & 31.7 \\
Total pollutant removal $^{\mathrm{a}}$ & -4.8 & 27.0 & 9.7 & -13.2 & 0.560 & 31.9 \\
\hline & & & & & & \\
$\quad$ C Sequestration and Storage & & & & & & \\
Live-tree C sequestration (i-Tree & -24.9 & -12.4 & $-30.0(-)$ & $-36.7(-)$ & 0.751 & 24.7 \\
Eco) & 24.9 & 4.4 & 8.9 & -14.7 & 0.757 & 44.6 \\
Live-tree C storage (i-Tree Eco) & 15.6 & -2.8 & 17.4 & -13.3 & 0.774 & 41.4 \\
Live-tree C storage (FFE-FVS) & & &
\end{tabular}

Symbols $(+$ or -$)$ following mean values indicate a significant $(\alpha=0.10)$ increase or decrease in comparison to untreated stands. A lack of symbols indicates a lack of significant treatment effects.

${ }^{\mathrm{a}}$ Variable could not be made to meet the ANOVA assumption of equal variances.

${ }^{b}$ Variables were square root transformed to meet the ANOVA assumption of equal variances.



Figure 4.2. Mean percent difference and standard error between untreated and treated stands for leaf area and air pollution removal.

Bars depict mean percent increase or decrease in treatment stand response variables in comparison to untreated stands. 


\subsubsection{Carbon Sequestration and Storage}

Table 4.2 shows mean i-Tree Eco outputs for gross live-tree carbon (C) sequestration and $\mathrm{C}$ storage in untreated and treated stands. For comparison purposes, live-tree $\mathrm{C}$ storage as calculated by FFE-FVS is shown as well. All three C-related variables represent wholetree $\mathrm{C}$ (aboveground plus belowground components). In Table 4.4, aboveground-only $\mathrm{C}$ storage is introduced in order to allow for further comparisons with recent results from the literature; however, aboveground-only C storage was not part of the current study's reported data values (Table 4.2) or statistical analysis (Table 4.3). 
Table 4.4. Mean whole and aboveground-only live-tree $\mathrm{C}$ storage $\left(\mathrm{Mg} \mathrm{C} \mathrm{ha}^{-1}\right)$ in untreated and treated stands, as compared to results of similar studies.

\begin{tabular}{lcccc} 
Whole live-tree C storage & $\begin{array}{c}\text { Control/ } \\
\text { Untreated }\end{array}$ & $\begin{array}{c}\text { Mechanical } \\
\text { Only }^{\mathrm{b}}\end{array}$ & $\begin{array}{c}\text { Fire } \\
\text { Only }\end{array}$ & $\begin{array}{c}\text { Mechanical } \\
\text { + Fire }^{\mathrm{c}}\end{array}$ \\
\hline \multicolumn{1}{c}{ Current Study } & & & & \\
i-Tree Eco & 168.4 & $151.0^{\mathrm{d}} ; 180.5^{\mathrm{e}}$ & 142.4 & 146.9 \\
FFE-FVS $^{\mathrm{a}}$ & 229.2 & $198.8^{\mathrm{d}} ; 238.0^{\mathrm{e}}$ & 197.6 & 229.9
\end{tabular}

\section{Other Studies}

Boerner et al., 2008

Campbell et al., 2009

Finkral and Evans, 2008

Large, 2010

North et al., 2009a

Stephens et al., 2009b

\begin{tabular}{lcccc} 
Aboveground-only live-tree C storage & $\begin{array}{c}\text { Control/ } \\
\text { Untreated }\end{array}$ & $\begin{array}{c}\text { Mechanical } \\
\text { Only }^{\mathrm{b}}\end{array}$ & $\begin{array}{c}\text { Fire } \\
\text { Only }\end{array}$ & $\begin{array}{c}\text { Mechanical } \\
+ \text { Fire }^{\mathrm{c}}\end{array}$ \\
\hline \multicolumn{1}{c}{ Current Study } & & & & \\
i-Tree Eco & - & - & - & - \\
FFE-FVS $^{\mathrm{a}}$ & 189.5 & $164.1^{\mathrm{d}} ; 196.3^{\mathrm{e}}$ & 163.2 & 189.8
\end{tabular}

Other Studies

Boerner et al., 2008

$\begin{array}{cccc}81.0 & 61.3 & 71.3 & 54.5 \\ \sim 62 & \sim 23^{\mathrm{e}} & - & - \\ 42.5 & \sim 30^{\mathrm{e}} & - & - \\ - & - & - & -\end{array}$

Campbell et al., 2009

$\begin{array}{cccc}- & - & - & - \\ \sim 87 & \sim 34^{\mathrm{e}} & - & - \\ - & - & - & - \\ \sim 317 & \sim 230 ; \sim 231^{\mathrm{e}} & \sim 217 & \sim 211 \\ 308.1 & 212.1 & 244.3 & 177.2 \\ - & - & - & -\end{array}$

Finkral and Evans, 2008

Large, 2010

North et al., 2009a

198.3

144.1

Stephens et al., 2009b

188.2

$154.8^{\mathrm{d}}$

180.3

$135.2^{\mathrm{f}}$

${ }^{2}$ Jenkins and others (2003) biomass equations used

${ }^{\mathrm{b}}$ Understory thin only, unless otherwise noted

${ }^{c}$ Understory thin + fire

${ }^{\mathrm{d}}$ Thin + Masticate

${ }^{\mathrm{e}}$ Thin + Pile Burn

${ }^{\mathrm{f}}$ Thin + masticate + fire

General linear model results for all $\mathrm{C}$ response variables are shown in Figure 4.3. The GLM analysis did not find any significant differences between treatment means. However, 90\% confidence intervals indicated that $\mathrm{C}$ sequestration was significantly 
reduced by the Thin + Fire and Fire Only treatments, as compared to untreated stands (Table 4.3).

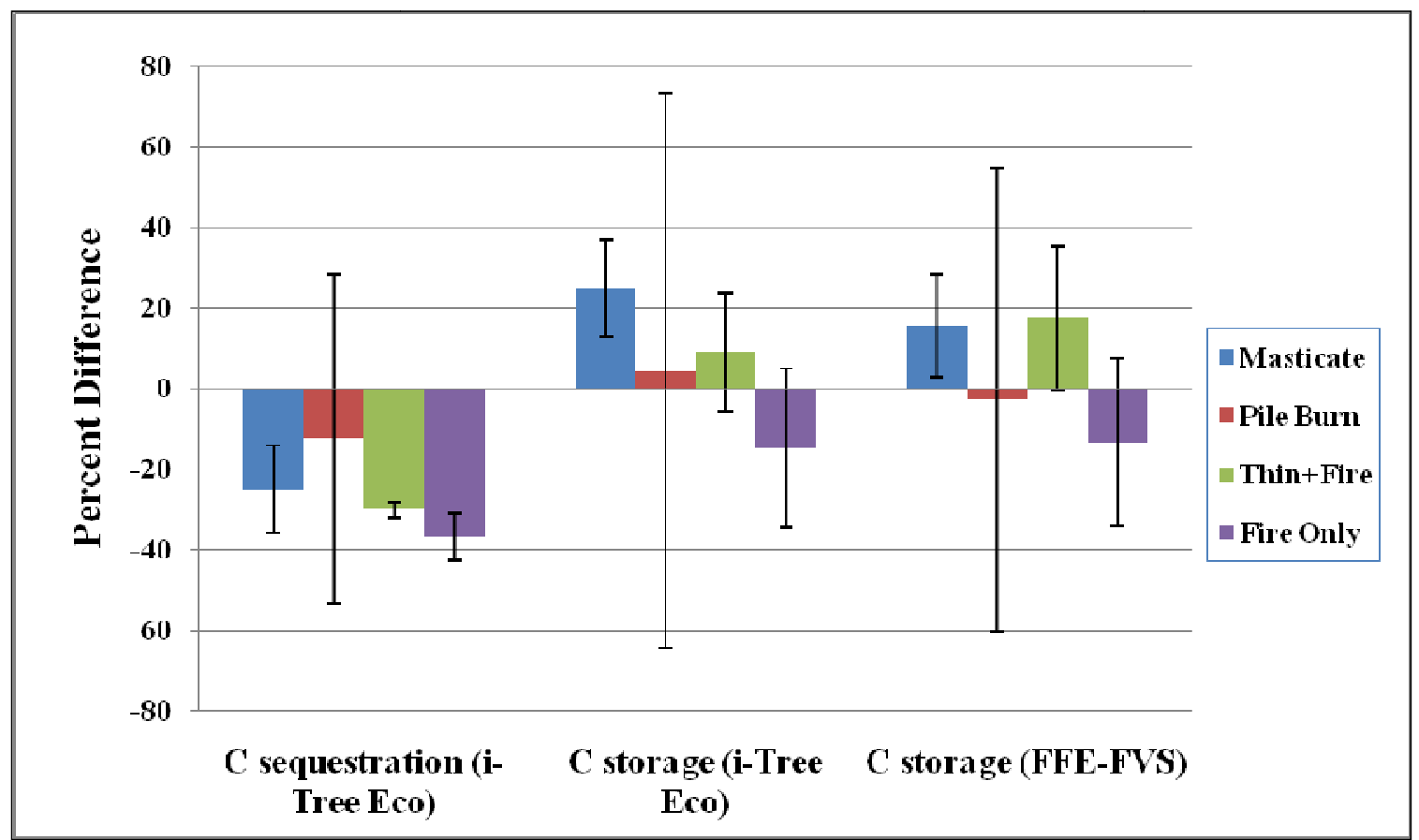

Figure 4.3. Mean percent difference and standard error between untreated and treated stands for gross live-tree $\mathbf{C}$ sequestration and storage.

Bars depict mean percent increase or decrease in treatment stand response variables in comparison to untreated stands.

\subsection{Discussion}

\subsubsection{Leaf Area and Air Pollution Removal}

As with any forest management activity that removes biomass, a fuel treatment has the potential to affect forest productivity (Campbell et al., 2009) and therefore, the ability of a given stand's ecological components to perform various ecosystem services. Air pollution removal capacity is dependent in part upon leaf area (Nowak et al., 2006). The 
leaves of trees and shrubs take in gaseous pollutants via their stomata, and intercept particulate matter on their leaf surfaces. In a study of urban forest air pollution removal, Nowak et al. (2006) noted that although average percent air quality improvement due to trees is relatively low (less than one percent), the improvement is for multiple pollutants and the actual magnitude of pollution removal can be significant, in the hundreds to thousands of $\mathrm{Mg}$ (metric tons) of pollutants per city per year. For example, the urban forest in Sacramento, California was estimated to have removed $378 \mathrm{Mg}$ of airborne pollutants in the year 1994, at a total value of over \$2.1 million (Ibid.).

The fuel treatment types examined in this study all removed living foliage, either directly or as a delayed effect of fire-induced mortality. Despite the fact that significant treatment effects on pollutant removal were not found, one would still expect leaf area, and thus the ability of a forest stand to remove airborne pollutants, to be reduced immediately following treatment, followed by a gradual increase over time as net primary production (NPP) recovers (Campbell et al., 2009).

However, as can be seen by comparing Table 4.2 with Table 4.3/Figure 4.2, lower mean values for response variables in treated stands, as calculated by i-Tree Eco, did not always translate into the expected findings of decreases for those response variables in the statistical analysis. In fact, the statistical analysis indicated that all treatments except Fire Only showed at least some increases in leaf area and air pollution removal capacity in the treated stands, although no statistically significant changes were found for any of the response variables. The greatest increases were seen with the Pile Burn and Thin + 
Fire treatments; in contrast, Fire Only consistently showed decreases in these responses. It is likely that small sample size, highly variable and/or poorly matched stands, and the effect of removing one study site due to impaired data quality played a role in the observed results.

\subsubsection{Carbon Sequestration and Storage}

In recent years, active management of forests for carbon (C) sequestration and storage has increasingly been perceived as a method of mitigating anthropogenic emissions of $\mathrm{CO}_{2}$ and other greenhouse gases to the atmosphere, and thus reducing the effects of global climate change (Saikku et al., 2008). Forest C pools include live trees (aboveground and belowground components), snags, soil, downed woody debris, forest floor materials, understory vegetation, and black C (charcoal). As woody vegetation grows, it stores $\mathrm{C}$ in its tissues; in the case of long-lived trees, this $\mathrm{C}$ can potentially be stored for hundreds of years.

In the United States, the forest $\mathrm{C}$ sink is believed to be higher at present than during the pre-Euroamerican era, due to both fire exclusion-related ingrowth and extensive regrowth following $19^{\text {th }}$ - and early $20^{\text {th }}$-century forest-clearing land uses (Hurtt et al., 2002). USFS Forest Inventory and Analysis (FIA) data for the years 2001-2005 indicates that California contains an estimated $1 \times 10^{9} \mathrm{Mg} \mathrm{C}$ in live trees and $1 \times 10^{6} \mathrm{Mg} \mathrm{C}$ in snags and downed woody debris, for a statewide average of $89.6 \mathrm{Mg} \mathrm{C} \mathrm{ha}^{-1}$ (Christensen et al., 2008). Recent calculations of mean C stored in unmanaged, fire-excluded stands in Sierra 
Nevada mixed-conifer forest have ranged from roughly $320 \mathrm{Mg} \mathrm{C} \mathrm{ha}^{-1}$ (Stephens et al., 2009b) to $426 \mathrm{Mg} \mathrm{C} \mathrm{ha}^{-1}$ (North et al., 2009a). However, in this and other dry, fireadapted forest types experiencing greatly increased stem density and surface fuel loads, the $\mathrm{C}$ sink is threatened by recent, climate change-associated increases in wildfire size and severity (Westerling et al., 2006; Miller et al., 2009; Stephens et al., 2009b), and is predicted to decrease substantially throughout the $21^{\text {st }}$ century as regrowth slows and large, severe wildfires increase (Hurtt et al., 2002).

This increase in severe wildfire activity has led to an increased emphasis on fuel treatment implementation, especially in or near the WUI (Schoennagel et al., 2009; Mell et al., 2010). Such treatments usually emphasize the removal of small trees that have established during the fire-exclusion era (North et al., 2005). These treatments reduce the risk of stand-replacing fire, and thus substantial $\mathrm{C}$ release to the atmosphere, by decreasing surface fire intensity and the probability of crown fire initiation (Agee and Skinner, 2005). Although empirical studies are rare, such treatments appear to be effective in reducing fire intensity and severity in Sierra Nevada mixed-conifer and other forest types with historic high-frequency, low-intensity fire regimes (Carey and Schumann, 2003; Graham et al., 2004; Stephens et al., 2009a). Such canopy thinning may simultaneously significantly increase growth rates in the leave trees (Latham and Tappeiner, 2002; Skov et al., 2005), but the effects of such treatments on C dynamics in active fire regimes are not well understood (North et al., 2009a; Stephens et al., 2009b). 
However, the treatment of fuels to reduce wildfire severity and effects is not without its costs to $\mathrm{C}$ storage and sequestration. Significant short-term $\mathrm{C}$ losses may occur through the removal or fire-induced mortality of trees; consumption of downed woody debris, forest floor materials, and understory vegetation; and fossil fuel emissions from mechanical equipment used during treatment implementation (Wiedinmyer and Neff, 2007; Finkral and Evans, 2008; Campbell et al., 2009; Hurteau and North, 2009; North et al., 2009a). North et al. (2009a) and Stephens et al. (2009b) reported that treatments incorporating mechanical thinning resulted in the greatest immediate reductions in livetree $\mathrm{C}$ storage, with overstory thinning removing the greatest amounts of $\mathrm{C}$ (North et al., 2009a).

These forest management-related $\mathrm{C}$ losses have resulted in restrictive $\mathrm{C}$ accounting policies such as the California Climate Action Registry guidelines (CCAR, 2007), which require that any trees harvested be counted as immediate $\mathrm{C}$ losses, thus penalizing landowners and land managers for undertaking fuel treatments and other management projects designed to improve long-term forest health, resilience to wildfire, and ironically, C storage (Hurteau et al., 2008) $)^{5}$. Compounding the situation, wildfire losses are considered to be "uncontrollable" and are not counted against landowners or managers; after a stand-replacing fire, the baseline $\mathrm{C}$ stock is simply recalculated for the disturbed site (Hurteau and North, 2009). This failure to acknowledge the threat of catastrophic $\mathrm{C}$ release from wildfire "amounts to a perverse incentive to increase fire risk through continued fire suppression" (Hurteau et al., 2008). Indeed, Stephens et al.

\footnotetext{
${ }^{5} 2011$ update: the most recent CCAR Forest Sector Protocol, Version 3.2 (CCAR, 2010) allows for C stored in wood products to be counted towards overall project storage; i.e., it is no longer a penalty.
} 
(2009b) found that under modeled conditions, $90 \%$ of the live-tree C pool in untreated stands had a high $(>75 \%)$ chance of being killed in a severe wildfire. A better solution would be to remove the penalty for fuel treatment-related emissions, include $\mathrm{C}$ released from wildfires in the accounting guidelines as recommended by the IPCC (2006), and account for $\mathrm{C}$ stored over the long term in wood products originating at the treatment site (Finkral and Evans, 2008; Stephens et al., 2009b).

Moreover, the underlying assumption that unmanaged, fire-excluded stands store the most C (Hurtt et al., 2002) may not hold true in all cases (Hurteau and North, 2010; Hurteau et al., 2010). Despite the fact that stem densities throughout Sierra Nevada mixed-conifer forests exceed their historic range of variability (Skinner and Chang, 1996), the total forest $C$ sink may have actually decreased instead of increased during the fire exclusion era, due to heavy logging that has removed the largest trees, which store the most C (Fellows and Goulden, 2008). Thus, despite findings that forest $\mathrm{C}$ dynamics appear to be essentially unaffected by forest management activities over the long term (Campbell et al., 2009), with $\mathrm{C}$ sequestration in prescribed-burned and thinned stands completely recovering to pre-treatment levels within seven years (Hurteau and North, 2010), the harvest of large, old trees results in a net loss of $\mathrm{CO}_{2}$ to the atmosphere in spite of the higher growth and $\mathrm{C}$ sequestration rates of the young trees that replace them (Harmon et al., 1990).

Whether or not the lifespan of a given fuel treatment outlasts the C recovery period is dependent upon site-specific factors; however, based on their research in the central 
Sierra Nevada, Hurteau and North (2010) reported that total C emissions from prescribed fire are likely to be sequestered by tree and shrub growth within a period of time that is shorter than the historic mean fire return interval. If this is true, the wildfire risk reduction and ecological benefits of prescribed fire could offset treatment-associated C emissions to the atmosphere. Overall, the temporary reduction in forest $\mathrm{C}$ sequestration and storage that results from fuel treatment implementation is a small price to pay for avoiding standreplacing wildfire and its disruption of long-term C stock stability (Hurteau and North, 2010; Hurteau et al., 2010).

\subsubsection{Live-tree C Sequestration}

In untreated stands, $\mathrm{C}$ sequestration (i-Tree Eco; 2008-2009) ranged from $2.3 \mathrm{Mg} \mathrm{C}^{-1}$ $\mathrm{yr}^{-1}$ for Thin + Fire to $4.0 \mathrm{Mg} \mathrm{C} \mathrm{ha}^{-1} \mathrm{yr}^{-1}$ for Pile Burn (Table 4.2). In treatment stands, sequestration ranged from 1.6 $\mathrm{Mg} \mathrm{Cha}^{-1} \mathrm{yr}^{-1}$ for Thin + Fire to $2.8 \mathrm{Mg} \mathrm{Cha}^{-1} \mathrm{yr}^{-1}$ for Pile Burn. The Thin + Fire and Fire Only treatments resulted in statistically significant reductions in mean annual gross $\mathrm{C}$ sequestration (Table 4.3). Similarly, a Thin + Fire treatment was found to significantly reduce $\mathrm{C}$ sequestration in the Klamath Mountains of northern California (Large, 2010).

The fact that the Thin + Fire and Fire Only treatments had significant effects on C sequestration may indicate the possibility that these two treatments removed and/or killed more small trees than was the case with the Masticate and Pile Burn treatments, as smaller trees grow, and therefore sequester $\mathrm{C}$, at a faster rate than older trees (Odum, 
1969; Gower et al., 1996). That the highest C sequestration values were calculated for the Pile Burn sites in Yosemite National Park is unsurprising, due to the very light thin applied (thin from below to 6" DBH).

\subsubsection{Live-tree C Storage}

Mean live-tree (aboveground plus belowground) C storage in untreated stands ranged from 123.4 $\mathrm{Mg} \mathrm{C}^{-1}$ (Eco)/178.1 $\mathrm{Mg} \mathrm{C}^{-1}$ (FFE-FVS) to 263.7 $\mathrm{Mg} \mathrm{C} \mathrm{ha}^{-1}$ (Eco)/331.6 $\mathrm{Mg} \mathrm{C} \mathrm{ha}^{-1}$ (FFE-FVS) (Table 4.2). In treated stands, mean C storage ranged from 142.4 $\mathrm{MgC} \mathrm{ha}^{-1}$ (Eco)/197.6 $\mathrm{Mg} \mathrm{C}^{-1}$ (FFE-FVS) to $180.5 \mathrm{Mg} \mathrm{C}^{-1}$ (Eco)/238.0 $\mathrm{Mg} \mathrm{C}^{-1}$ (FFE-FVS). The statistical analysis did not find significant fuel treatment effects on livetree $\mathrm{C}$ storage with either the Eco or the FFE-FVS outputs.

Intuitively, fuel treatments would be expected to remove biomass (and therefore C) from, not add it to, forest stands; recent research in the central and southern Sierra Nevada has found this to be the case (Stephens et al., 2009b and North et al., 2009a, respectively). However, in the current study, both the i-Tree Eco/FFE-FVS calculations and the statistical analysis found that the Masticate and Thin + Fire treatments appeared to increase $\mathrm{C}$ storage in the treated sites, as can be seen in Tables 4.2 and 4.3 and Figure 4.3 (although, as noted above, no significant changes were found). The fact that fuel treatments often focus predominantly on the removal of smaller trees that contribute relatively little to overall stand biomass and thus $\mathrm{C}$ storage (North et al., 2009a) may help account for the lack of significant $\mathrm{C}$ storage results in the current study; however, it is 
also likely that the effects of small sample size, high variability in the data, and poorly matched treated vs. untreated plots account partly for these results.

Mean live-tree $\mathrm{C}$ storage (Eco and FFE-FVS) in untreated and treated stands is shown in comparison to results from recent, similar studies in Table 4.4. The table is divided into two parts: whole live-tree $\mathrm{C}$ storage and aboveground-only live-tree $\mathrm{C}$ storage. The addition of aboveground-only live-tree $\mathrm{C}$ storage to the table allows for the comparison of results to studies for which belowground biomass (root) data was not calculated. Where thinning was used, Table 4.4 includes only understory (not overstory) thinning results from the other studies referenced, because only understory thinning was evaluated in the current research.

As can be seen in Table 4.4, estimates of tree-based C storage are highly variable. North et al. (2009b) calculated mean whole live-tree storage in untreated Sierra Nevada mixedconifer stands as being $308.1 \mathrm{Mg} \mathrm{C} \mathrm{ha}^{-1}$; all treatment types significantly reduced $\mathrm{C}$ storage. In contrast, both of the methods used in the current study gave lower estimates for whole-tree storage, ranging from 168.4 $\mathrm{Mg} \mathrm{C} \mathrm{ha}^{-1}$ to $229.2 \mathrm{Mg} \mathrm{C} \mathrm{ha}^{-1}$, and significant treatment effects on $\mathrm{C}$ storage were not found. (When FFE-FVS carbon reports were generated for the present data, but replacing Jenkins and others [2003] equations with the FFE default biomass equations [results not shown], this value was 191.8 $\mathrm{Mg} \mathrm{C} \mathrm{ha}^{-1}$.)

Results from a mixed-conifer study in the Klamath Mountains of northern California give a mean whole-tree $\mathrm{C}$ storage estimate of approximately $317 \mathrm{Mg} \mathrm{C} \mathrm{ha}^{-1}$ (i-Tree Eco) in 
untreated stands; fuel treatments had no significant effect on C storage (Large, 2010). In contrast, untreated stands in a 44-year old ponderosa pine plantation in the north-central Sierra Nevada were estimated to store only $87 \mathrm{Mg} \mathrm{C} \mathrm{ha}^{-1}$ on average, with thinning resulting in a significant decrease in storage to roughly $34 \mathrm{Mg} \mathrm{C} \mathrm{ha}^{-1}$ (Campbell et al., 2009).

Thinning in an Arizona ponderosa pine forest resulted in a reduction from $42.5 \mathrm{Mg} \mathrm{C}^{-1}$ to approximately $30 \mathrm{Mg} \mathrm{C} \mathrm{ha}^{-1}$ stored in live-tree biomass when only aboveground $\mathrm{C}$ was analyzed (Finkral and Evans, 2008). In a Sierra Nevada mixed-conifer study, Stephens et al. (2009b) estimated an average of $188.2 \mathrm{Mg} \mathrm{C} \mathrm{ha}^{-1}$ in untreated stands, a value that closely matches the current study's calculation of $189.5 \mathrm{Mg} \mathrm{C} \mathrm{ha}^{-1}$ (FFE-FVS). Stephens et al. (2009b) found that Mechanical Only and Mechanical + Fire fuel treatments significantly reduced aboveground live-tree C storage, while the Fire Only treatment did not. North et al. (2009b) found somewhat higher values for C storage in aboveground live-tree vegetation (e.g., $249.8 \mathrm{Mg} \mathrm{C} \mathrm{ha}^{-1}$ in untreated stands); all treatment types significantly reduced $\mathrm{C}$ storage. In contrast, the current study did not find any significant treatment effects on aboveground live-tree $\mathrm{C}$ storage, possibly reflecting lower treatment intensities.

Looking at $\mathrm{C}$ stored in aboveground live vegetation across the entire US Fire and Fire Surrogate (FFS) study network, Boerner et al. (2008) found that C storage averaged approximately $81 \mathrm{Mg} \mathrm{ha}^{-1}$ for untreated stands; Fire Only treatments had little effect on 
this number, but treatments involving mechanical thinning significantly reduced $\mathrm{C}$ storage at over half of the study sites, by approximately $30 \mathrm{Mg} \mathrm{ha}^{-1}$ on average.

\subsection{Conclusions}

In removing forest biomass for fire hazard reduction, fuel reduction treatments inevitably reduce forest capacity to provide numerous ecosystem services, including air pollution removal and $\mathrm{C}$ storage, leading to concerns over long-term ecosystem integrity. As a result, current $\mathrm{C}$ accounting methods penalize landowners and managers for any forest $\mathrm{C}$ loss, including losses incurred during implementation of fuel treatments (Hurteau et al., 2008). However, these losses are temporary and relatively minor (Hurteau and North, 2010), and furthermore, such treatments are critically important if significant C loss due to stand-replacing wildfire is to be avoided in Sierra Nevada mixed-conifer and similar

dry forest types (North et al., 2009a; Stephens et al., 2009b). This is particularly true in light of the uncertainties associated with projected climatic trends of increased drought and wildfire occurrence (Millar et al., 2007; Moritz and Stephens, 2008; Hurteau et al., 2010).

In the current study, there were no findings of significant treatment effects on air pollution removal. Only minimal findings of significance were obtained as regards standlevel, tree-based C pools. In contrast, North et al. (2009b) and Stephens et al. (2009b) did find significant treatment-related reductions in stand $\mathrm{C}$ storage. The present statistical analysis was likely hampered by high variability in the data and small sample size, 
concerns that were exacerbated by the removal of one experimental unit due to data quality concerns. While the i-Tree Eco software proved capable of calculating air pollution removal and live-tree C pool characteristics in the study's WUI mixed-conifer stands, the differences between $\mathrm{C}$ results reported by Eco and FFE-FVS demonstrate that the selection of methods used in modeling has a strong influence on the outcomes obtained.

While stand-level studies like this one are necessary in order to understand the fundamentals of forest biomass dynamics, much remains unclear about the relationship between stand-level and landscape-level forest processes. Furthermore, it is only at the regional scale that the effects of forest disturbances on atmospheric $\mathrm{C}$ concentrations and global climate change are relevant; hence the need for process models that can simulate forest dynamics across large spatial domains (Campbell et al, 2009). Modeling efforts to evaluate landscape-level fuel treatment effects on wildfire severity have shown promising results, but have also served to highlight the difficult choices that managers face, given limited resources (Ager et al., 2010). If disturbances such as fuel treatments have minimal long-term effects on forest ecosystem services, the management decisions required for optimal forest management should, ideally, become less controversial and more likely to be embraced by WUI stakeholders. 


\subsection{Final Conclusions}

The results of the present research should be interpreted with caution. Variability between experimental units was high, sample size was small, and the accuracy of a true before-and-after study could not be achieved. In addition, fire behavior modeling relies on assumptions of idealized conditions that do not reflect the real world. However, although few significant treatment effects on ecosystem services were found, fuel loading and fire behavior findings largely reflected trends identified in other studies in Sierra Nevada mixed-conifer forest. These trends showed significant treatment effects on trees $\mathrm{ha}^{-1}$, canopy cover, canopy bulk density, and predicted flame length, as well as significant increases in canopy base height and predicted torching index and crowning index, and were most consistent with other research for treatments combining mechanical thinning with prescribed fire.

The accumulating body of evidence that fuel treatments effectively reduce fire intensity, however, is limited mostly to experimental burning conditions and post facto analysis of wildfires. Anecdotal evidence shows that fuel treatments do not always mitigate severe fire behavior, especially under extreme weather conditions. Given that (1) the influence of climate is at least as strong as the influence of land use history on fuels production in this forest type, (2) increased warming and summer drought are occurring in California and are predicted to increase, and (3) these conditions will likely exacerbate wildfire activity, the overall, long-term efficacy of fuel treatments is unknown. However, fuel treatment implementation should continue to be a priority for land managers, as not all wildfires occur under extreme weather conditions, and such treatments can not only save 
lives and homes, but may also double as ecological restoration efforts in dry forest types like Sierra Nevada mixed-conifer and southwestern ponderosa pine. In particular, allowing the reintroduction of slow-moving, low-intensity fires into the aforementioned forest types, whether alone or in conjunction with preceding mechanical treatments, helps restore the inherent fire-resilience of these systems and improves overall forest health, at costs far below those of large-fire suppression. Future research should include controlled experimentation with the use of prescribed burning and mechanical treatments to reduce potential fire hazard in a variety of forest and other vegetation types.

The legacy of Bambi and the ever-present Smokey Bear continue to have a strong influence on our increasingly urban (and wildland-urban) population, who are to this day bombarded with messages that fire is bad and that the government can be (and should be) trusted to put forest fires out - the exact scenario that got us into the current, disastrous situation. Various concerns remain as obstacles to fuel treatment implementation; these include the health effects of smoke from prescribed fire; treatment effects on wildlife habitat, carbon storage, and other ecosystem services; and fears of increased government influence on land use planning in the largely-private WUI. Thus, the way forward must include continuous, science-based public outreach and education on the part of land managers. 


\subsection{Literature Cited}

Agee, J.K., 1993. Fire Ecology of Pacific Northwest forests. Island Press, Washington, DC.

Agee, J.K., 1996. The influence of forest structure on fire behavior. P. 52-68 in Proc., 17th Forest Vegetation Management Conf., S.L. Cooper (comp.). Univ. of California, Shasta County Coop. Ext., Redding, CA.

Agee, J.K., Bahro, B., Finney, M.A., Omi, P.N., Sapsis, D.B., Skinner, C.N., van Wagtendonk, J.W., Weatherspoon, C. P., 2000. The use of shaded fuelbreaks in landscape fire management. Forest Ecology and Management 127, 55-66.

Agee, J.K., Skinner, C.N., 2005. Basic principles of forest fuel reduction treatments. Forest Ecology and Management 211, 83-96.

Ager, A.A., McMahan, A.J., Barrett, J.J., McHugh, C.W., 2007. A simulation study of thinning and fuel treatments on a wildland-urban interface in eastern Oregon, USA. Landscape and Urban Planning 80, 292-300.

Ager, A. A., Vaillant, N. M., Finney, M. A., 2010. A comparison of landscape fuel treatment strategies to mitigate wildland fire risk in the urban interface and preserve old forest structure. Forest Ecology and Management 259, 1556-1570.

AIR Worldwide. 2010. Wildfire. Available at:

http://www.air-worldwide.com/wildfire.aspx?Page=2. Verified 12/20/10.

Allen, B.H., 2005. California Wildlife Habitat Relationships System: Sierran Mixed Conifer. California Department of Fish and Game and California Interagency Wildlife Task Group. Available at: http://www.dfg.ca.gov/biogeodata/cwhr/pdfs/SMC.pdf. Verified 10/02/10.

Allen, C.D., Savage, M., Falk, D.A., Suckling, K.F., Swetnam, T.W., Schulke, T., Stacey, P.B., Morgan, P., Hoffman, M., Klingel, J.T., 2002. Ecological restoration of Southwestern ponderosa pine ecosystems: a broad perspective. Ecological Applications $12,1418-33$.

Anderson, H.E., 1982. Aids to determining fuel models. USDA Forest Service, Intermountain Research Station, General Technical Report INT-122, Ogden, UT, 22 pp.

Andrews, P.L., Bevins, C.D., Seli R.C., 2008. BehavePlus fire modeling system, version 4.0: User's Guide. USDA Forest Service, Rocky Mountain Research Station, General Technical Report RMRS-GTR-106WWW Revised, Ogden, UT. 
Andrews, P.L. 2009. BehavePlus fire modeling system, version 5.0: Variables. USDA Forest Service, Rocky Mountain Research Station, General Technical Report RMRSGTR-213WWW Revised, Fort Collins, CO, 111 p. Available at: http://www.fs.fed.us/rm/pubs/rmrs_gtr213.pdf. Verified 10/02/10.

Bachelet, D., Neilson, R.P., Lenihan, J.M., Drapek, R.J., 2001. Climate change effects on vegetation distribution and carbon budget in the United States. Ecosystems 4, 164-185.

Baines, C., 2000. A forest of other issues. Landscape Design 294, 46-47.

Barbour, R.J., Singleton, R., Maguire, D.A., 2007. Evaluating forest product potential as part of planning ecological restoration treatments on forested landscapes. Landscape and Urban Planning 80, 237-248.

Battaglia, M.A., Smith, F.W., Shepperd, W.D., 2008. Can prescribed fire be used to maintain fuel treatment effectiveness over time in Black Hills ponderosa pine forests? Forest Ecology and Management 256, 2029-2038.

Bessie, W.C., Johnson, E.A., 1995. The relative importance of fuels and weather on fire behaviour in subalpine forests. Ecology 76, 747-762.

Blanchi, R., Leonard, J.E., Leicester, R.H., 2006. Lessons learnt from post bushfire surveys at the urban interface in Australia. Available online at http://www.bushfirecrc.com/research/d11/publicdocuments.html. Verified 12/20/10.

Boerner, R.E., Huang, J., Hart, S.C., 2008. Fire, thinning, and the carbon economy: Effects of fire and fire surrogate treatments on estimated carbon storage and sequestration rate. Forest Ecology and Management 255, 3081-3097.

Boxall, B. 2008. "Spending to fight California wildfires surpasses $\$ 1$ billion". Available at: http://articles.latimes.com/2008/dec/31/local/me-wildfires31. Verified 12/20/10.

Bradshaw, L., McCormick, E., 2000. FireFamily Plus user's guide, Version 2.0. USDA Forest Service, Rocky Mountain Research Station, General Technical Report RMRS67WWW.

Brown, J.K., 1974. Handbook for inventorying downed woody material. USDA Forest Service, Intermountain Range and Forest Experiment Station, General Technical Report INT-16, Ogden, UT, 24 pp.

Brown, J.K., Johnston, C.M., 1976. Debris prediction system. USDA Forest Service, Intermountain Forest and Range Experiment Station, Fuel Science RWU 2104, Missoula, MT, 28 pp.

Brown, P.M., Wu, R., 2005. Climate and disturbance forcing of episodic tree recruitment in a southwestern ponderosa pine landscape. Ecology 86(11), 3030-3038. 
Bryant, B. P., Westerling, A.L., 2009. Potential effects of climate change on residential wildfire risk in California: draft paper. CEC-500-2009-048-D. Available at:

http://www.energy.ca.gov/2009publications/CEC-500-2009-048/CEC-500-2009-048-

D.PDF. Verified 10/02/10.

CAFRAP [California Fire Resource and Assessment Program], 2001. Comparison of areas burned in developed and undeveloped wildland areas in the northwestern Sierra Nevada foothills. California Department of Forestry and Fire Protection, Sacramento, California, USA.

Campbell, J., Alberti, G., Martin, J., Law, B.E., 2009. Carbon dynamics of a ponderosa pine plantation following a thinning treatment in the northern Sierra Nevada. Forest Ecology and Management 257, 453-463.

Cardille, J. A., Ventura, S. J., Turner, M. G., 2001. Environmental and social factors influencing wildfires in the Upper Midwest, United States. Ecological Applications 11, 111-127.

Carey, H., Schumann, M., 2003. Modifying wildfire behavior - the effectiveness of fuel treatments. National Community Forestry Center - Southwest Region Working Paper 2. Available at:

http://maps.wildrockies.org/ecosystem_defense/Science_Documents/Carey_Schumann_2 003.pdf

Verified 11/14/10.

CCAR (California Climate Action Registry). 2007. Forest Sector Protocol. http://www.climateregistry.org/tools/protocols/industry-specific-protocols.html. Verified 10/27/10.

CCAR (California Climate Action Registry). 2010. Forest Sector Protocol, Version 3.2. http://www.climateactionreserve.org/how/protocols/adopted/forest/development/.

Verified 3/17/11.

Chalmers, S.R., Hartsough, B.R., no date. Thinning and prescribed fire as methods to reduce fuel loading - a cost analysis. USDA Forest Service, Washington, D.C. Available at:

http://www.fs.fed.us/ffs/docs/Chalmers\%20\&\%20Hartsough.pdf. Verified 12/20/10.

Chandler, C., Cheney, P., Thomas, P., Trabaud, L., Williams, D., 1991. Fire in forestry: Forest fire behavior and effects. Malabar, F.L.: Krieger Publishing Company; 91; Volume 1.

Chen, W.Y., Jim, C.Y., 2008. Assessment and valuation of the ecosystem services provided by urban forests. Ecology, Planning, and Management of Urban Forests: International perspectives. Part I, 53-83. 
Christensen, G.A., Campbell, S.J., Fried, J.S., Eds., 2008. California's forest resources, 2001-2005: five-year Forest Inventory and Analysis report. USDA Forest Service, Pacific Northwest Research Station, General Technical Report PNW-GTR-763, Portland, OR, 183 p.

Cleaves, D.A., Brodie, J.D., 1990. P. 271-282 in Economic analysis of prescribed burning. In Natural and Prescribed Fire in Pacific Northwest Forests, J.D. Walstad, et al. (eds.). Oregon State Univ. Press, Corvallis.

Cleaves, D.A., Martinez, J., Haines, T.K., 2000. Influences on prescribed burning activity and costs in the National Forest System. USDA Forest Service, Southern Research Station, General Technical Report SRS-37.

Cohen, J., Saveland, J., 1997. Structure ignition assessment can help reduce fire damages in the W-UI. Fire Management Notes 57(4), 19-23.

Cohen, J.D., 2000. Preventing disaster: home ignitability in the wildland-urban interface. Journal of Forestry 98, 15-21.

Collins, B.M., Omi, P.N., Chapman, P.L., 2006. Regional relationships between climate and wildfire-burned area in the Interior West, USA. Canadian Journal of Forest Research 36, 699-709.

Committee on Natural Resources. 2009. Rahall highlights year of accomplishment for America's natural resources. Available at:

http://resourcescommittee.house.gov/index.php?option=com_content\&task=view\&id=61



Crimmins, S.M., Dobrowski, S.Z., Greenberg, J.A., Abatzoglou, J.T., Mynsberge, A.R., 2011. Changes in climatic water balance drive downhill shifts in plant species' optimum elevations. Science 331, 324-327.

Dellasala, D.A., Williams, J.E., Williams, C.D., Franklin, J.F., 2004. Beyond smoke and mirrors: a synthesis of fire policy and science. Conservation Biology 18(4), 976-986.

Dettinger, M.D., Cayan, D. R., Diaz, H. F., Meko, D. M., 1998. North-south precipitation patterns in western North America on interannual-to-decadal time scales. Journal of Climate 11, 3095-3111.

Dicus, C.A., Scott, M.E., 2006. Reduction of potential fire behavior in wildland-urban interface communities in southern California: a collaborative approach. In: Andrews, P.L., Butler, B.W. (comps), Fuels Management-How to Measure Success: Conference Proceedings. Portland, OR, March 28-30, 2006, pp. 729-738; Proceedings RMRS-P-41, USDA Forest Service, Rocky Mountain Research Station, Fort Collins, CO, 809 pp. 
Dicus, C.A., 2009. Changes to simulated fire behaviour and societal benefits after two levels of thinning in a mixed-conifer wildland-urban interface community. Proceedings of the Royal Society of Queensland 115, 37-44. Brisbane. ISSN 0080-469X.

Dicus, C.A., Delfino, K., Weise, D.R., 2009. Predicted fire behavior and societal benefits in three eastern Sierra Nevada vegetation types. Fire Ecology 5(1), 67-78.

Dodge, M., 1972. Forest fuel accumulation. Science 177, 139-142.

Dombeck, M.P., Williams, J.E., and Wood, C.A., 2004. Wildfire policy and public lands: integrating scientific understanding with social concerns across landscapes. Conservation Biology 18, 883-89.

Elliot, W.J., Miller, I.S., Audin, L., Eds., 2010. Cumulative watershed effects of fuel management in the western United States. USDA Forest Service, Rocky Mountain Research Station. General Technical Report RMRS-GTR-231, Fort Collins, CO, 299 p.

Farnham, J., Beimborn, E., 2003. Noise barrier design guidelines. Center for Urban Transportation Studies, University of Wisconsin-Milwaukee, Milwaukee, WI. Available at: http://www4.uwm.edu/cuts/. Verified 11/14/10.

Fellows, A.W., Goulden, M.L., 2008. Has fire suppression increased the amount of carbon stored in western U.S. forests? Geophysical Research Letters 35, L12404.

Finkral, A.J., Evans, A.M., 2008. The effects of a thinning treatment on carbon stocks in a northern Arizona ponderosa pine forest. Forest Ecology and Management 255, 27432750 .

Finney, M.A., 2001. Design of regular landscape fuel treatment patterns for modifying fire growth and behavior. Forest Science 47, 219-228.

Finney, M.A., Cohen, J.D., 2003. Expectation and evaluation of fuel management objectives. In: Omi, P.N., Joyce, L.A. (Eds.) Fire, Fuel Treatments, and Ecological Restoration. Proceedings RMRS-P-29. USDA Forest Service, Rocky Mountain Research Station, pp. 353-366.

Finney, M.A., Seli, R.C., McHugh, C.W., Ager, A.A., Bahro, B., Agee, J.K., 2007. Simulation of long-term landscape-level fuel treatment effects on large wildfires. International Journal of Wildland Fire 16, 712-727.

Firewise Communities/USA, 2009. A user reference guide to the Firewise Communities/USA recognition program. Available at:

http://www.firewise.org/files/FirewiseUserGuide.pdf. Verified 12/22/10. 
Fong, P.K., 2007. Statement before the Senate Committee on energy and natural resources. USDA, Office of Inspector General, 30 January 2007. Available at: http://energy.senate.gov/public/_files/fongwildfiretestimony.pdf. Verified 12/20/10.

Foote, E.I.D., 1994. Structure survival on the 1990 Santa Barbara "Paint" fire: a retrospective study of urban-wildland interface fire hazard mitigation factors. MS thesis, University of California at Berkeley.

Franklin, J. E, Agee, J. A., 2003. Forging a science-based national forest fire policy. Issues in Science and Technology 20, 59-66.

FRAP (Fire and Resource Assessment Program), 2010. California's Forests and Rangelands: 2010 Assessment. California Department of Forestry and Fire Protection, Sacramento, CA.

Fried, J.S., Torn, M.S., Mills, E., 2004. The impact of climate change on wildfire severity: a regional forecast for Northern California. Climatic Change 64, 169-191.

Fried, J.S., Gilless, J.K., Riley, W.J., Moody, T.J., Simon de Blas, C., Hayhoe, K., Moritz, M., Stephens, S., Tom, M., 2008. Predicting the effect of climate change on wildfire behavior and initial attack success. Climatic Change 87 [Supplement 1], S251S264.

GAO [Government Accountability Office], 1999. Western national forests: a cohesive strategy is needed to address catastrophic wildland fire threats. GAO/RCED-99-65, Washington, D.C.

GAO, 2003. Forest service fuels reduction. GAO-03-689R, Washington, D.C.

GAO, 2004. Report to Congressional Requesters. Wildland Fire Suppression: Funding Transfers Cause Project Cancellations and Delays, Strained Relationships, and Management Disruptions. GAO-04-612. Available at: http://www.gao.gov/new.items/d04612.pdf. Verified 12/20/10.

GAO, 2007. Wildland fire management: a cohesive strategy and clear cost-containment goals are needed for federal agencies to manage wildland fire activities effectively. US Government Accountability Office, GAO-07-1017T. Available at: http://www.gao.gov/new.items/d071017t.pdf. Verified 12/20/10.

Glitzenstein, J.L., Streng, D.R., Achtmeier, G.L., Naeher, L.P., Wade, D.D., 2006. Fuels and fire behavior in chipped and unchipped plots: implications for land management near the wildland/urban interface. Forest Ecology and Management 236, 18-29.

Gower, S.T., McMurtrie, R.E., Murty, D., 1996. Aboveground net primary production decline with stand age: potential causes. Trends in Ecology \& Evolution 11, 378-82. 
Graham, R.T., Harvey, A.E., Jain, T.B., Tonn, J.R., 1999. The effects of thinning and similar stand treatments on fire behavior in Western forests. USDA Forest Service, Pacific Northwest Research Station, General Technical Report PNW-GTR-463, Portland, OR, $27 \mathrm{p}$.

Graham, R.T., 2003. Hayman Fire Case Study. Technical Editor. USDA Forest Service, General Technical Report RMRS-GTR-114.

Graham, R.T., McCaffrey, T.S., Jain, T.B., 2004. Science basis for changing forest structure to modify wildfire behavior and severity. USDA Forest Service, Rocky Mountain Research Station. General Technical Report RMRS-120.

Gruell, G.E., 2001. Fire in Sierra Nevada Forests: A Photographic Interpretation of Ecological Change Since 1849. Mountain Press Publishing Company, Missoula, MT.

Gude, P.H., Rasker, R., van den Noort, J., 2008. Potential for future development on fireprone lands. Journal of Forestry 106(4), 198-205.

Gude, P.H., Cookson, J.A., Greenwood, M.C., Haggerty, M., 2009. Homes in wildfireprone areas: an empirical analysis of wildfire suppression costs and climate change. Headwaters Economics, Bozeman, MT. Available at: http://www.headwaterseconomics.org/wildfire/Gude_Manuscript_4-24-09_Color.pdf. Verified 10/02/10.

Haight, R.G., Cleland, D.T., Hammer, R.B., Radeloff, V.C., Rupp, T.S., 2004. Assessing fire risk in the wildland-urban interface - a landscape ecosystem approach. Journal of Forestry 102, 41-48.

Hammer, R.B., Radeloff, V.C., Fried, J.S., Stewart, S.I., 2007. Wildland-urban interface growth during the 1990s in California, Oregon and Washington. International Journal of Wildland Fire 16, 255-265.

Harmon, M. E., Franklin, J. F., Swanson, F. J., Sollins, P., Gregory, S. V., Lattin, J. D., Anderson, N. H., Cline, S. P., Aumen, N. G., Sedell, J. R., Lienkamper, G. W., and others. 1986. Ecology of coarse woody debris in temperate ecosystems. Pp. 133-302 in A. MacFadyen and E.D. Ford [Eds.], Advances in ecological research. Harcourt Brace Jovanovich, New York.

Harmon, M.E., Ferrell, W.K., Franklin, J.F., 1990. Effects on carbon storage of conversion of old-growth forests to young forests. Science, New Series, 247, 699-702.

Hartsough, B. R., Abrams, S., Barbour, R. J., Drews, E. S., McIver, J. D., Moghaddas, J. J., Schwilk, D. W., Stephens, S. L., 2008. The economics of alternative fuel reduction treatments in western United States dry forests: financial and policy implications from the National Fire and Fire Surrogate Study. Forest Economics and Policy 10, 344-354. 
Heyerdahl, E.K., Brubaker, L.B., Agee, J.K., 2002. Annual and decadal climate forcing of historical fire regimes in the interior Pacific Northwest, USA. The Holocene 12(5), 597-604.

HFRA [Healthy Forest Restoration Act], 2003. Public Law 108-148. Available at: http://frwebgate.access.gpo.gov/cgi-

bin/getdoc.cgi?dbname=108_cong_bills\&docid=f:h1904enr.txt.pdf. Verified 12/20/10.

Hurteau, M., North, M., 2009. Fuel treatment effects on tree-based forest carbon storage and emissions under modeled wildfire scenarios. Frontiers in Ecology and the Environment, 7.

Hurteau, M., North, M., 2010. Carbon recovery rates following different wildfire risk mitigation treatments. Forest Ecology and Management, 260, 930-937.

Hurteau, M.D., Koch, G.W., Hungate, B.A., 2008. Carbon protection and fire risk reduction: toward a full accounting of forest carbon offsets. Frontiers in Ecology and the Environment 6, 493-498.

Hurteau, M.D., Stoddard M.T., Fule, P.Z., 2010. The carbon costs of mitigating highseverity wildfire in southwestern ponderosa pine. Global Change Biology, doi: 10.1111/j.1365-2486.2010.02295.x.

Hurtt, G.C., Pacala, S.W., Moorcroft, P.R., Caspersen, J., Shevliakova, E., Houghton, R.A., Moore III, B., 2002. Projecting the future of the U.S. carbon sink. Proceedings of the National Academy of Sciences 99, 1389-1394.

Ingalsbee, T., 2010. Getting burned: a taxpayer's guide to wildfire suppression costs. Firefighters United for Safety, Ethics, \& Ecology. Available at:

http://www.fusee.org/content_pages/docs/FUSEE\%20suppression\%20costs\%20paper\%2 OFINALOPT.pdf. Verified 1/19/11.

Innes, J., North, M., Williamson, N., 2006. Effect of thinning and prescribed fire restoration treatments on woody debris and snag dynamics in a Sierran old-growth mixed-conifer forest. Canadian Journal of Forest Research 36, 3183-3193.

IPCC [Intergovernmental Panel on Climate Change], 2006. 2006 IPCC guidelines for national greenhouse gas inventories, prepared by the National Greenhouse Gas Inventories Programme. http://www.ipcc-nggip.iges.or.jp/public/2006gl/index.html. Verified 10/27/10.

IPCC, 2007. Summary for Policymakers. In: Climate Change 2007: The Physical Science Basis. Contribution of Working Group I to the Fourth Assessment Report of the Intergovernmental Panel on Climate Change [Solomon, S., D. Qin, M. Manning, Z. Chen, M. Marquis, K.B. Averyt, M.Tignor and H.L. Miller (eds.)]. Cambridge University Press, Cambridge, United Kingdom and New York, NY, USA. 
Jenkins, J.C., Chojnacky, D.C., Heath, L.S., Birdsey, R.A., 2004. Comprehensive database of diameter-based biomass regressions for North American tree species. USDA Forest Service, Northeastern Research Station. General Technical Report NE-319, Newtown Square, PA. 45 p. (1 CD-ROM).

Kane, J.M., Knapp, E.E., Varner, J.M., 2006. Variability in Loading of Mechanically Masticated Fuel Beds in Northern California and Southwestern Oregon. In: Andrews, P.L., Butler, B.W., comps. 2006. Fuels Management-How to Measure Success: Conference Proceedings. 28-30 March 2006; Portland, OR. USDA Forest Service, Rocky Mountain Research Station, Proceedings RMRS-P-41, Fort Collins, CO, pp. 341-350.

Kane, J.M., Varner, J.M., Knapp, E.E., 2009. Novel fuelbed characteristics associated with mechanical mastication treatments in northern California and southwestern Oregon, USA. International Journal of Wildland Fire 18, 686-697.

Kaufmann, M. R., Graham, R. T., Boyce, D. A., Jr., Moir, W. H., Perry, L., Reynolds, R. T., Bassett, R. L., Mehlhop, P., Edminster, C. B., Block, W. M., Corn, P. S., 1994. An ecological basis for ecosystem management. USDA Forest Service, Rocky Mountain Forest and Range Experiment Station. General Technical Report RM-246, Fort Collins, CO. 22 p.

Keeley, J. E., 1982. Distribution of lightning and man-caused wildfires in California. Pages 431-437 in C. E. Conrad and W. C. Oechel, editors. Proceedings of the International Symposium on the Dynamics and Management of Mediterranean-type Ecosystems. USDA Forest Service, Pacific Southwest Forest and Range Experiment Station, Berkeley, California, USA.

Keeley, J. E., Fotheringham, C. J., Morais, M., 1999. Reexamining fire suppression impacts on shrubland fire regimes. Science 284, 1829-1832.

Keifer, M.B., van Wagtendonk, J.W., Buhler, M. 2006. Long-term surface fuel accumulation in burned and unburned mixed-conifer forests of the central and southern Sierra Nevada, CA (USA). Fire Ecology 2(1), 53-72.

Keyes, C.R., O'Hara, K.L., 2002. Quantifying stand targets for silvicultural prevention of crown fires. Western Journal of Applied Forestry 17(2), 101-109.

Kitzberger, T., Brown, P.M., Heyerdahl, E.K., Swetnam, T.W., Veblen, T.T., 2007. Contingent Pacific-Atlantic Ocean influence on multicentury wildfire synchrony over western North America. Proceedings of the National Academy of Sciences 104(2), 543548.

Knapp, E.E., Busse, M.D., Varner, J.M., Skinner, C.N., Powers, R.F., 2006. Behavior and short-term effects of fire in masticated fuel beds. Proceedings of the Third International Fire Ecology and Management Congress, November 13-17, 2006, San Diego, CA. 
Kobziar, L.N., Stephens, S.L., McBride, J.R., 2009. The efficacy of fuels reduction treatments in a Sierra Nevada pine plantation. International Journal of Wildland Fire 18, 791-801.

Large, J.A., 2010. Effects of wildland urban interface fuel treatments on fire behavior and ecosystem services in the Klamath Mountains of California. Master's Thesis, California Polytechnic State University, San Luis Obispo, CA. 93 p.

Latham, P., Tappeiner, J., 2002. Response of old-growth conifers to reduction in stand density in western Oregon forests. Tree Physiology 22, 137-146.

Liang, J., Calkin, D.E., Gerbert, K.M.T.J.V., Silverstein, R.P., 2008. Factors influencing large wildland fire suppression expenditures. International Journal of Wildland Fire 17, 650-659.

Littell, J.S., McKenzie, D., Peterson, D.L., Westerling, A.L., 2009. Climate and wildfire area burned in western U.S. ecoprovinces, 1916-2003. Ecological Applications 19(4), $1003-1021$.

Lutes, D. C., Keane, R. E., Caratti, J. F., Key, C. H., Benson, N. C., Sutherland, S., Gangi, L. J., 2006. FIREMON: Fire effects monitoring and inventory system. USDA Forest Service, Rocky Mountain Research Station, General Technical Report RMRSGTR-164-CD, Fort Collins, CO.

Martinson, E.J., Omi, P.N., 2008. Assessing mitigation of wildfire severity by fuel treatments - an example from the Coastal Plain of Mississippi. International Journal of Wildland Fire 17, 415-420.

Mason, L.C., Lippke, B.R., Zobrist, K.W., Bloxton Jr., T.D., Ceder, K.R., Comnick, J.M., McCarter, J.B., Rogers, H.K., 2006. Investments in fuel removals to avoid forest fires result in substantial benefits. Journal of Forestry 104, 27-31.

Massada, A.B., Radeloff, V., Stewart, S., Hawbaker, T.J., 2009. Wildfire risk in the wildland-urban interface: a simulation study in northwestern Wisconsin. Forest Ecology and Management 258, 1990-1999.

McCaffrey, S.M., Rhodes, A., 2009. Public response to wildfire: is the Australian "Stay and Defend or Leave Early" approach an option for wildfire management in the United States? Journal of Forestry 107(1), 9-15.

McCandliss, D.S., 2002. Prescribed burning in the Kings River Ecosystems Project Area: lessons learned. In: Verner, J., Ed. Proceedings of a symposium on the Kings River Sustainable Forest Ecosystems Project: progress and current status. USDA Forest Service, Pacific Southwest Research Station, General Technical Report PSW-GTR-183, Albany, CA, pp. 37-48. Available at: 
http://www.fs.fed.us/psw/publications/documents/gtr-183/005gtr183_mccand.pdf.

Verified 10/02/10.

McDonald, J.H., 2009. Handbook of Biological Statistics, 2nd Ed. Sparky House Publishing, Baltimore, Maryland.

McIver, J., Youngblood, A., Stephens, S. L., 2009. The national Fire and Fire Surrogate study: ecological consequences of fuel reduction methods in seasonally dry forests. Ecological Applications 19, 283-284.

McKelvey, K.S., Skinner, C.N., Chang, C., Erman, D.C., Husari, S.J., Parsons, D.J., van Wagtendonk, J.W., Weatherspoon, C.P., 1996. An overview of fire in the Sierra Nevada. In: Sierra Nevada Ecosystem Project. Final Report to Congress. Status of the Sierra Nevada. Centers for Water and Wildland Resources. University of California, Davis, pp. 1033-1040.

McKelvey, K.S., Busse, K.K., 1996. Twentieth-century fire patterns on forest service lands. In: Sierra Nevada Ecosystem Project. Final Report to Congress, Vol. II. Assessments and Scientific Basis for Management Options. Centers for Water and Wildland Resources. Report No. 37. University of California, Davis, pp. 1119-1138.

McPherson, E.G., Simpson, J.R., 2002. A comparison of municipal forest benefits and costs in Modesto and Santa Monica, California, USA. Urban Forestry and Urban Greening 1, 61-74.

Mell, W.E., Manzello, S.L., Maranghides, A., Butry, D., Rehm, R.G., 2010. The wildland-urban interface fire problem - current approaches and research needs. International Journal of Wildland Fire 19, 238-251.

Menakis J.P., Cohen J., Bradshaw, L., 2003. Mapping wildland fire risk to flammable structures for the conterminous US. In 'Proceedings of Fire Conference 2000: the First National Conference on Fire Ecology, Prevention and Management'. (Eds. Galley, K.E.M., Klinger, R.C., Sugihara, N.G.) Tall Timbers Research Station, Miscellaneous Publication No. 13, pp. 41-49. (Tallahasse, FL)

Mercer, D. E., Prestemon, J. P., 2005. Comparing production function models for wildfire risk analysis in the wildland-urban interface. Forest Policy and Economics 7, $782-795$.

Millar, C.I., Stephenson, N.L., Stephens, S.L., 2007. Climate change and forests of the future: managing in the face of uncertainty. Ecological Applications 17, 2145-2151.

Miller, C., Urban, D.L., 2000. Modeling the effects of fire management alternatives on Sierra Nevada mixed-conifer forests. Ecological Applications 10, 85-94. 
Miller, J.D., Safford, H.D., Crimmins, M., Thode, A.E., 2009. Quantitative evidence for increasing forest fire severity in the Sierra Nevada and southern Cascade mountains, California and Nevada, USA. Ecosystems 12, 16-32.

Minitab, 2007. Minitab statistical software, release 15.1.30.0 [Computer software]. State College, PA.

Moghaddas, J.J., Craggs, L., 2007. A fuel treatment reduces fire severity and increases suppression efficiency in a mixed conifer forest. International Journal ofWildland Fire 16, 673-678. doi:10.1071/WF06066.

Moghaddas, J.J., Collins, B.M., Menning, K., Moghaddas, E.E.Y., Stephens, S.L., 2010. Fuel treatment effects on modeled landscape-level fire behavior in the northern Sierra Nevada. Canadian Journal of Forest Research 40, 1751-1765.

Moritz, M. A., Stephens, S. L., 2008. Fire and sustainability: considerations for California's altered future climate. Climatic Change 87 [Supplement 1], S265-S271.

Murphy, K., Rich, T., Sexton, T., 2007. An assessment of fuel treatment effects on fire behavior, suppression effectiveness, and structure ignition on the Angora Fire. USDA Forest Service, Lake Tahoe Basin Management Unit, Research Paper R5-TP-025, Vallejo, CA.

Myneni, R. B., Dong, J., Tucker, C. J., Kaufmann, R. K., Kauppi, P. E., Liski, J., Zhou, L., Alexeyev, V., Hughes, M. K., 2001. A large carbon sink in the woody biomass of Northern forests. Proceedings of the National Academy of Sciences of the United States of America 98, 14784-14789.

NASF [National Association of State Foresters], 2010. Communities at risk report FY 2009. Available at: http://www.stateforesters.org/files/NASF-finalCAR-reportFY09.pdf. Verified 12/20/10.

NIFC [National Interagency Fire Center], 2010. Fire information - wildland fire statistics. Available at: http://www.nifc.gov/fire_info/fire_stats.htm. Verified 10/02/10.

NOAA [National Oceanic and Atmospheric Administration], 2008. Wind speed conversion charts. Available at: http://www.wrh.noaa.gov/sew/fire/olm/fire/10togust.htm. Verified 10/02/10.

NOAA, 2010. National Climatic Data Center: Billion dollar weather disasters, 19802009. Available at:

http://www.ncdc.noaa.gov/oa/reports/billionz.html. Verified 10/02/10.

NWCG [National Wildfire Coordinating Group], 2006. Glossary of wildland fire terminology. Available at: http://www.nwcg.gov/pms/pubs/glossary/pms205.pdf. Verified 10/02/10. 
North, M., Hurteau, M., Fiegener, R., Barbour, M., 2005. Influence of fire and El Niño on tree recruitment varies by species in Sierran mixed conifer. Forest Science 51, 187-97.

North, M., Innes, J., Zald, H., 2007. Comparison of thinning and prescribed fire restoration treatments to Sierran mixed-conifer historic conditions. Canadian Journal of Forest Research 37, 331-42.

North, M., Hurteau, M., Innes, J., 2009a. Fire suppression and fuels treatment effects on mixed-conifer carbon stocks and emissions. Ecological Applications 19, 1385-1396.

North, M., Stine, P., O’Hara, K., Zielinski, W., Stephens, S., 2009b. An ecosystem management strategy for Sierran mixed-conifer forests. USDA Forest Service, Pacific Southwest Research Station, General Technical Report PSW-GTR-220, Albany, CA, 56 pp.

Nowak, D.J., Crane, D.E., 2000. The Urban Forest Effects (UFORE) Model: quantifying urban forest structure and functions. In: Hansen, M., Burk, T. (eds.) Proceedings Integrated Tools for Natural Resources Inventories in the 21st Century. IUFRO Conference, 16-20 August 1998, Boise, ID. USDA Forest Service, North Central Research Station. General Technical Report NC-212, St. Paul, MN, pp. 714-720.

Nowak, D.J., Dwyer, J.F., 2000. Understanding the benefits and costs of urban forest ecosystems. In: Kuser, J.E. (ed.) Handbook of Urban and Community Forestry in the Northeast. Kluwer Academic/Plenum, New York, pp. 11-25.

Nowak, D.J., Dwyer, J.F., 2007. Understanding the benefits and costs of urban forest ecosystems. Urban and Community Forestry in the Northeast, $2^{\text {nd }}$ ed., pp. 25-41.

Nowak, D.J., Crane, D.E., Stevens, J.C., 2006. Air pollution removal by urban trees and shrubs in the United States. Urban Forestry \& Urban Greening 4, 115-123.

Odum, E.P., 1969. The strategy of ecosystem development. Science 164, 262-270.

Office of the President, 2002. Healthy forests: an initiative for wildfire prevention and stronger communities. Office of the President, Washington, D.C.

OIG [US Office of the Inspector General], 2006. Forest service large fire suppression costs. US Department of Agriculture, Office of Inspector General, Western Region. Report No. 08601-44-SF.

Oke, T.R., 1989. The micrometeorology of the urban forest. Philosophical Transactions of the Royal Society of London Series B, Biological Sciences 324, 335-348.

Penman, J.M., Gytarzky, M., Hiraishi, M., Krug, T., Kruger, D., Pipatti, R., Buendia, L., Miwa, K., Ngara, T., Tanabe, K., Wagner, F., 2003. Good Practice Guidance for Land 
Use, Land Use Change, and Forestry. Institute for Global Environmental Strategies for the Intergovernmental Panel on Climate Change, Hayama, Kanagawa, Japan.

Perry, D.A., 1994. Forest Ecosystems. The Johns Hopkins University Press. 672 p.

Peterson, D.L., Johnson, M.C., Agee, J.K., Jain, T.B., McKenzie, D., Reinhardt, E.D., 2005. Forest structure and fire hazard in dry forests of the Western United States. USDA Forest Service, Pacific Northwest Research Station, General Technical Report PNWGTR-628, Portland, OR, 38 pp.

Pollet, J., Omi, P.N., 2002. Effect of thinning and prescribed burning on crown fire severity in ponderosa pine forests. International Journal of Wildland Fire 11, 1-10.

Prestemon, J. P., Pye, J. M., Butry, D. T., Holmes, T. P., Mercer, D. E., 2002. Understanding broadscale wildfire risks in a human-dominated landscape. Forest Science 48, 685-693.

Price, C., Rind, D., 1994. Possible implications of global climate change on global lightning distributions and frequencies, Journal of Geophysical Research 99(D5), 10,82310,831, doi:10.1029/94JD00019.

Public Resources Code 4291, 2010. Available at: http://www.leginfo.ca.gov/. Verified 12/20/10.

Radeloff, V.C., Hammer, R.B., Stewart, S.I., Fried, J.S., Holcomb, S.S., McKeefry, J.F., 2005. The wildland-urban interface in the United States. Ecological Applications 15, 799805.

Rasker, R., 2009. Solutions to the rising costs of firefighting in the wildland-urban interface. Headwaters Economics, Bozeman, MT. Available at:

http://www.headwaterseconomics.org/wildfire/HeadwatersFireCosts.pdf.

Verified 10/02/10.

Rebain, S.A., comp. 2009. The Fire and Fuels Extension to the Forest Vegetation Simulator: Updated Model Documentation. USDA Forest Service, Forest Management Service Center, Internal Report, Fort Collins, CO. [Last Revised: November 2009].

Reiner, A.L., Vaillant, N.M., Fites-Kaufman, J., Dailey, S.M., 2009. Mastication and prescribed fire impacts on fuels in a 25-year old ponderosa pine plantation, southern Sierra Nevada. Forest Ecology and Management 258, 2365-2372.

Reinhardt, E.D., Crookston, N.L. [Eds]., 2003. The fire and fuels extension to the forest vegetation simulator. USDA Forest Service, Rocky Mountain Research Station, General Technical Report RMRS-GTR-116, Ogden, UT. 
Reinhardt, E.D., Keane, R.E., Calkin, D.E., Cohen, J.D., 2008. Objectives and considerations for wildland fuel treatments in forest ecosystems of the interior western United States. Forest Ecology and Management 256, 1997-2006.

Ritchie, M. W., Skinner, C. N., Hamilton, T. A., 2007. Probability of tree survival after wildfire in an interior pine forest of northern California: effects of thinning and prescribed fire. Forest Ecology and Management 247, 200-208.

Rocky Mountain Insurance Information Association, 2009. Widlfire and insurance. Available at: http://www.rmiia.org/Catastrophes_and_Statistics/Wildfire.asp. Verified 12/20/10.

Rollins, M.G., Frame, C.K. (Technical editors), 2006. The LANDFIRE prototype project: nationally consistent and locally relevant geospatial data for wildland fire management. USDA Forest Service, Rocky Mountain Research Station, General Technical Report RMRS-GTR-175, pp. 834.

Romme, W.H., Turner, M.G., Tinker, D.B., Knight, D.H., 2004. Emulating natural forest disturbances in the wildland-urban interface of the Greater Yellowstone Ecosystem. In: Perera, A.H., Buse, L.J., Weber, M.G. (Eds). Emulating natural forest landscape disturbances: concepts and applications. New York: Columbia University Press.

Rothermel, R.C., 1972. A mathematical model for predicting fire spread in wild land fuels. USDA Forest Service, Research Paper INT-115, Ogden, UT, 40 pp.

Rowntree, R.A., Nowak, D.J., 1991. Quantifying the role of urban forests in removing atmospheric carbon dioxide. Journal of Arboriculture 17, 269-275.

Ryan, M.G., Harmon, M.E., Birdsey, R.A., Giardina, C.P., Heath, L.S., Houghton, R.A., Jackson, R.B., McKinley, D.C., Morrison, J.F., Murray, B.C., Pataki, D.E., Skog, K.E., 2010. A Synthesis of the Science on Forests and Carbon for U.S. Forests. Issues in Ecology. Vol. 13. Ecological Society of America, Washington, DC, p 1-16.

Safford, H.D., Schmidt, D.A., Carlson, C.H., 2009. Effects of fuel treatments on fire severity in an area of wildland-urban interface, Angora Fire, Lake Tahoe Basin, California. Forest Ecology and Management 258, 773-787.

Saikku, L., Rautiainen, A., Kauppi, P.E., 2008. The sustainability challenge of meeting carbon dioxide targets in Europe by 2020. Energy Policy 36, 731-743.

Schimel, D. S., House, J. I., Hibbard, K. A., Bousquet, P., Ciais, P., Peylin, P., Braswell, B. H., Apps, M. J., Baker, D., Bondeau, A., Canadell, J., Churkina, G., Cramer, W., Denning, A. S., Field, C. B., Friedlingstein, P., Goodale, C., Heimann, M., Houghton, R. A., Melillo, J. M., Moore III, B., Murdiyarso, D., Noble, I., Pacala, S. W., Prentice, I. C., Raupach, M. R., Rayner, P. J., Scholes, R. J., Steffen, W. L., Wirth, C., 2001. Recent patterns and mechanisms of carbon exchange by terrestrial ecosystems. Nature 414, 169172. 
Schmidt, D. A., Taylor, A. H., Skinner, C. N., 2008. The influence of fuels treatment and landscape arrangement on simulated fire behavior, Southern Cascade range, California. Forest Ecology and Management 255, 3170-3184.

Schmidt, K.M., Menakis, J.P., Hardy, C.C., Hann, W.J., Bunnell, D.L., 2002. Development of coarse-scale spatial data for wildland fire and fuel management. USDA Forest Service, General Technical Report RMRS-GTR-62.

Schoennagel, T., Nelson, C.R., Theobald, D.M., Carnwath, G.C., Chapman, T.B., 2009. Implementation of National Fire Plan treatments near the wildland-urban interface in the western United States. Proceedings of the National Academy of Sciences of the United States of America 106, 10706-10711.

Schwilk, D.W., Keeley, J.E., Knapp, E.E., McIver, J., Bailey, J.D., Fettig, C.J., Fiedler, C.E., Harrod, R.J., Moghaddas, J.J., Outcalt, K.W., Skinner, C.N., Stephens, S.L., Waldrop, T.A., Yaussy, D.A., Youngblood, A., 2009. The national Fire and Fire Surrogate study: effects of fuel reduction methods on forest vegetation structure and fuels. Ecological Applications 19, 285-304.

Scott, J.H., 1999. NEXUS: a system for assessing crown fire hazard. Fire Management Notes 59, 20-24.

Scott, J.H., Reinhardt, E.D., 2001. Assessing crown fire potential by linking models of surface and crown fire behavior. USDA Forest Service, Rocky Mountain Research Station, Research Paper RMRS-RP-29, Fort Collins, CO, 59 pp.

Scott, J.H., Burgan, R.E., 2005. Standard fire behavior fuel models: a comprehensive set for use with Rothermel's surface fire spread model. USDA Forest Service, Rocky Mountain Research Station, General Technical Report RMRS-GTR-153, Fort Collins, $\mathrm{CO}, 72 \mathrm{pp}$.

Skinner, C.N., Chang, C., 1996. Fire regimes, past and present. In: Sierra Nevada Ecosystem Project: Final report to Congress, Vol. II: Assessments and Scientific Basis for Management Options. Centers for Water and Wildland Resources, University of California, Davis, Water Resources Center Report No. 37, pp. 1041-1069.

Skinner, C.N., 2005. Reintroducing fire into the Blacks Mountain Research Natural Area: effects on fire hazard. In: Ritchie, M.W., Maguire, D.A., Youngblood, A. (tech. coords.), Proceedings of the Symposium on Ponderosa Pine: Issues, Trends and Management, Klamath Falls, Oregon. USDA Forest Service, Pacific Southwest Research Station, General Technical Report PSW-GTR-198, Albany, CA, pp. 245-258.

Skov, K.R., Kolb, T.E., Wallin, K.F., 2005. Difference in radial growth response to restoration thinning and burning treatments between young and old ponderosa pine in Arizona. Western Journal of Applied Forestry 20, 36-43. 
Smith, W.H., 1990. Air pollution and forests. Springer-Verlag, New York.

Stephens, S.L., 1998. Evaluation of the effects of silvicultural and fuels treatments on potential fire behaviour in Sierra Nevada mixed-conifer forests. Forest Ecology and Management 105, 21-35.

Stephens, S.L., 2004. Fuel loads, snag density, and snag recruitment in an unmanaged Jeffrey pine-mixed conifer forest in northwestern Mexico. Forest Ecology and Management 199, 103-113.

Stephens, S.L., 2005. Forest fire causes and extent on United States Forest Service lands. International Journal of Wildland Fire 14, 213-222.

Stephens, S.L., Collins, B.M., 2004. Fire regimes of mixed conifer forests in the northcentral Sierra Nevada at multiple spatial scales. Northwest Science 78, 12-23.

Stephens, S.L., Moghaddas, J.J., 2005a. Experimental fuel treatment impacts on forest structure, potential fire behavior, and predicted tree mortality in a California mixed conifer forest. Forest Ecology and Management 215, 21-36.

Stephens, S.L., Moghaddas, J.J., 2005b. Fuel treatment effects on snags and coarse woody debris in a Sierra Nevada mixed conifer forest. Forest Ecology and Management 214, 53-64.

Stephens, S.L., Moghaddas, J.J., 2005c. Silvicultural and reserve impacts on potential fire behavior and forest conservation: Twenty-five years of experience from Sierra Nevada mixed conifer forests. Biological Conservation 125, 369-379.

Stephens, S. L., Ruth, L. W., 2005. Federal forest fire policy in the United States. Ecological Applications 15, 532-542.

Stephens, S. L., Fry, D.L., Franco-Vizcaino, E., Collins, B.M., Moghaddas, J.J., 2007a. Coarse woody debris and canopy cover in an old-growth Jeffrey pine-mixed conifer forest from the Sierra San Pedro Martir, Mexico. Forest Ecology and Management 240, $87-95$.

Stephens, S. L., Martin, R. E., Clinton, N. E., 2007b. Prehistoric fire area and emissions from California's forests, woodlands, shrublands and grasslands. Forest Ecology and Management 251, 205-216.

Stephens, S.L., Moghaddas, J.J., Edminster, C., Fiedler, C. E., Haase, S., Harrington, M., Keeley, J. E., Knapp, E. E., McIver, J. D., Metlen, J. D., Skinner, C. N., Youngblood, A., 2009a. Fire treatment effects on vegetation structure, fuels, and potential fire severity in western U.S. forests. Ecological Applications 19, 305-320. 
Stephens, S.L., Moghaddas, J.J., Hartsough, B.R., Moghaddas, E.E.Y., Clinton, N.E., 2009b. Fuel treatment effects on stand-level carbon pools, treatment-related emissions, and fire risk in a Sierra Nevada mixed-conifer forest. Canadian Journal of Forest Research 39, 1538-1547.

Stephenson, N. L., 1999. Reference conditions for giant sequoia forest restoration: structure, process, and precision. Ecological Applications 9, 1253-1265.

Stewart, S.I., Radeloff, V.C., Hammer, R.B., Hawbaker, T.J., 2007. Defining the wildland urban interface. Journal of Forestry 105, 201-207.

Swetnam, T.W., Betancourt, J. L., 1990. Fire-Southern Oscillation relations in the southwestern United States. Science 249, 1017-1020.

Swetnam, T.W., Betancourt, J. L., 1998. Mesoscale disturbance and ecological response to decadal climatic variability in the American Southwest. Journal of Climate 11, 31283147.

Syphard, A. D., Radeloff, V. C., Keeley, J. E., Hawbaker, T. J., Clayton, M. K., Stewart, S. I., Hammer, R. B., 2007. Human influence on California fire regimes. Ecological Applications 17, 1388-1402.

Syphard, A. D., Radeloff, V. C., Keuler, N. S., Taylor, R. S., Hawbaker, T. J., Stewart, S. I., Clayton, M. K., 2008. Predicting spatial patterns of fire on a southern California landscape. International Journal of Wildland Fire 17, 602-613.

Taha, H., Douglas, S., Haney, J., 1997. Mesoscale meteorological and air quality impacts of increased urban albedo and vegetation. Energy and Buildings 25, 169-177.

Theobald, D.M., Romme, W.H., 2007. Expansion of the US wildland-urban interface. Landscape and Urban Planning 83, 340-354.

UFORE Methods, no date. Available at:

http://www.itreetools.org/eco/resources/UFORE\%20Methods.pdf. Verified 11/14/10.

USDA-USDI [US Department of Agriculture and US Department of Interior], 2000. Managing the impact of wildfires on communities and the environment: a report to the President in response to the wildfires of 2000. USDA and USDI. Available at: http://clinton4.nara.gov/CEQ/firereport.pdf. Verified 12/20/10.

USDA-USDI, 2001a. Review and Update of the 1995 Federal Wildland Fire Management Policy. USDA and USDI, Boise, ID. Available at: http://www.nwcg.gov/branches/ppm/fpc/archives/fire_policy/history/index.htm. Verified $12 / 20 / 10$.

USDA-USDI, 2001b. Urban wildland interface communities within vicinity of federal lands that are at high risk from wildfire. Federal Register 66, 751-777. Available at: 
http://www.gpoaccess.gov/fr/advanced.html. Verified 10/02/10.

USDA-USDI, 2003. Large fire cost reduction action plan. Washington, DC. 23 p. Available at: http://www.wflccenter.org/news_pdf/46_pdf.pdf. Verified 12/21/10.

USDA Forest Service, 2004a. Fuels planning - Economic Uses Fact Sheet 1: Mastication Treatments and Costs. Research Note RMRS-RN-20-1-WWW. Available at: http://www.fs.fed.us/rm/pubs/rmrs_rn020_01.pdf. Verified 10/02/10.

USDA Forest Service, 2004b. Sierra Nevada Forest Plan Amendment. Final Supplemental Environmental Impact Statement, Record of Decision. Pacific Southwest Region, R5-MB-046. Available at: http://www.fs.fed.us/r5/snfpa/final-seis/rod. Verified 10/02/10.

USDI National Park Service, 2001. Cerro Grande prescribed fire: Board of Inquiry final report. Available at: http://www.nps.gov/cerrogrande/Board_report-feb26final.pdf. Verified 12/20/10.

USDI-USDA, 2006. Protecting people and natural resources: a cohesive fuels treatment strategy. USDI and USDA, Washington, DC. 26 p.

USFA [US Fire Administration, Federal Emergency Management Agency, Department of Homeland Security], 2009. USFA releases provisional 2008 firefighter fatality statistics. Available at: http://www.usfa.dhs.gov/media/press/2009releases/010709.shtm. Verified 12/20/10.

US Forest Service Chiefs, 2008. Letter to Congress regarding HR 5541, the FLAME Act. Available at: http://westinstenv.org/sosf/2008/03/24/letter-to-congress-re-flame-act-fromformer-usfs-chiefs/. Verified 12/20/10.

U.S. National Research Council, 1983. Changing climate: report of the Carbon Dioxide Assessment Committee. Washington, DC: National Academy Press. 496 p.

Vaillant, N.M., Fites-Kaufman, J., Reiner, A.L., Noonan-Wright, E.K., Dailey, S.N., 2009. Effect of fuel treatments on fuels and potential fire behavior in California, USA, national forests. Fire Ecology 5, 14-29.

Van Wagner, C. E., 1977. Conditions for the start and spread of crown fire. Canadian Journal of Forest Research 7, 23-24.

Van Wagtendonk, J.W., 1996. Use of a deterministic fire growth model to test fuel treatments. Sierra Nevada Ecosystem Project. Final Report to Congress, Vol. II. Assessments and Scientific Basis for Management Options. Centers for Water and Wildland Resources. University of California, Davis, pp. 1155-1165. 
Van Wagtendonk, J.W., 2007. The history and evolution of wildland fire use. Fire Ecology Special Issue 3(2), 3-17.

Veblen, T. T., Kitzberger, T., Donnegan, J., 2000. Climatic and human influences on fire regimes in ponderosa pine forests in the Colorado Front Range. Ecological Applications $10,1178-1195$.

Verner, J., McKelvey, K.S., Noon, B.R., Gutierrez, R.J., Gould, Jr., G.I., Beck, T.W., 1992. The California spotted owl: a technical assessment of its current status. USDA Forest Service, Pacific Southwest Research Station, General Technical Report PSW-133.

Weatherspoon, C.P., Skinner, C.N., 1996. Landscape-level strategies for forest fuel management. Sierra Nevada Ecosystem Project. Final Report to Congress, Vol. II. Assessments and Scientific Basis for Management Options. Centers for Water and Wildland Resources. University of California, Davis, pp. 1471-1492.

Weatherspoon, C.P., 2000. A proposed long-term national study of the consequences of fire and fire surrogate treatments. In: Neuenschwander, L.F., Ryan, K.C. [Technical Eds.] Proceedings from The Joint Fire Science Conference and Workshop, Crossing the Millennium: Integrating Spatial Technologies and Ecological Principles for a New Age in Fire Management, Boise, ID, June 15-17, 1999. Moscow, ID: University of Idaho. 10 p. Available at:

http://frames.nbii.gov/documents/ffs/ffs003_weatherspoon_general.pdf.

Verified 10/02/10.

Weatherspoon, C. P., McIver, J., 2000. A national study of the consequences of fire and fire surrogate treatments. USDA Forest Service, Pacific Southwest Research Station, Redding, California, USA.

Weise, D.R., Wotton, B.M., 2010. Wildland-urban interface fire behaviour and fire modelling in live fuels. International Journal of Wildland Fire 19, 149-152.

Westerling, A. L., Gershunov, A., Brown, T. J., Cayan, D. R., Dettinger, M.D., 2003. Climate and wildfire in the western United States. Bulletin of the American Meteorological Society 84, 595-604.

Westerling, A. L., Swetnam, T. W., 2003. Interannual to decadal drought and wildfire in the western United States. Eos 84, 545, 554-555.

Westerling, A.L., Hidalgo, H.G., Cayan, D.R., Swetnam, T.W., 2006. Warming and earlier spring increase western US forest wildfire activity. Science 313, 940-943.

Westerling, A. L., Bryant, B. P., 2008. Climate change and wildfire in California. Climatic Change 87 [Supplement 1], S231-S249. 
Westerling, A.L., Bryant, B. P., Preisler, H. K., Holmes, T. P., Hidalgo, H. G., Das, T., Shrestha, S. R., 2009. Climate change, growth, and California wildfire: final paper. CEC500-2009-046-F. California Climate Change Center. Available at:

http://www.energy.ca.gov/2009publications/CEC-500-2009-046/CEC-500-2009-046-

F.PDF. Verified 10/02/10.

Wiedinmyer, C., Neff, J.C., 2007. Estimates of $\mathrm{CO}_{2}$ from fires in the United States: implications for carbon management. Carbon Balance and Management 2, 10.

Wilson, A.A.G., Ferguson, I.S., 1985. Fight or flee? A case study of the Mount Macedon bushfire. Operations 156, 1-8.

WRCC [Western Regional Climate Center], 2009. Cherry Valley Dam Climate Station Record, 1955-2009. Available at:

http://www.wrcc.dri.edu/summary/Climsmcca.html. Verified 10/02/10. 